NIST Special Publication 1900-604

\title{
Economics of Interoperability in the Context of Smart Grid Architectures
}

Cheyney O’Fallon

Avi Gopstein

This publication is available free of charge from:

https://doi.org/10.6028/NIST.SP.1900-604

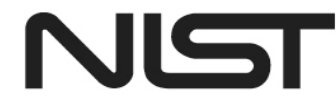

National Institute of Standards and Technology U.S. Department of Commerce 


\title{
Economics of Interoperability in the Context of Smart Grid Architectures
}

\author{
Cheyney O'Fallon \\ Applied Economics Office \\ Engineering Laboratory \\ Avi Gopstein \\ Smart Grid Program Office \\ Engineering Laboratory
}

This publication is available free of charge from:

https://doi.org/10.6028/NIST.SP.1900-604

December 2019

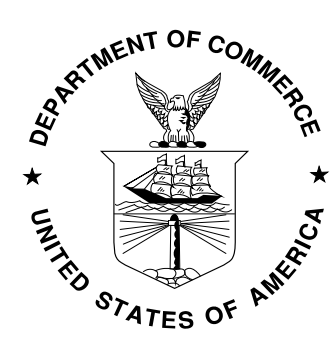

U.S. Department of Commerce

Wilbur L. Ross, Jr., Secretary

National Institute of Standards and Technology Walter Copan, NIST Director and Undersecretary of Commerce for Standards and Technology 
Certain commercial entities, equipment, or materials may be identified in this document in order to describe an experimental procedure or concept adequately. Such identification is not intended to imply recommendation or endorsement by the National Institute of Standards and Technology, nor is it intended to imply that the entities, materials, or equipment are necessarily the best available for the purpose.

National Institute of Standards and Technology Special Publication 1900-604

Natl. Inst. Stand. Technol. Spec. Pub. 1900-604, 84 pages (December 2019) CODEN: NSPUE2

This publication is available free of charge from: https://doi.org/10.6028/NIST.SP.1900-604 


\begin{abstract}
Technological change in the electric power sector has progressed rapidly and there now is need for the development and evaluation of new smart grid architectures. This technical note discusses the current conditions of the U.S. electric grid and the economics of interoperability within the context of five representative architectural tracks developed by Pacific Northwest National Labs.
\end{abstract}

\author{
Keywords \\ Interoperability; Platforms; Smart Grid; Electricity; Critical Infrastructure; Network Effects; \\ Transaction Costs; Technological Change; Decentralization; Microgrid; Resilience; Converged \\ Networks.
}




\section{PREFACE}

This special publication was developed by the Applied Economics Office (AEO) and the Smart Grid Program (SGP), both of the Engineering Laboratory (EL) at the National Institute of Standards and Technology (NIST).

\section{Disclaimers}

The policy of the National Institute of Standards and Technology is to use metric units in all its published materials.

Certain commercial entities, equipment, or materials may be identified in this document to describe an experimental procedure or concept adequately. Such identification is not intended to imply recommendation or endorsement by the National Institute of Standards and Technology, nor is it intended to imply that the entities, materials, or equipment are necessarily the best available for the purpose. 


\title{
ACKNOWLEDGEMENTS
}

The authors wish to thank all those who contributed ideas and suggestions for this report. We thank Dr. Joshua Kneifel, Anand Kandaswamy, and Dr. Dave Butry of EL AEO for sharing helpful written comments and conversation throughout the development of this document. We also thank Dr. Jennifer Helgeson for many thoughtful conversations concerning tangencies and overlap between research in the fields of community resilience and smart grid. The authors benefited from discussions with Chris Villarreal regarding regulatory perspectives on interoperability matters.

\section{AUTHOR INFORMATION}

\author{
Cheyney O’Fallon \\ Economist \\ National Institute of Standards and Technology \\ Engineering Laboratory \\ 100 Bureau Drive, Mailstop 8603 \\ Gaithersburg, MD 208998603 \\ Tel.: 301-975-6481 \\ Email: cheyney.ofallon@nist.gov \\ Avi Gopstein \\ Smart Grid Program Manager \\ National Institute of Standards and Technology \\ Engineering Laboratory \\ 100 Bureau Drive, Mailstop 8200 \\ Gaithersburg, MD 208998200 \\ Tel.: 301-975-2214 \\ Email: avi.gopstein@nist.gov
}




\section{TABLE OF CONTENTS}

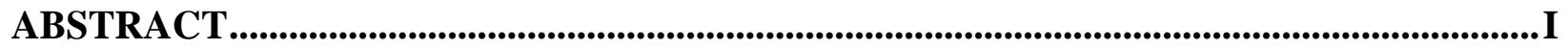

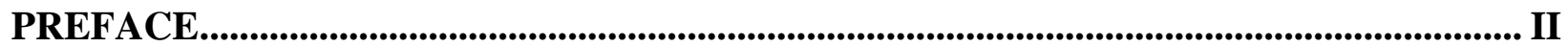

ACKNOWLEDGEMENTS ...............................................................................................III

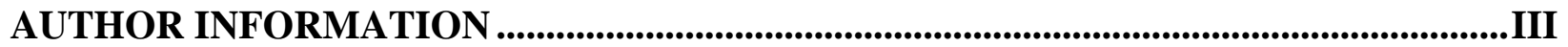

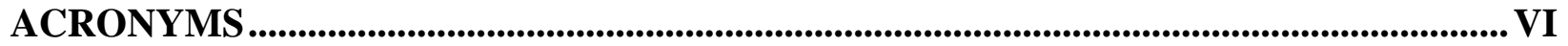

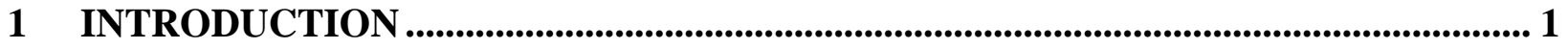

2 BACKGROUND.................................................................................................................. 2

2.1 TRENDS AND DEVELOPMENTS ………………………………………………………. 2

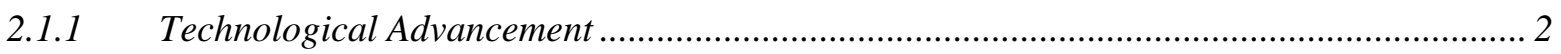

2.1.2 Physical Grid Conditions ............................................................................................. 3

2.1.3 Operations......................................................................................................... 4

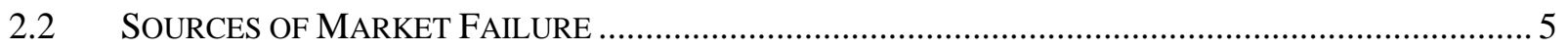

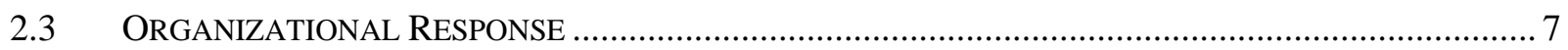

2.4 TRANSACTION COSTS AND INTEROPERABILITY ………………………………………...... 8

2.5 BARRIERS TO ENTRY AND THE INCENTIVES FOR INTEROPERABILITY ………………..................10

2.6 INTEROPERABILITY AND INCLUSIVE INSTITUTIONS FOR THE SMART GRID....................................13

3 TRACK 1: ADVANCED BULK ENERGY SYSTEMS (ABES) ....................................... 14

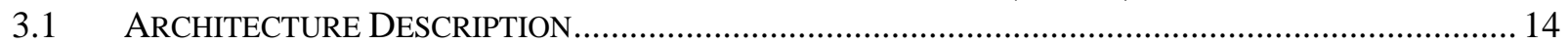

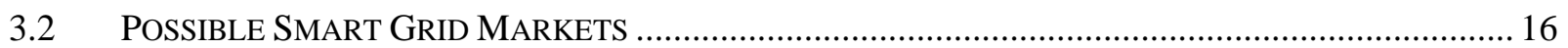

3.3 EXISTING MARKETS WITH SIMILAR CHARACTERISTICS ........................................................... 16

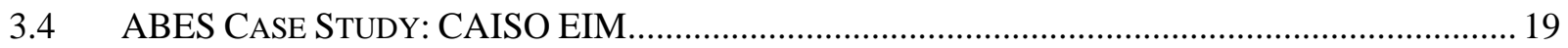

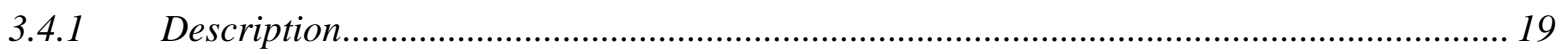

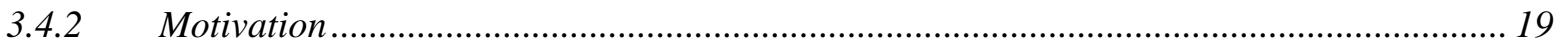

3.4.3 Technical Concerns and Requirements......................................................................... 21

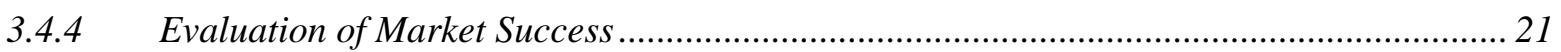

3.4.5 Lessons from CAISO EIM Case Study …………………………………………... 22

4 TRACK 2: HIGH RESILIENCE GRID (HRG),........................................................ 22

$4.1 \quad$ ARCHITECTURE DESCRIPTION...................................................................................... 22

4.2 PosSIBLE PatHS TO RESILIENCE IN THE SMART GRID ……………………………………... 24

4.3 INTERNAL STRATEGIES AND COMPONENTS OF GRID RESILIENCE..............................................2 26

4.4 EXTERNAL MARKETS FOR RESILIENCE............................................................................ 28

4.5 POTENTIAL BARRIERS TO GRID RESILIENCE ……………….............................................. 31

4.6 INTEROPERABILITY AND GRID RESILIENCE ........................................................................... 32

5 TRACK 3: HIGH DER/HIGH AUTOMATION DISTRIBUTION GRID (HADG).... 32

$5.1 \quad$ ARCHITECTURE DESCRIPTION......................................................................................... 32

5.2 TECHNOLOGICAL CHANGE AND DECENTRALIZATION.................................................................. 34

5.3 BUSINESS STRATEGY AND THE REGULATORY ENVIRONMENT ....................................................... 36

5.4 Market Structure, ORganizational Conduct, AND EConomic Performance .............. 39

5.5 EXISTING EXTERNAL MARKETS WITH SIMILAR CHARACTERISTICS ..............................................40

5.6 DISCUSSION OF INTEROPERABILITY, PLATFORMS AND THE SMART GRID................................... 41 
6 TRACK 4: MICROGRID \& DISTRIBUTION GRID SEGMENTATION (MDGS)... 43

6.1 ARCHITECTURE DESCRIPTION....................................................................................... 43

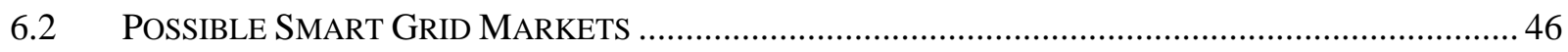

6.3 EXISTING EXTERNAL MARKETS WITH SIMILAR CHARACTERISTICS ………………………….....4 48

6.4 MARKET SUCCESS OR FAILURE.....

51

6.5 APPLICATIONS TO SMART GRID QUESTIONS

52

7 TRACK 5: URBAN CONVERGED NETWORKS (UCN)

53

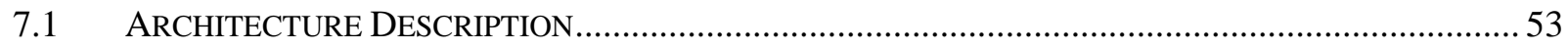

7.2 CONVERGENCE OF ELECTRICITY AND NATURAL GAS NETWORKS

53

7.3 CONVERGENCE OF ELECTRICITY AND WATER NETWORKS

54

7.4 CONVERGENCE OF ELECTRICITY AND TRANSPORTATION NETWORKS......................................... 55

7.5 LESSONS FOR CONVERGENCE AND INTEROPERABILITY

57

8 CONCLUSION

58

8.1 FUTURE RESEARCH

60

REFERENCES

62

APPENDIX A: MARKET FAILURES

70

V 


\section{ACRONYMS}

$\begin{array}{ll}\text { ABES } & \text { Advanced Bulk Energy System } \\ \text { AEO } & \text { Applied Economics Office } \\ \text { AMS } & \text { Asset Management Systems } \\ \text { AT } & \text { Algorithmic Trading } \\ \text { ATC } & \text { Available Transfer Capacity } \\ \text { BA } & \text { Balancing Authority } \\ \text { BAA } & \text { Balancing Authority Area } \\ \text { BTM } & \text { Behind the Meter } \\ \text { CAISO } & \text { California Independent System Operator } \\ \text { CIM } & \text { Common Information Model } \\ \text { COSR } & \text { Cost of Service Regulation } \\ \text { DAM } & \text { Day-Ahead Market } \\ \text { DER } & \text { Distributed Energy Resources } \\ \text { DOE } & \text { Department of Energy } \\ \text { DPO } & \text { Distribution Platform Optimizer } \\ \text { DR } & \text { Demand Response } \\ \text { DSO } & \text { Distribution System Operator } \\ \text { DTC } & \text { Dynamic Transfer Capacity } \\ \text { EIM } & \text { Energy Imbalance Market } \\ \text { EL } & \text { Engineering Laboratory } \\ \text { EMS } & \text { Energy-Management System } \\ \text { EPRI } & \text { Electric Power Research Institute } \\ \text { EPS } & \text { Electric Power System } \\ \text { EV } & \text { Electric Vehicle } \\ \text { FERC } & \text { Federal Energy Regulatory Commission } \\ \text { FNM } & \text { Full Network Market } \\ \text { GHG } & \text { Greenhouse Gas } \\ \text { GMLC } & \text { Grid Modernization Lab Consortium } \\ \text { HADG } & \text { High DER/High Automation Distribution Grid } \\ \text { HOT } & \text { High Occupancy/Toll } \\ \text { HOV } & \text { High Occupancy Vehicle } \\ \text { HRG } & \text { High Resilience Grid } \\ \text { ICT } & \text { Information and Communication Technology } \\ \text { IED } & \text { Intelligent Electronic Devices } \\ \text { IEI } & \text { Interoperability Enhancing Investment } \\ \text { IOT } & \text { Internet of Things } \\ \text { IOU } & \text { Investor-Owned Utility } \\ \text { IPP } & \text { Independent Power Producer } \\ \text { ISO } & \text { Independent System Operator } \\ \text { IT } & \text { Information Technology } \\ \text { LNG } & \text { Liquefied Natural Gas } \\ \text { MAG } & \text { Mutual Assistance Group } \\ \text { MDGS } & \text { Microgrid and Distribution Grid Segmentation } \\ \text { MISO } & \text { Midcontinent Independent System Operator } \\ \text { MSC } & \text { Market Surveillance Committee } \\ \text { NEFL } & \text { Net Energy for Load } \\ \text { NIST } & \text { National Institute of Standards and Technology } \\ \text { NREL } & \text { National Renewable Energy Laboratory } \\ & \end{array}$


NSI Net Schedule Interchange

NWS National Weather Service

OMS Outage Management Service

PCC Point of Common Coupling

PNNL Pacific Northwest National Labs

PUC Public Utility Commission

PV Photovoltaic

RTED Real-Time Economic Dispatch

RTM Real-Time Market

RTO Regional Transmission Organization

SGP Smart Grid Program

TMS Tree Management Services

UCN Urban Converged Networks

UCSD University of California, San Diego

VG Variable Generation

WECC Western Electric Coordinating Council

WIT Western Interchange Tool 


\section{INTRODUCTION}

As electric power systems continue to evolve towards smarter grids, diverse economic actors are confronted with numerous unresolved questions concerning the future economics and changing nature of competition in the electric power sector. Underlying uncertainty regarding how innovation in information and communication technology (ICT) will drive business and regulatory decisions often hinders efforts to forecast future trends. While electric sector data will undoubtedly continue the present trend of increasing availability and finer granularity, the presence of additional data will not a priori improve grid operations. Data becomes information when conveyed in a timely, readable, and actionable manner, and dissemination of information to market actors within and beyond the electric power sector will be the greatest enabler of system optimization. The key concept for this transformation is interoperability; defined as "[t]he capability of two or more networks, systems, devices, applications, or components to work together, and to exchange and readily use information-securely, effectively, and with little or no inconvenience to the user" [1]. In the case of the smart grid, interoperability can facilitate the exchange of information across devices, firms, and systems with the express purpose of operational optimization and novel value creation.

This paper identifies key economic questions that revolve around interoperability in the smart grid, and investigates how the answers to these questions are influenced by or consistent across the choice of smart grid architecture. ${ }^{1}$ This investigation began with an evaluation of five distinct, but not necessarily mutually exclusive, representative architectural tracks developed by researchers at the Pacific Northwest National Laboratory (PNNL) [2]. Our discussion moves on from descriptive analyses to identification of market structures that might emerge within these architectures. Throughout this document, the term market is used in the tradition of the economics literature ${ }^{2}$ and is not intended to carry implications with respect to restructuring efforts that have transpired in certain geographic regions. Tirole [3] argues that the definition of a market should "allow a single description of the main interactions among firms."

\footnotetext{
${ }^{1}$ The following definition of architecture is developed in NIST SP 1108: "The structure and overall organization of the smart grid from the point of view of its use or design. This includes technical and business designs, demonstrations, implementations, and standards that together convey a common understanding of the smart grid. The architecture embodies high-level principles and requirements that designs of smart grid applications and systems must satisfy” (NIST 2010).

${ }^{2}$ Efforts to define the extent of a market are often confined to antitrust analysis and left unaddressed elsewhere. Even seminal textbook treatments of industrial organization concede that "the 'right' definition of a market depends on the use to which it will be put," it is generally "assumed that the market is well defined" [3] Nevertheless, several definitions are worth stating here, with emphasis added. "Originally a market was a public place in a town where provisions and other objects were exposed for sale; but the word has been generalized, so as to mean any body of persons who are in intimate business relations and carryon extensive transactions in any commodity" [4] More recent definitions offer a similar view. "The market is the area within which price is determined: the market is that set of suppliers and demanders whose trading establishes the price of a good" [5] The Federal Energy Regulatory Commission defines a market as "[a] venue where participants buy and sell products or services. Usually there is agreement of product description and some standard terms to enable determination of value and price" [6] For the purpose of this study, each definition offers a unifying view of the interactions or transactions between market participants. Furthermore, none of these definitions precludes the presence of a non-restructured monopolist supplier.
} 
In this paper, potential future market structures are discussed, when possible, within the context of existing markets inside and outside of the electric power sector. Market failures and successes in each of these analogues are identified to evaluate the usefulness of each market structure within the context of the smart grid. The discussion originating from each architectural track concludes with lessons that can be drawn from market analogues.

\section{BACKGROUND}

While each representative architectural track ${ }^{3}$ is distinct, many key trends and developments are common to multiple architectures. What follows is a brief, non-exhaustive accounting of key influences informing development and innovation in the electric power sector. While the following section is brief by design, further discussion of key trends and developments are referenced in footnotes and the appendix.

\subsection{TRENDS AND DEVELOPMENTS}

All grid architectures are constrained by economic, physical, and organizational limitations. Technological advancement pushes the envelope of the possible when operating the electric grid, and restructuring efforts of varying significance ${ }^{4}$ have followed as firms reorganize internally to optimize implementation of new technologies (and management of new skill sets), and markets develop to mediate the interaction of a diversifying set of economic actors providing services through the electric grid. This paper does not judge or select between competing architectural tracks, but rather identifies and evaluates constraints on the ability of each architecture to deliver value to stakeholders.

\subsubsection{TeChnological Advancement}

Technological advancement in ICT has led to innovation and disruption in numerous economic sectors. The electric grid has always been a network, but the complexity of the network has increased, and operational control requires greater signals capabilities than in the past. Elements of the grid are coordinated across a considerable distance-across even state and international borders - to accommodate spatial and temporal differences in generation and load. These grid elements are technologically diverse and operated by a variety of firms ${ }^{5}$ with differing organizational structures and incentive schemes. Beyond simply conveying data between organizations, in a smart grid, signals must be actionable to provide value. The present focus on interoperability arises from the communications needs of grid operators and the collection of participants in various electricity-related markets.

\footnotetext{
${ }^{3}$ The five architectural tracks developed by the Grid Modernization Lab Consortium (GMLC) describe the "domain, focus, and essential elements of a set of architecture views to be developed for a particular scenario for grid modernization" [7].

${ }^{4}$ Large regions of the electric grid are still operated effectively by conventional, vertically integrated firms. But even there, these firms have grown and changed as the markets for their products and services have changed their regulations, institutional inputs, and needs.

${ }^{5}$ For the purpose of this statement, the definition of a firm is inclusive of sole proprietorships and households or individuals participating in electricity-related markets.
} 
Technological advancement in other aspects of the electric grid has been swift as well. Distributed Energy Resources (DER) such as rooftop solar photovoltaics (PV), responsive load, and energy storage technologies are being installed with considerable speed both around the country and the globe as costs have fallen and performance has improved [8]. As generation and other DER services have increased, these resources have moved from the fringe of the electric power system to a position of technological and cultural prominence. Spread across the edge of the grid, the rise of DER has placed important elements of the grid in the hands of non-traditional market actors.

\subsubsection{PHYSICAL GRID CONDITIONS}

Organizationally, the electric grid has witnessed major structural changes. The physical underpinning of the traditional, legal demarcation between the transmission system and distribution systems is eroding as new participants have entered the market through the installation of DER. At present, these new entrants include many small actors venturing into large commodity markets heretofore left to relatively well-capitalized firms. ${ }^{6}$ Eventually, these edge-connected market players may compete in the provision of services that render electricity consumption as an experience rather than a commodity. While the margins on commodities tend to diminish with competitive pressures over time, the margins earned by experiential goods and services appear more resilient to these forces as a function of their greater differentiability. ${ }^{7}$

The composition of generating technologies is changing significantly. The falling costs and modularity $^{8}$ of natural gas power plants, wind, and now solar PV have led these technologies to dominate investment and new capacity deployments in the United States for the past thirty years [11]. Furthermore, considering low demand growth, the rise in natural gas and renewables has meant the displacement of the least economically efficient thermal generating plants in the economic dispatch stack [12]. ${ }^{9}$

Reliability and effective system control continue to be concerns for grid operators as the technologies and market mechanisms for achieving these outcomes have evolved with time.

\footnotetext{
${ }^{6}$ The aggregate impact of market entry by new classes of actors should not be dismissed. In one case, "DER are poised to transform New York's wholesale electric system", and "[t]he NYISO generally considers DER to be behind-the-meter resources" [9].

${ }^{7}$ Highly differentiated products generally exhibit lower price elasticities of demand than do undifferentiated products (commodities). That is, consumer demand is far more responsive to price when little differentiates one option from another. Consumers are more willing to bear a price increase when there are few other options for obtaining the same bundle of attributes in a product or service. In imperfectly competitive markets, the markup over marginal cost earned by producers is inversely proportional to the elasticity of demand. To the extent that experiential goods and services are harder for competitors to replicate, they should exhibit lower price elasticities of demand and support higher markups. However, many energy services offer the potential to reduce customer costs as consumption of energy commodities can fall with improved use patterns.

${ }^{8}$ The impetus for developing modular technologies arose from "[t]he Public Utility Regulatory Policies Act of 1978 along with subsequent deregulation and other market shifts [that] altered the finance structure for deploying new generation, limiting tolerance for technologies with large capital costs” [10].

${ }^{9}$ The Energy Policy Act of 2005 defines "economic dispatch" as "the operation of generation facilities to produce energy at the lowest cost to reliably serve consumers, recognizing any operational limits of generation and transmission facilities” [13].
} 
Restructuring towards competitive markets for electricity generation has led to the rise of independent power producers (IPP), which have slowly gained market share from electric utilities as overall net generation remained flat for nearly two decades. The incentives facing IPPs differ from those confronted by traditional electric utilities and many IPPs have sought to maximize generation and associated revenue through energy markets at the expense of other grid services. In one example, the physical inertia historically provided to the grid from thermal plants owned by vertically integrated electric utilities is generally uncompensated in restructured market settings [14]. ${ }^{10}$ Modern mechanisms for system control include the provision of synthetic inertia and ancillary services from DER that may, in some cases, outperform legacy approaches to system control through conventional assets [15], ${ }^{11}$ but new market designs are required to adequately value the provision of this service so that all generators will provide the necessary inertial support to the grid. Continued development, demonstration, and deployment of improved power electronics will increase the breadth of operational strategies for reliability available to system operators.

Output from the electric power sector is a critical input to production in every sector of the economy [16]. However, compositional changes to the U.S. economy and improvements in energy efficiency have acted as strong headwinds for growth in electricity consumption. Demand for electricity has stagnated at the national level and some communities have even exhibited reductions in customer load [17]. Regions that have experienced deindustrialization have seen the greatest reductions in electricity demand as factories close and new industry is generally less energy intensive. In the transportation sector, electrification of road vehicles could significantly increase electricity demand, although electric vehicles constitute a small share of current vehicle miles traveled and represent one of the largest sources of uncertainty regarding future electricity demand.

\subsubsection{OPERATIONS}

The decentralization of generation has led some to question whether the industry will experience a paradigm shift from system control to system coordination. Some electric operations are relatively amenable to coordination through market mechanisms while others still require direct control on the part of a system operator. Regions may differ on how they choose to strike a balance between the coordination of economic activity and the legacy command and control approach. Demand response for example can take different forms, including incentives to induce households and other end use consumers to reduce load or customers agreeing to grant their utility direct load control for enabled devices and systems. At the heart of this debate is an effort to enjoy the economic benefits of entrepreneurial innovation while mitigating the potential for negative network externalities stemming from uncoordinated strategies and actions. There is a

\footnotetext{
10 The operational value provided by inertia was internalized by conventional utilities, but restructured markets are generally not set up to compensate firms for the provision of such services.

${ }^{11}$ A recent study conducted by the National Renewable Energy Laboratory (NREL), First Solar and the California Independent System Operator (CAISO) demonstrated that "PV power plants can be used to mitigate the impact of variability on the grid, a role typically reserved for conventional generators”. The regulation accuracy of the tested PV plant even surpassed the level of performance typical of fast natural gas turbines.
} 
broad need to reconcile our latent preference for individual agency in our economic decisions with the physical necessities ${ }^{12}$ of operating the world's most intricate integrated system. ${ }^{13}$

Every sector of the economy requires access to electricity, both directly as a factor of production and indirectly, embodied in inputs from other industries. It is therefore critical that the electric grid is resilient to threats. Damage from hazard events including hurricanes, flooding, tornados, and earthquakes has threatened electric grids since the outset of their development. A set of threats of increasing salience to the public is that of cyber-physical attacks. While the sheer force of a hurricane is undeniable, natural disasters are extensively modeled and lack the targeting capability of a thinking adversary. While physical design or strategic placement of electric sector assets to lower hazard exposure is possible, alternate strategies must be developed and deployed to maintain and improve the cyber-security posture of the electric grid. While the challenge of implementing preventative cybersecurity measures during the planning phase can seem large, doing so may simplify the process of fixing problems after they become manifest.

Utilities are far from the only industries with a need for the technical skills to build out cybersecurity capabilities. As a result, utilities must compete across sectoral boundaries for the talent to build and maintain cyber-resilience within their systems. The personnel requirements of utilities are evolving with the technology stacks these firms employ. With changing technology and personnel comes the development of new organizational structures to coordinate business practices. $^{14}$

These trends constitute strong pressures on managers and business models to generate the revenue needed to cover the components of cost structures that are rising. In time, the collection of changes must be formed into new, cohesive business models. The development of new business models offers the opportunity to improve not only firm-level performance, but market efficiency as well. The next sections outline sources of market failure that are present in various markets for electricity and the role of smart grid technologies and improved interoperability to remedy extant inefficiencies.

\subsection{SOURCES OF MARKET FAILURE}

Ideal markets are classically thought of as perfectly competitive and exhibit a variety of characteristics that contribute to their proper function. Harris and Carman [20] discusses the conditions for market success in the development of a typology of market failures. Few, if any, real markets satisfy these conditions in full. Nevertheless, the conditions summarized in Table 1 are instructive when identifying the root cause of market failures.

\footnotetext{
12 The perishable nature of electricity implies an instantaneous balancing requirement with respect to load and generation.

${ }^{13}$ Given the degree to which electrification has “improved people’s quality of life”, Wulf [18] lists the development of the "vast networks of the electric grid" as the greatest engineering achievement of the $20^{\text {th }}$ century.

${ }^{14}$ Bresnahan et al. argues that, "[f]irms do not simply plug in computers or telecommunications equipment and achieve service quality or efficiency gains. Instead they go through a process of organizational redesign and make substantial changes to their product and service mix” Bresnahan, Brynjolfsson [19].
} 


\begin{tabular}{|ll|}
\hline Condition & Description \\
\hline Perfect Competition & $\begin{array}{l}\text { Parties to a market exchange possess roughly equivalent bargaining power with many } \\
\text { small producers and consumers each individually unable to affect the market price of a } \\
\text { given good or service. }\end{array}$ \\
Perfect Information & $\begin{array}{l}\text { Parties to the exchange must be perfectly informed about the good or service being } \\
\text { exchanged as well as substitute options. }\end{array}$ \\
Absence of Externalities & $\begin{array}{l}\text { All benefits and costs associated with the exchange need to be internalized by the } \\
\text { exchanging parties }\end{array}$ \\
Divisibility & $\begin{array}{l}\text { The product or service must be divisible into units of exchange. } \\
\text { Excludability }\end{array}$ \\
Zero Transaction Costs & $\begin{array}{l}\text { Parties to an exchange must be able to exclude those not engaging in the exchange } \\
\text { from enjoying its benefits. }\end{array}$ \\
Zero Barriers to Entry & $\begin{array}{l}\text { There should be no barriers to market entry in the form of long-term constraints on } \\
\text { supply. }\end{array}$ \\
Economic Rationality & Consumers (producers) will act in their self-interest to maximize their utility (profits). \\
Fair Distribution of & $\begin{array}{l}\text { Market institutions deliver a distribution of wealth and income that aligns with the } \\
\text { "social consensus of fairness". }\end{array}$ \\
\hline
\end{tabular}

It is important to recognize that the physical laws governing the operation of the electric grid preclude many of these conditions from manifesting in reality. Transaction costs will never truly reach zero. ${ }^{16}$ The capital expenditures necessary to build generating, transmission, and distribution assets are sufficiently large to constitute a practical barrier to entry. ${ }^{17}$

Market failures can be organized into categories including: imperfect competition, excessive competition, anticompetitive conduct, imperfect information, side effects (externalities), public goods, and income maldistributionHarris and Carman [20]. ${ }^{18}$ Each of these problems may be present in the electric power sector and therefore, market failure is a real concern that must be addressed with diligent market design efforts. The challenges posed by each cause vary in severity across the architecture tracks used for this analysis. Efforts to mitigate market failures through the development of new devices, systems, and market mechanisms constitute important investment opportunities, regardless of which architectural tracks eventually dominate in any given region or market. Accounting for the motivating role of these failures in the migration to

\footnotetext{
15 The network structure of electric grids makes this condition for success especially unattainable.

16 There is, of course, strong incentive to reduce transaction costs so that a greater number of mutually beneficial transactions can take place.

17 The falling cost of DER suggests this barrier to entry may yet be diminished.

${ }^{18}$ A more detailed accounting of sources of market failure can be found in Appendix A.
} 
new architectures, and identifying their attenuation or persistence is of crucial importance to the development of a smart electric grid. ${ }^{19}$

\subsection{ORgANiZATIONAL RESPONSE}

Historical business models in the electric power sector have centered around cost of service regulation (COSR) and have relied on maintenance of the regulatory compact, which strikes a balance between utility and customer stakeholder groups. ${ }^{20}$ The regulatory bargain of the 1940's to the 1970's was underpinned by increasing sales, economies of scale in generation, and input price stability. Over time, the assumptions underlying the regulatory compact have changed and regulation in the electricity industry has evolved. ${ }^{21}$ In the 1970 's, inflation and the accompanying rise in interest rates increased the long run financing costs of power plants. This coupled with slower demand growth towards the end of the decade and high fuel prices to squeeze the economic viability of many electric utilities. These challenges to the regulatory compact and others have provided the impetus for the regulatory innovations that followed: "construction work in progress, ${ }^{22}$ cost trackers, riders, fuel and energy cost adjustment mechanisms, and balancing/true-up mechanisms” [19]. The need to make significant investments in a variety of smart grid technologies in the presence of aggregate demand growth stagnation has engendered some to call for new adjustments to the regulatory compact.

Technological change and the evolution of energy prices have led some to argue that existing tariff structures fail to value and thus compensate many attributes of generation assets that are beneficial to the reliability and resilience of the grid. Furthermore, even in the absence of unvalued attributes, generators and electric service providers generally earn revenues that loosely track marginal costs and appear increasingly incapable of covering the substantial fixed costs of doing business in the electric power sector [24].

Not content to wait for regulatory leadership, some emergent firms and industry incumbents are developing new business models for competing in the electric power sector. A major component of this organizational response is the rise of platform business models. To what extent platform

\footnotetext{
${ }^{19}$ At issue is the reality that even the best-intentioned evolutions of complex markets may experience incomplete success in mitigating the real or perceived presence and effects of market failures. Change in firm level strategy can be motivated internally or externally; as a matter of innovation driven by market and operating conditions, or in response to changes in regulatory policy (which may themselves be driven by trends in market performance). The likelihood of success in mitigating market failure may differ substantially as a function of what motivates the change. The authors make no claim to the relative supremacy of internal or external motivations for change. ${ }^{20}$ COSR is a form of incentive regulation used extensively for electric utilities, in which "there is in principle a dollar-for-dollar correspondence between prudently incurred costs and rates” [21]. Under COSR, utilities earn an approved rate of return on their rate-base (the value of prudently incurred costs) that should be sufficient to generate the revenue required to cover operating, depreciation, and tax expenses, in addition to a positive return on investment large enough to attract new capital. For a comparison of COSR and several performance-based regulatory regimes, see Hill [21].

21 "The history of regulation is a history of adaptation to the stress on the system as a result of changes in the operating environment that created an imbalance in the regulatory compact and, more than once, threatened its continued existence" [22].

${ }^{22}$ The concept of construction work in progress (CWIP) is nicely described in the New York State Public Services Commission - Glossary of terms. CWIP is "[a]n account for capital expenditures on facilities not yet in service because they do not produce cash earnings. In recent years, the Commission has met the financial straits of some utilities by transferring some CWIP into rate base where it does produce cash earnings" [23].
} 
business models will penetrate the electric power sector and augment or replace existing business models remains an open question. Regardless of the precise market structures that will emerge for electric power, platform business models appear situated to play a larger role in the industrial organization of the sector. Weiller and Pollitt [22] make the following argument regarding platforms in the electric power sector.

The increasing differentiation of electricity consumers by type and elasticity of demand, as well as the new complexity of interactions between actors on the distribution network, may lead to the emergence of "platform"-mediated interactions as has been the case in other industries whose business models have been radically affected by information and communication technologies (ICT) [25].

The first mover advantage often enjoyed by the businesses that can effectively implement platforms is sufficient motivation for innovation among newcomers. However, incumbent firms face a distinct first mover disadvantage. While incumbent investor-owned utilities (IOUs) may encounter difficulty in convincing a public utility commission (PUC) to allow platform development costs into the rate base, startups that are able to reach critical mass and get to market early could establish strong market positions in the provision of electricity or related services.

\subsection{TRANSACTION COSTS AND INTEROPERABILITY}

Efforts to characterize the mechanisms through which interoperability will impact the electric power sector must contend with the fact that while the benefits of interoperability are often clear in theory, rigorous empirical work is hindered by a lack of operational metrics. Nevertheless, a lack of interoperability generally corresponds with high transaction costs. Improving interoperability (especially with respect to communications) directly impacts the transaction costs on which firms attempt to economize ${ }^{23}$ and may materially change patterns of exchange within and between organizations (firms, households, etc.). It is for this reason that among potential market imperfections influencing the economic efficiency of the electric power sector, transaction costs constitute a primary target for mitigation through interoperability enhancements.

The linkage between market failure and the presence of transaction costs deserves some elaboration and refinement. Even decades ago, market failure literature recognized the influence of transaction costs in market imperfections.

Current writing has helped bring out the point that market failure is not absolute; it is better to consider a broader category, that of transaction costs, which in general impede and in particular cases completely block the formation of markets. It is usually though not always emphasized that transaction costs are costs of running the economic system [27].

\footnotetext{
${ }^{23}$ Williamson argues that "the modern corporation is mainly to be understood as the product of a series of organizational innovations that have had the purpose and effect of economizing on transaction costs” [26].
} 
This last comment regarding the properly broad definition of transaction costs is crucial. It is important to note that, "the origins of transaction costs must often be sought in influences and motives that lie outside the normal domain of economics" [26]. Fundamentally, the most influential transaction costs associated with the provision of electric energy derive directly from physics. As the electric grid is integrated with information technology, transaction costs associated with establishing and sustaining interoperability are becoming similarly important.

The characterization of the transaction as "the basic unit of analysis" [28] naturally leads to the question of how to define a transaction. Economic research tends to focus on the nature of exchange taking place between market participants or internal divisions of a firm. "A transaction may thus be said to occur when a good or service is transferred across a technologically separable interface" [26]. ${ }^{24}$ While somewhat nebulous, the interface-centric definition of a transaction is complementary to the study of grid interoperability, where challenges to the exchange of information are often most prominent at the metering and control interfaces [31] - a paradigm where complexity will increase substantially with the number and types of gridconnected devices that must be monitored and controlled. This is because interoperability improvements are implemented at the interfaces between technologically separable entities.

Enhancements to interoperability will heterogeneously impact the technology stacks of firms in the electric power sector and the transactions in which they engage. Three principal dimensions of transactions have been identified - the frequency of recurrence, uncertainty, and the technological specificity of assets that support the transaction Williamson [32]. Asset specificity arises naturally during product development, production, and deployment activities, and is particularly important to understanding the value of interoperability.

Within the context of the smart grid, there are important spatial, temporal, technical, customer, workforce, and communications facets of asset specificity. ${ }^{25}$ Specificity emerges as device and system engineers work to meet technical requirements and successfully differentiate product and service offerings from those of competitors. Therefore, some forms of asset specificity may be deliberate, desirable, or too costly to eliminate. ${ }^{26}$ Indeed, certain facets of specificity are artifacts of the need to meet regulatory expectations regarding system and device performance. ${ }^{27}$

However, other facets of specificity may serve little to no value-enhancing purpose from the customer perspective and could thus be targeted for cost-mitigation without deleterious effects

\footnotetext{
${ }^{24}$ Ramstad offers some clarification regarding the definition of a technologically separable interface, stating that a transaction "entails the transference of assets across discrete stages of a multistage production process" Ramstad [29]. The interface between these discrete stages of production is crucial to the definition of a transaction, and the number of these interfaces is likely to increase as traditional grid functions are provided by more equipment in more locations. This complexity grows because "technologically separable interfaces in the Williamson sense are not given; they have to be discovered. Most likely a very great number of alternative technologically separable interfaces can be defined in any product development process or indeed in any production activity” [30]

${ }^{25}$ Williamson categorizes the differences in transaction-supporting assets as deriving from site specificity, physical asset specificity, and human asset specificity Williamson [26].

${ }^{26}$ The geographic distribution of population and load as well as the physical characteristics and requirements of various energy technologies influences the level of spatial asset specificity exhibited by components of the electric grid.

${ }^{27}$ Regulatory approval of utility investments may be predicated on the conformance of systems to specific standards.
} 
on value propositions. Specificity in communications systems can be useful, but it can also limit the extent of communications and the size of the network with which any one node can communicate. In the context of the smart grid, communications are an intermediate aspect of the operation of the system but not an end in itself. ${ }^{28}$ Interoperability improvements can effectively transcend the boundaries imposed by specificity; beginning with communications systems and moving on to the operations they support.

Interoperability in communications may enable smart grid devices to offer services beyond that which they were originally designed to provide; both through aggregation of existing services and the combination of disparate services into new composite offerings. The delivery of these aggregate and composite services has historically been associated with very high transaction costs. $^{29}$ As a result, these high transaction costs have formed significant barriers to entry, and in some cases, have entirely precluded market formation for new grid services. Interoperability improvements lead to the creation of shared networks over which new classes of transactions can take place, and new markets can emerge. The value of any interoperability enhancement will vary with the value of newly facilitated transactions.

Early improvements to smart grid interoperability have focused on reducing the transaction costs that are internal to the firm. The deployment of advanced metering infrastructure is one clear example where the benefits realized heretofore have accrued predominantly to the utilities making the investments and the customers they serve directly. Initial steps to improve interoperability between utilities and their customers can subsequently be harnessed to reduce the transaction cost impacts of other forms of asset specificity. When effectively targeted, interoperability enhancements can overcome the limits of specific communications regimes, enabling the creation of shared networks ${ }^{30}$ and the new transactions they facilitate. Ultimately, the diversity of asset specificity present in the electric grid could evolve from a factor contributing to the escalation of transaction costs into a factor enabling the creation of myriad innovative value propositions.

\subsection{BARRIERS TO ENTRY AND THE INCENTIVES FOR INTEROPERABILITY}

The technical and regulatory complexity of the modern electric grid, coupled with the high costs of infrastructure, constitute significant barriers to entry in electricity markets. Furthermore, the low capacity utilization of many generating and delivery assets during most hours of the year may act as a deterrent to entry, ${ }^{31}$ as could the cost of interconnecting new resources to the existing grid—which can be considerable even for incumbent firms. With time, improved

\footnotetext{
${ }^{28}$ To be clear, some firms offer communications systems and services as final products in a business to business context. However, unlike communications between human parties who might simply enjoy talking with each other, the value of communications between components of the smart grid is manifested only in the systematic improvements such communication confers on system operations.

${ }^{29}$ This is a function of a fragmented production environment and concomitant high coordination costs.

30 These shared networks may still be wholly owned by one company, but create value from interoperability through the merging of the information and operations technology that constitutes the distribution grid.

${ }^{31}$ As capacity investments traditionally needed to be sufficient to accommodate seldom-achieved peak demand, low capacity utilization throughout the year is concomitant with conventional grid architectures. Recent research and practice with demand response (DR) strategies suggests that the perception of peak demand as inflexible may deserve reexamination [33].
} 
interoperability within the electric grid may increase utilization and reduce interconnection costs as industry standards-based approaches to operation and interconnection displace ad hoc pointto-point integration efforts. To the extent that interoperability improvements reduce barriers to entry, the impact on market competition is likely to be greatest where reductions to entry costs constitute the largest structural changes.

One core value proposition for interoperability as a concept is that when devices, systems, and systems of systems are designed to be interoperable, the markets predicated on these technologies are enlarged and market liquidity is improved. As markets increase in size, the prize that is to be won through competition grows and firms encounter greater incentives to develop products and services for consumption. The fixed costs of serving a market may grow with market size, but the average fixed costs of production are likely to fall. As a result, electricity consumers may enjoy lower prices when greater interoperability reduces the utility's average fixed cost of serving its customers. To the extent that greater interoperability occurs at the end-user level, and in conjunction with greater automation, facilitates algorithmic operations by small electricity market participants, there is potential for improved market outcomes. ${ }^{32}$

The producers of complementary technologies have an interest in interoperability-enhancing investments that provide access to new customers or markets. At the same time, firms have an interest in limiting interoperability with other firms and their offerings if such interconnection threatens to siphon off customers. The fundamental trade-off of interest to the firm is one of new customer acquisitions and sales gained versus those lost to competitors now capable of interoperating with your devices and systems. ${ }^{33}$

In developing a model of the incentives for organizations to produce compatible products and services, Katz and Shapiro find that "firms with good reputations or large existing networks will tend to be against compatibility, even when welfare is increased by the move to compatibility," while "firms with small networks or weak reputations will tend to favor product compatibility, even in some cases where the social costs of compatibility outweigh the benefits” [35]. Given these countervailing incentives of market actors, Katz and Shapiro suggest that the social incentives for compatibility are generally higher than “firms' joint incentives for product compatibility.”

Conceptually interoperability goes beyond compatibility, but the incentive structures evaluated in the study of compatibility exhibit some consistency across different economic networks. ${ }^{34}$

\footnotetext{
${ }^{32}$ Evidence from the New York Stock Exchange suggests that algorithmic trading (AT) "narrows spreads, reduces adverse selection, and reduces trade-related price discovery" [34]. Furthermore, AT improves the information content of quotes and liquidity. Interoperability could thus be central to the realization of more robust electricity markets at the distribution level through improved opportunities for automation.

${ }^{33}$ Some online platforms have implemented the ability to create a customer account through the use of preexisting social network credentials. This is an example of firms pursuing a strategy of interoperability between platforms with the express purpose of reducing transaction costs and the firm's costs of customer acquisition. Within the context of the electric power sector reducing customer acquisition costs is most important to emerging firms without large user and technological bases.

${ }^{34}$ As noted in Blind [36] "[i]n mainstream economic literature, interoperability is either not used at all [37] or is used more or less synonymously with compatibility. And compatibility is achieved simply via standardization.”
} 
Achieving interoperability is central to the formation of shared networks, and conditions are most conducive to the emergence of a shared network when demand for transactions handled within private networks is equaled by demand for transactions handled across private networks. Under these hypothetical conditions, firms face a net improvement in sales with the establishment of interoperability and shared networks. Conversely, shared networks are least likely to emerge when there is little demand for services provided across networks [38]. ${ }^{35}$

Consider a scenario in which two adjacent balancing authorities lack the interoperability to exchange energy with each other. The incentive to develop interoperability and facilitate trade will depend on the opportunities for mutually beneficial trade between these balancing authorities. ${ }^{36}$ If the load profiles of the two balancing authorities are complementary, with peak demand periods tending not to overlap temporally, there may be opportunities to reduce the marginal cost of electricity by utilizing relatively more competitive neighboring generation or delivery assets when appropriate. If the demand for electricity in the two balancing authorities is coincident in their peaks, the opportunity for both entities to realize benefits from interoperability may be attenuated. A region with high renewable generation capacity, but little native load, might wish to improve system interoperability with a neighboring region home to a large metropolitan area with the intention of pursuing trades over a shared network. That same community with the large renewable generation is less likely to improve interoperability with another community that mirrors it structurally.

The actual incentives faced by any given firm with respect to interoperability investments are generally firm-specific and may vary across components of the firm's installed technological base. For example, a balancing authority (BA) may wish to increase its ability to exchange electricity with an adjacent balancing authority when conditions render neighboring generation assets more economically efficient. Achieving such a capacity for exchange entails the development of sufficient transmission infrastructure as well as investments that render the two systems (balancing authorities) interoperable. If the costs of achieving interoperability can be reduced, more opportunities for mutually beneficial exchange of electricity should be realized by market actors. Improving interoperability between organizations increases the strategy space and set of operational options through which each authority can maintain system balance. Those balancing authorities that are most operationally constrained by current system characteristics may have the greatest incentive to relax these constraints through interoperability enhancing investments (IEI).

These investments may target interoperability between entities of the same organizational strata (i.e. two balancing authorities) or entities of different types (i.e. a balancing authority and a local rooftop solar aggregator). Interoperability investments may increase the set of options available to a system operator or other entity, enhancing the value proposition of existing systems. The best investments will establish options that are regularly exercised and not previously available. Interoperability enhancing investments can improve the capacity utilization of various grid assets. Ideal examples of IEI will themselves exhibit high capacity utilization rates.

\footnotetext{
${ }^{35}$ An incumbent firm fearing competition from owners of other networks may thus face an incentive to limit the emergence of demand for services that would require the use of shared networks.

${ }^{36}$ The same would hold for two neighboring microgrids or other entities at varying organizational levels.
} 


\subsection{INTEROPERABILITY AND INCLUSIVE INSTITUTIONS FOR THE SMART GRID}

A web of institutions has evolved to make the numerous and complicated transactions necessary to ensure reliable operation of the electric grid - the most complex machine ever built by humanity - appear effortless to the end use consumer. It is therefore easy for any single stakeholder group to overlook the value of some of these "quiet" institutions. But transacting in a complex system with specialization is not aptly described as costless, and as North explains, "with positive transaction costs, institutions matter" [39]. Fundamental changes to the relative price of distributed energy resources and the costs of information have led diverse stakeholder groups to perceive an opportunity to benefit from changing the institutions that determine their relationships with the electric grid.

A simple definition of what makes institutions inclusive or extractive may not exist. However, inclusive institutions are so named because they tend to ensure that diverse stakeholder groups can secure the gains from their own efforts. Extractive institutions, on the other hand, tend to facilitate the appropriation of returns to effort by a relatively narrow subset of stakeholders. Within the electric power sector, efforts to improve interoperability promise to originate and strengthen inclusive institutions that elsewhere have contributed to economic growth by encouraging investment, harnessing the power of markets, and generating broad-based participation among stakeholder groups [40]. Acemoglu and Robinson argue that investment in new technology and creative destruction are central to economic growth, and these forces are more likely to arise from systems characterized by inclusive rather than extractive institutions. Such change tends to entail winners and losers both economically and politically, and thus any given inclusive institution may be viewed variably by stakeholder groups as both threats and opportunities. If institutional change can drive growth through becoming sufficiently more inclusive, the marginal benefits of change are likely to outweigh the associated marginal costs.

Figure 1 presents the diversity of opportunities emerging within and between different organizational levels of the electric grid and the economy it serves. At the level of individual households, technological change is reducing the deployment costs associated with distributed energy resources ranging from rooftop PV to electric vehicles, while simultaneously expanding the controllability of these assets and improving the ability to measure and value their outputs. At the proximal level, neighborhoods of households with these capabilities and resources are realizing new opportunities to work together in preventing outages, improving grid performance, and creating economic growth. Regions concerned with optimizing operations against emerging priorities while effectively planning for the future and stewarding scarce resources such as fresh water are able to meet these increasingly complex challenges with strategies only made possible through the thoughtful and comprehensive integration of systems. When aggregated further, these emergent strategies can deliver value on a global scale to all segments of society. 


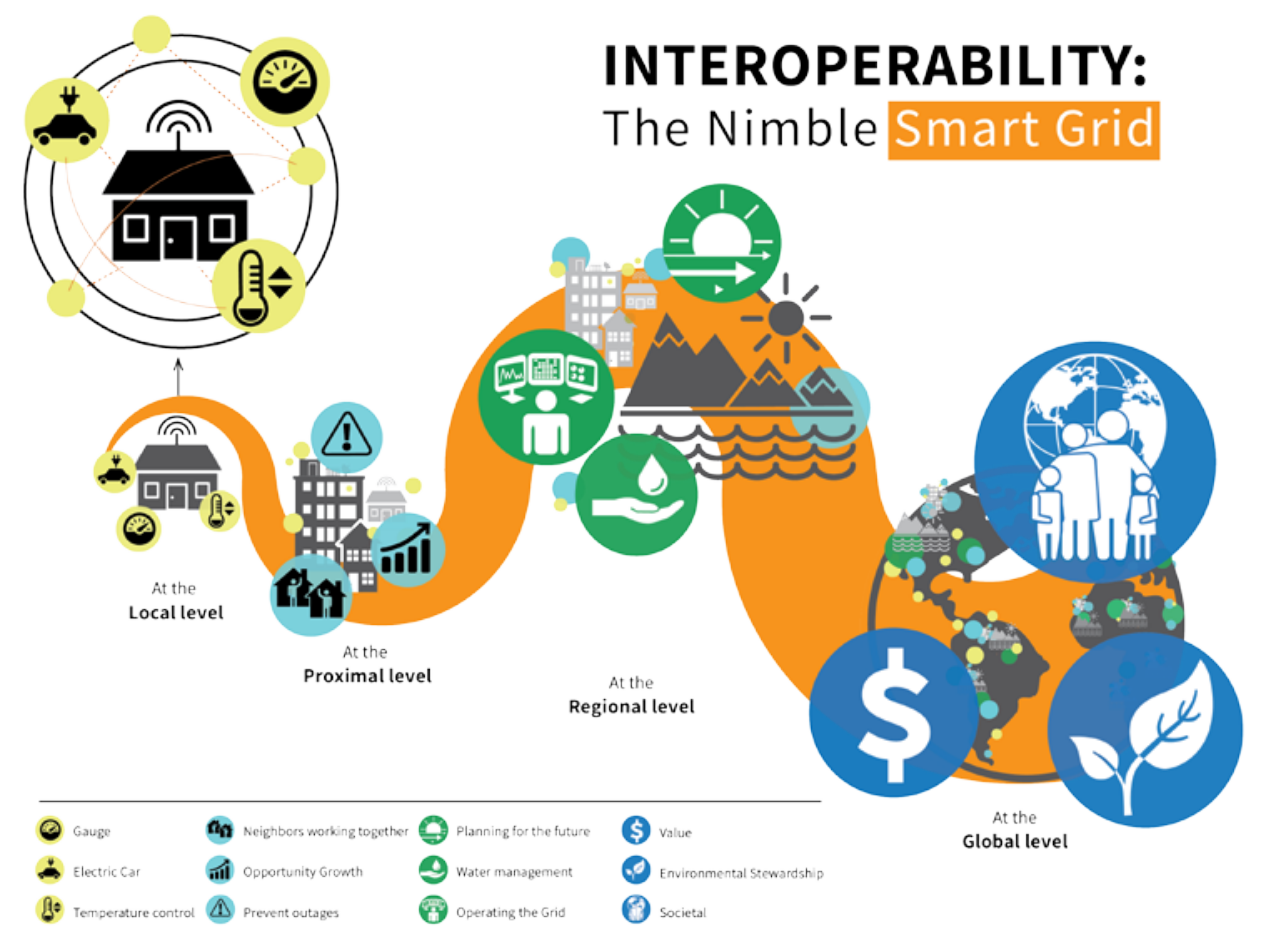

FIGURE 1: INTEROPERABILITY AND THE INSTITUTIONS OF THE SMART GRID

The potential benefits from a smarter electric grid are manifold and of a potential magnitude with little precedent in human endeavor. That such success will be realized should not be taken for granted as the historical record makes clear that it is "the costs of transacting that are the key obstacles that prevent economies and societies from realizing well being” [39]. Improving interoperability is critical to reducing the costs of transacting within and between the levels of smart grid organization depicted in Figure 1. Therefore, interoperability is crucial to ensuring that the smart grid underlining the economy of the future is itself an inclusive institution, in which broad participation, investment, and market mechanisms enable stakeholders of all types to contribute to the value network of emergent electrical and other systems.

\section{TRACK 1: ADVANCED BULK ENERGY SYSTEMS (ABES)}

\subsection{ARCHITECTURE DESCRIPTION}

The first representative architecture track is centered around advancements to the bulk generation and transmission system. The implementation of closed-loop protection and control over wide areas and increased installation and utilization of DC transmission backbones constitute two major components of the Advanced Bulk Energy Systems (ABES) architecture track. Through developing the capability for protection and control over a wider area, system operators increase the set of options at their disposal for ensuring system balance. The improvements to system control and flexibility are thought to outweigh any additional challenges from conducting balancing operations for a larger region. Investments in the transmission assets connecting 
current balancing authorities could enable greater shifting of generation and load along spatial and temporal dimensions. Operating a single balancing authority may be simpler than coordinating the efforts of two or more such entities. Under the ABES architectural track, the economies of scale and scope associated with system operation could act as a force for organizational agglomeration.

Examples of organizational agglomeration are present in the recent history of the electric power sector. The Midcontinent Independent System Operator (MISO) expanded its footprint in late 2013 to include an additional $30 \mathrm{GW}$ of generating capacity and 15,500 miles of transmission lines formerly operated by Entergy. In a press release, the MISO stated that the, "[g]reater economies of scale from the addition of Entergy will create more value for MISO members, including a 15 percent reduction in administrative fees" [41]. The MISO claimed, "projected savings of \$1.4 billion over a 10-year period as a result of the new members joining MISO” [42].

Regional transmission organizations (RTO) and independent system operators (ISO) may make investments that reflect the value of wide-area operations described within the ABES architectural track to more closely integrate their own systems with those found in adjacent regions. Fundamentally, integrative advancements to the bulk energy system should prove to expand electricity markets and reduce price volatility. ${ }^{37}$ A core tradeoff for a larger system is that of local versus system-wide optimization. Policies and investments that are optimal for a local community could either enhance or conflict with efforts to improve overall system performance. The relative importance of individual stakeholder groups may change with the progression of the ABES architectural track. How the integration of system operations over larger regions will be reconciled with the general trend towards decentralization remains an open question.

Characteristics of the ABES architecture track include improved system observability leading to greater situational awareness. Achieving a more resilient electric grid requires that operators progress from the historic management of single, isolated contingencies ( $\mathrm{N}-1)$ towards an ability to translate situational awareness into control actions that can respond to multiple, compounding contingencies (N-X).

Improvements to the transmission grid network form a central component of the ABES architectural track. Investments in transmission infrastructure can be capital intensive, but the organizations responsible for these developments have argued that they are cost effective [44]. Congestion on transmission infrastructure can limit the ability of remote resources to contribute to the electric grid value network [45]. Krishnan, McCalley [46] argue that a high-capacity multi-regional transmission grid spanning the three U.S. interconnections under a scenario of high DER penetration could reduce costs by $\$ 250$ billion to $\$ 500$ billion over a 40 -year planning horizon while also improving infrastructure resilience. In addition to direct cost savings, such a transmission overlay could also expand benefits in the form of reduced water consumption and environmental pollution as newer generation can displace older, marginal plants which are generally less resource efficient. There is simulation evidence that a transmission overlay could improve system resilience through attenuating the operating cost increase that generally follows

\footnotetext{
${ }^{37}$ Jacks et al. found that world market integration led to reductions in commodity price volatility. The integration of
} multiple jurisdictionally distinct electricity markets may thus attenuate price volatility Jacks, O'Rourke [43]. 
a major disruption [46]. Finally, advancements to the bulk energy system may offer greater flexibility when system operators are confronted with unforeseen events. Ultimately, investments targeting improvements in the coordination of transmission level assets must contend with, and hopefully compliment, similar efforts at the distribution level of the grid. Optimal strategies are likely to draw on opportunities at all levels of organization and segmentation.

\subsection{Possible SMART GRID MARKETS}

Conceptually, the ABES architecture bifurcates electricity markets along familiar lines of demarcation. Traditional electricity markets are split between wholesale and retail sales. Economically, the difference between wholesale and retail electricity trade has been that the former class of transactions involves sale for resale. Technically, the difference between these markets has been one of local versus regional transactions, constrained by the unidirectional electricity flows of the conventional distribution grid. Local electricity markets will match supply and demand within cities, counties, or metropolitan areas. When local assets prove unable to balance supply and demand in either direction (net surplus or net shortage) at an acceptable cost (monetarily, environmentally, politically) local market participants will avail themselves of regional markets.

Given sufficient interoperability between various balancing authorities or local market participants, the choice of sourcing locally versus regionally could become more fluid and responsive to marginal changes in system conditions. A result of this increased contestability of local markets may be the eventual dissolution of the lines between wholesale and retail electricity markets that ABES would initially reinforce. Regional markets could act as suppliers or buyers of last resort, aid in ensuring system balance, and increase the number of options from which both a system operator and end-use consumer may choose.

The following section will evaluate examples of market structures that mirror both the present state of the bulk energy system and the direction in which it is likely to evolve along the ABES architecture track.

\subsection{EXISTING MARKETS WITH SimiLAR CHARACTERISTICS}

Every community in the U.S., large or small, produces and consumes electricity. Large cities are served by multiple power plants and may draw power generated in neighboring states, while even the smallest of remote rural communities maintain small generators. The local markets do not operate in complete isolation from the rest of the economy as fuel and other inputs must be acquired, but the challenges inherent in electricity transmission, distribution, and storage as well as the critical nature of the product, render pure import strategies less tenable at higher levels of market aggregation.

Imperfect market analogues exist beyond the energy sector, but even so these external markets can provide insight into the changing architecture of the electrical grid. For instance, markets for agricultural products share some similarities with the local and regional markets of the ABES architectural track. In the case of a significant surplus with high storage and transport costs, produce could whither on the vine or degrade in storage before it can be brought to market in 
optimal form. Planning efforts in agriculture and electrical power have some similarities. Building generating capacity and planting next year's crops both have lead times that are long enough to introduce potentially significant amounts of uncertainty in the planning process. When too many farms plant a given crop and environmental conditions are favorable for growing, the resultant crop surplus may depress local market prices. A sufficiently large surplus could diminish prices over a wider region. Furthermore, monoculture farming may prove overly susceptible to a given set of hazards or threats in a manner that is mirrored by reliance on a single generating technology. ${ }^{38}$ Analogous to long-haul refrigerated trucking services in the agricultural sector, transmission infrastructure - and the energy imbalance services they enablefacilitate trade in electricity from a place where it would go to waste (fail to be dispatched) to another location in which there is a shortage (of low cost generation). ${ }^{39}$

Ample transport capacity and accurate forecasting of environmental and other conditions that impact supply and demand are crucial to both the agriculture and electricity sectors. The buildout of transport capacity in agriculture increased the value of adjacent land and the business prospects of firms operating there. As the railroad improved the export possibilities of ranchers on the high plains, improved bulk electricity transmission systems can facilitate the marketing of remote generation to distant load centers.

In addition to the transportation infrastructure needed to move finished products to market, infrastructure through which to source crucial inputs to production is also necessary. For agricultural lands in the American west, often this entailed the development of extensive reservoir and irrigation systems. For the electric grid described by the ABES architectural track, heavily reliant on natural gas generation, reliable operation will require adequate pipeline and transmission infrastructure to source fuel and export power to neighboring regions, as well as adequate water supplies for cost-effective cooling of thermal generation.

While dry-land farmers have long faced the trade-off between investments in increased water acquisition and increased efficiency of water use, ${ }^{40}$ electricity producers now face a similar quandary. Should resources be expended to more-efficiently coordinate natural gas and electricity systems given the increased linkage between the two components of the bulk energy system? Or, would a shift towards renewables that need transmission capacity, but do not require a network infrastructure for the sourcing of fuel, prove to be a more efficient architecture? ${ }^{41}$ Such trade-offs must again be considered for water access, where consumption for thermal

\footnotetext{
${ }^{38}$ Fuel shortages or disasters that reveal existing operational deficiencies may lead a region to curtail a large share of production capacity until the underlying problem can be mitigated. For example, Japan idled its 54 nuclear power plants after the March 2011 Tohoku earthquake and related meltdown at a plant in the Fukushima Prefecture, returning only five plants to operation by early September 2017 [47].

${ }^{39}$ Should the growth in DER in a given location outpace local demand growth, the presence of considerable transmission capacity and advanced control equipment may prove instrumental to ensuring the best return on investment for DER owners. Of course, distribution infrastructure must also be up to the task of delivering distributed generation to the transmission system for export to adjacent markets or balancing authorities.

${ }^{40}$ Water withdrawals for agricultural purposes have long needed to be coordinated with other societal needs, such as for sufficient flows to enable navigation along inland waterways, fishery health, and recreation.

${ }^{41}$ While a network of parts suppliers and firms capable of conducting maintenance and repair services is needed for wind, solar, and other renewables, existing transport networks could facilitate these needs without the development of pipelines and storage facilities.
} 
power generation has steadily increased as generators have migrated from once-through to recirculated cooling technologies [11]. Views are likely to fall along ownership lines, but the costs of major infrastructure build-outs are generally borne across wide segments of society. ${ }^{42}$

The concrete industry, like thermal generation, is described by high transport costs and the stockpiling of precursors. Once mixed, wet concrete must arrive at the build site within a relatively short period of time to avoid it being rendered an economic burden. Several strategies exist for the effective operation of concrete plants. One approach is the geographic distribution of conventional, central batching plants that can deliver the mixed, perishable product locally via truck. ${ }^{43}$ Another method is to build portable batching plants to set up on site and avoid the need for long-distance vehicular delivery. Regions with significant road congestion or high uncertainty regarding delivery times may be good candidates for mobile plants while regions with exceptionally high demand and low delivery costs constitute the best opportunities for centralized production. The level and predictability of transport costs are central to the selection of production strategy in the concrete industry.

Transmission costs are likewise pivotal to the siting and technological choices faced by developers of generation resources in the electric power sector. Within the ABES architectural track, the relative importance of efforts to improve electricity transmission and natural gas pipeline infrastructure, as well as the efficacy of coordination, will be material to the growth of renewable and natural gas generation as well as power electronics and energy efficiency investments at the consumer edge of the grid. ${ }^{44}$ The interaction of these investments in both delivery infrastructures and their coordination could evolve along a variety of paths that might favor any one of many competing generating technologies.

Similarities could emerge between the ABES architectural track and traditional local and longdistance phone service markets. Like telecommunications networks, the value of any given electric network (grid) is a function of entities connected. The installation of a landline in a home is of little value if the only other connected nodes are to be found in houses within walking distance. When joining a communication network facilitates conversations with businesses across town, or relatives across the country, the value increases commensurately. In more recent history, the value of a cell phone contract increased when the cost of communicating with individuals using different carriers became the same (to the end user) as the cost of communicating with others (using the same carrier) who were deemed "in network". Development along the ABES architectural track would improve transmission resources and capabilities and similarly enable the strategic coordination of diverse actors and systems through greater integration of distant segments of the electric grid.

\footnotetext{
${ }^{42}$ To the extent that recent merger and acquisition activity has brought together electric and natural gas utilities, ownership structures are changing in a manner that allows such firms to internalize the costs and benefits of investments in energy delivery infrastructure.

${ }^{43}$ Sanchez, Perez [48] explains that "unlike other perishable products that can be produced and stocked economically as inventory to absorb supply chain uncertainty, concrete must be mixed on demand lasting approximately two hours after water has been added to the mix of dry materials”.

${ }^{44}$ For example, the installation of a new transmission resource may lower the local cost of electricity through cheap imports sufficiently to impact a household's incentive to invest in rooftop solar, and the local utility may find that it needs to improve its control infrastructure in order to make the most of the new transmission options.
} 
While discussion of non-energy markets is instructive, the best analogue for the markets that could arise in a future described by the ABES architecture track may be that of the energy imbalance market (EIM) currently growing in the American west with the steering of the California Independent System Operator (CAISO). In the case of an imbalance market, "[e]xpanding the geographic scope of the real-time dispatch has the potential to improve market efficiency and lower costs to consumers, in part because the real-time dispatch will be better able to take advantage of the spatial diversity of variable renewable production" [49]. ${ }^{45}$ The local markets under the ABES architecture could evolve from their current form, serviced by municipalities, cooperatives, and investor-owned utilities into markets in which customers play a more active role in consumption and production decisions. On the other hand, given sufficient transmission capacity, investments in the ABES architectural track could ensure that large renewable plants enjoying economies of scale and low marginal costs are always available to serve load. What follows is a discussion of the CAISO EIM.

\subsection{ABES CASE STUDY: CAISO EIM}

\subsubsection{DESCRIPTION}

Rapid growth in the installed base of variable output renewable generation has led to the development of new organizational structures for ensuring reliable operation of the grid. One such structure, the EIM implemented by CAISO initially with PacifiCorp in 2014, has continued to grow. An energy imbalance is the discrepancy between actual and scheduled energy production or usage. ${ }^{46}$ Schedules are established through local day-ahead markets in line with forecasted levels of load. For a variety of reasons, generation and load will differ from the levels anticipated by even the most detailed forecasts. ${ }^{47}$ Conventionally, imbalances are remedied through re-dispatch of resources within a given Balancing Authority Area (BAA), sometimes at considerable cost when only low-efficiency options remain. With the advent of an EIM, resources can be re-dispatched from any of the integrated BAA. In theory, the benefits from operating an EIM can include greater economic efficiency in the dispatch of resources, lower local reserve requirements, improved operational reliability, and reductions in pollution.

\subsubsection{Motivation}

Members of the CAISO Market Surveillance Committee (MSC) noted in an opinion of the EIM implementation that, "expansion of the EIM would very likely enhance competition by

\footnotetext{
${ }^{45}$ The Pacific DC Intertie is an example of transmission infrastructure implemented to facilitate trade in electricity between the large hydroelectric power plants of the relatively less-populous northwest with the highly populated region of southern California. Peak demand at the north and south endpoints of the intertie are generally not coincident, allowing the direction of trade to serve system needs on either end.

${ }^{46}$ The CAISO EIM is an energy only market. The acquisition of ancillary services is still the responsibility of individual balancing authorities. The EIM is a real-time market composed of fifteen-minute and five-minute market runs that produce schedules and prices for energy [50].

${ }^{47}$ Demand might fall below the forecasted level if a day anticipated to be quite warm turns out to be more moderate. Generating plants may experience unscheduled shutdowns as a result of mechanical failure, natural hazard, or malicious act. If either generation or load depart significantly from the forecasted level, the maintenance of system balance may require the dispatch or curtailment of additional resources.
} 
expanding the contestability of regional markets" [49]. Fundamentally, this is an argument that economic efficiency will improve as an EIM allows the lowest marginal cost resources to be dispatched to balance fluctuations in load, even if they are managed by an adjacent BA That is, mutually beneficial transactions between generators and consumers that might previously have gone unrealized due to system boundaries are rendered feasible by the operation of an EIM, ${ }^{48}$ displacing less efficient trades. A direct result of implementing an EIM is a reduction in the cost of generation, lowering the cost of service. ${ }^{49}$

Implementation of an EIM can increase the options available to a system operator in the event of a contingency. The level of reserves required to reliably operate the electric grid could fall as the establishment of an EIM allows individual balancing authorities to share reserves [51]. The fewer reserves that must be maintained to achieve a given level of reliability, the lower the cost of service. While increased exposure to variable generation, perhaps as a result of involvement in an EIM, may place some upwards pressure on reserve requirements, advancements in control technologies — such as those recently demonstrated at a utility-scale solar power plant [15] —are likely to mitigate such concerns.

As many of the lowest marginal cost generating resources are high-efficiency natural gas plants and renewable generation facilities, implementation of an EIM can reduce the emission of pollutants through the displacement of less-efficient, higher-pollution plants. Changes to the composition of generating plants will induce changes in the spatial and temporal distribution of water consumption [52].

Most electricity is transacted in forward markets like the DAM. On the other hand, "[t]he realtime market is run hourly and in 5-minute intervals and clears a much smaller volume of energy and ancillary services than the day-ahead market, typically accounting for only 5 percent of scheduled energy" [53]. However, increasing penetration of intermittent generating resources may lead to a higher proportion of wholesale energy transactions occurring over highly responsive imbalance markets. ${ }^{50}$ Success for the EIM is likely to be followed by further expansion of the services traded between EIM members. Once interoperability between balancing authorities is sufficient to deliver energy imbalance services, the incremental costs of achieving interoperability for the sake of DAM, and ancillary services may be relatively small. ${ }^{51}$

Interoperability is necessary for the exchange of information to operationalize energy imbalance services, but it serves a further purpose as well. Interoperability is both an input to operational

\footnotetext{
${ }^{48}$ An EIM operates on a shared network formed from the distinct networks of participating BAs. Over time, BAs that see an opportunity to improve performance through participation in the EIM will work to join.

${ }^{49}$ To lower the cost of service, the reduced cost of generation must exceed that expense required to implement the EIM.

${ }^{50}$ There is evidence from the past experiences of the natural gas and electricity industries that technological, regulatory, and market forces will lead to a compositional change in the share of transactions handled with specific contract structures. "As in the natural gas industry, the ratio of long-term to short-term contracts for electricity will decline rapidly" [54]. The rapid growth in short-term contracts is especially clear in the electric power sector. "In the first nine months of 1996, the spot market for electricity was approximately $\$ 3$ billion, up from $\$ 500$ million in 1995 and only $\$ 50$ million in 1993” [54].

${ }^{51}$ The hardware upgrades outlined by the CAISO for the implementation of the EIM include the capability to handle 5 min dispatch [55].
} 
improvement and an important product, enhancing transparency between balancing authorities. Interregional markets always pose questions regarding which regions and participants benefit the most and least from trade. The ability of balancing authorities to exchange information on the EIM transactions allows them to see how they themselves benefit and what their transacting partners stand to gain from trade.

\subsubsection{TECHNICAL CONCERNS AND REQUIREMENTS}

The CAISO EIM requires enough information on the infrastructure and conditions of partnering balancing authorities to integrate the partner's electric grid into the CAISO full network model (FNM). This data already exists, but must be shared in full and timely fashion with the ISO to facilitate efficient dispatch schedules. When new market participants are interconnected within an EIM-connected balancing authority, these changes must be incorporated into to the CAISO full network model. Net schedule interchange data is required to calculate the loop flow impact of external schedules on the CAISO and EIM network [50]. Other necessary data includes the schedule and path information for transactions scheduled with the Western Interchange Tool. The network model from each EIM entity's Energy-Management System (EMS) is needed. CAISO states that all EIM entities shall use the Common Information Model industry standard when exchanging the network data. An EIM requires the sharing of information on the "net energy for load" (NEFL) for each constituent balancing authority so that the EIM may allocate reliability costs appropriately among entities. At present, NEFL data is collected annually. Information on maximum transfer limits in the form of Available Transfer Capacity and Dynamic Transfer Capacity must be exchanged between individual EIM entities and CAISO. The CAISO must also maintain awareness of any unscheduled flows on the EIM through the exchange of this data between EIM BAs.

Achieving this level of interoperability between balancing authorities for an EIM requires additional investments in hardware, software, and systems. The CAISO outlines the cost structure of the EIM in implementation agreements between itself and other western balancing authorities that are submitted to the Federal Energy Regulatory Commission for filing and acceptance. The CAISO determined the one-time implementation costs for an EIM that extends to all balancing authorities in the Western Electricity Coordinating Council (WECC) to be $\$ 19.7$ million and allocates to individual partnering BAs part of these costs in proportion to the share of benefits that will accrue to the BA through its involvement in the EIM [55].

Of the 11 cost categories outlined in the implementation agreement, licenses for software systems development (\$12.2 million), data storage (\$2.0 million), testing (\$1.5 million), and production software modifications (\$1.0 million) collectively account for nearly $85 \%$ of implementation costs [55]. However, given the indivisible nature of investments in the EIM system improvements, the composition of costs borne by the CAISO to expand the EIM to individual balancing authorities may vary.

\subsubsection{Evaluation of Market Success}

The core value proposition of the EIM is that through greater integration of existing physical infrastructure, and the exchange of information on system conditions and requirements, a wellcoordinated group of balancing authorities can achieve a dispatch schedule that is more efficient 
than would be possible as a set of uncoordinated entities. A high level of interoperability between balancing authorities was necessary for the EIM to generate value greater than implementation costs. A series of quarterly benefits reports, detailing the performance of the EIM indicate that success has been achieved in delivering the interoperability between balancing authorities that is necessary for economic benefit.

The most recent benefits report at the time of writing is for the first quarter of 2019. More efficient dispatch within and between balancing authorities involved in the EIM delivered \$85.38 million in gross benefits during Q1 of 2019, bringing the total gross benefits since market inception in November 2014 to $\$ 650.26$ million. By preventing the curtailment of renewable generation resources, the EIM had the effect of reducing emissions equivalent to 22365 metric tons $\mathrm{CO}_{2}$ in $\mathrm{Q} 1$ of 2019 . Flexibility reserves were reduced by an average of $45 \%$ across the EIM footprint for the same period [56].

The success of the EIM is evident in the extent to which benefits exceed implementation costs. However, a more salient piece of evidence is that additional balancing authorities are working to improve interoperability with the CAISO and the EIM continues to grow. With the addition of the Los Angeles Department of Water and Power to the list of pending EIM participants, one of the largest municipal utilities in the country has demonstrated interest in the market [57].

\subsubsection{LESSONS FROM CAISO EIM CASE STUDY}

Improvements in the exchange of information between adjacent balancing authorities for operating an EIM or similar market reduces the propensity for neighboring energy imbalances to impact local operations in an unanticipated manner. Greater interoperability among balancing authorities allows for improved utilization of existing physical infrastructure such as transmission lines, as well as more economic integration of variable generation renewables through reduced curtailment. Improved interoperability, manifested through a functioning EIM can improve resilience while reducing the need to invest in costly, underutilized reserve generation. Additionally, those plants still operating, and which no longer must provide reserves can operate at a more efficient level of output, improving their performance as investments. For example, some relatively efficient thermal plants that previously operated below optimal output to provide reserves are likely to see their value proposition improve with the increase in interoperability between BA that comes with an EIM.

\section{TRACK 2: HigH RESILIENCE GRID (HRG)}

\subsection{ARCHITECTURE DESCRIPTION}

There is a strong national interest in the design and implementation of an electric grid that is resilient to myriad hazards as well as thinking adversaries. Increasingly, there is a view that resilience to such threats should be designed into the grid architecture from the outset rather than implemented as a set of bolt-on solutions. The guiding question driving the development of this architecture track is "what does a modern grid look like from a resilience perspective?" [7].

Events and acts that disrupt the functioning of the electric grid can entail severe consequences 
for all segments of the economy, impacting safety, productivity, comfort, and quality of life. A fundamental question is how can the grid tolerate disruptive events without serious degradation of operation and performance outcomes? Furthermore, how can the concept and design principle of interoperability be leveraged to deliver higher levels of resilience to the electric grid and those reliant on its services?

"Historically, one of the primary means of achieving system resilience in the event of accidental component failure is through redundancy" [58]. Redundancy of electricity supply has been achieved historically through reserve generation capacity requirements and redundant circuitry to transmit power from generator to customer site. Possession of multiple on-site generators may help to ensure backup capacity is available in the event of a contingency. The fundamental challenge with redundancy can be that certain components will, by definition, rarely be used, and therefore exhibit low capacity factors and higher associated costs. As the fixed costs of grid operation rise with the conventional approach to resilience, strategies of pure redundancy may become prohibitively costly to implement. ${ }^{52}$ A set of strong economic pressures have reduced the operating margins of many electricity sector firms at a time when the need for further investment in infrastructure is rising. When margins are threatened, it is natural for firms to seek new and incremental efficiencies. ${ }^{53}$

One complicating factor is the general difficulty in arriving at consensus on a working definition of resilience within the context of the smart grid. This challenge derives from the common conflation of reliability and resilience. The Electric Power Research Institute (EPRI) defines resilience as consisting of three components: prevention, recovery, and survivability. ${ }^{54}$ However, other organizations view recovery efforts as beyond the scope of resilience as the need to recover implies a system that was insufficiently resilient to a given hazard event. Work on the architecture of the smart grid at PNNL offers the following definition that is adopted for this paper: "Grid resilience is the ability to withstand grid stress events without suffering operational compromise or to adapt to the strain so as to minimize compromise via graceful degradation. It is in large part about what does not happen to the grid or electricity consumers" [60]. Of course, "what does not happen" is inherently difficult to measure and therefore challenging to design into a system. Grid architects can make a collection of design choices with the intention of creating a system that is prepared for the litany of threats it faces and capable of survival even in the face of the most severe challenges. This is important as, "[f]or at least the next two decades, most customers will continue to depend on the functioning of the large-scale, interconnected, tightly organized, and hierarchically structured electric grid for resilient electric service” [58].

\footnotetext{
52 This is not to suggest that redundancy should be eliminated as a strategy entirely. As was seen in the ABES track, interoperability between balancing authorities enabled an EIM to function that rendered some existing redundancy (reserves) no longer necessary, and later architecture tracks will highlight the value brought by modular and distributed resources that can also improve resilience by mitigating the impact of individual component failure through effective coordination. Communication systems will still need to be fault tolerant: an outcome currently architected through the deployment of mesh networks.

${ }^{53}$ Detailing the presence of a "catch-22" in the PV industry, Powell, Fu [59] notes that "technological innovation is needed to lower per unit costs and increase technology competitiveness, but high [capital expenditure and] low margins increase the degree of difficulty of executing an innovation-oriented business plan”. While the nexus of these challenges may be especially acute in the PV industry, it is present in the broader electric power sector as well. ${ }^{54}$ EPRI, “Grid Resiliency,” available online: https://www.epri.com/\#/pages/sa/grid-resiliency?lang=en-US, Accessed 12-09-2019.
} 
Many of the technological innovations that fall under the umbrella of ICT and offer the opportunity to realize efficiencies through greater interoperability have value propositions that could be aligned with resilience needs. Interoperability enhancements (such as smart meter or other sensor deployments) can improve the situational awareness of system operators in a manner that enables them to coordinate uncompromised resources to resist further grid stress. A lack of sufficient interoperability between DER and system operators has meant that DER can sit idle during outage events to avoid damaging equipment or injuring work crews. Greater interoperability could enable grid operators to dispatch DER services more effectively during contingencies as well as normal operating conditions. Improvements to interoperability will be crucial to efforts to deliver greater grid resilience without bankrupting firms in the energy sector, as these investments can reduce the frictions within and between organizations.

\subsection{Possible Paths to Resilience in the SMART GRid}

The key questions electric utilities must address are what is the minimum level of service that must be provided to each customer class (residential, commercial, industrial, critical infrastructure), and what is needed to make sure the provision of these services is resilient to the threats faced? The next question is whether these resilience-focused business activities will take place internal to the utilities or if electric power firms will simply source solutions from outside organizations that perhaps provide resilience goods and services to firms and government entities across economic sectors.

The increasing focus of the electric power sector on resilience will lead many utilities and their partners to seek additional capabilities that are beyond the traditional response and recovery activities they already possess. Some of these efforts will be internal, taking the form of incremental improvements to personnel and equipment. The important markets for the internal structure amount to factor markets like that for labor skilled in the operation and maintenance of complex systems. As the goods and services that are inputs to resilience in the electric power sector are also in demand by other critical infrastructure sectors (telecommunications, transportation, natural gas, water, sewer) entrepreneurial organizations may seek to develop platforms that can deliver resilience-enhancing resources and capabilities to a wide variety of customers. Such a development might constitute a force for network convergence and create an affinity between architecture tracks 2 (high resilience) and 5 (urban converged networks). Early approaches composed of internally focused strategies for resilience may thus transition into greater utilization of services developed by a growing class of firms specializing in resilience services.

If resilience is sought externally by electric utilities, the most important markets may be for products and services designed to attenuate the impact of hazards through preparation and services that allow for grids to operate beyond historically ideal conditions without reducing service quality or efficiency. Some of these inputs are straight-forward: steel and concrete power poles that are stronger than wood poles, buried conduits rather than suspended wires, hardened power electronics equipment and robust communications equipment. Other, more complex inputs to resiliency in the electric grid include various components of firms' software stacks and the adoption of best practices by personnel. Early examples of organizations that produce goods and services that improve the resilience of the electric grid include the National Weather Service 
(NWS) and other entities that model and predict the conditions of the physical environment in which the grid operates. Preparation requires information to ensure proper resource allocation before, during, and after a severe weather event. Similarly, governmental and private sector organizations that monitor and mitigate cyber-physical threats to critical infrastructure are likely to factor more prominently in the electric sector's ecosystem going forward.

"While many distribution automation technologies are available that would enhance system resilience, their cost of deployment remains a barrier, particularly in light of challenges in monetizing the benefits of such installations” [58]. Furthermore, electric utility investments in resilience enhancing technologies may be suboptimal if there is uncertainty about whether their regulatory overseers will allow the expenditures to be rate-based. Often, approval of rate-basing expenditures is tied to the presence of tangible examples of similar investments being deemed prudent on comparable grids. Where the benefits from investments in resilience can be readily and sufficiently internalized by incumbent utilities, those actions are likely to proceed along the internal track described above. Where the capture of such benefits is difficult for reasons that could include but are not limited to an inability to fold required investments into the rate base, external actors (non-utilities) are likely to make more significant progress in the near term.

When the benefits of an investment are primarily tied to losses avoided in the event of a severe hazard, the absence of such a hazard over a planning horizon can make a priori prudent investments in resilience look unnecessary. Recent work in the field of economics of community resilience investigates the co-benefits of resilience enhancing investments. ${ }^{55}$ Electric system investments targeting improved resilience are likely to entail significant, quantifiable co-benefits ${ }^{56}$ which are important to identify and quantify, as the accrual of community benefits in the absence of a severe hazard may provide the justification for resilience investments on costbenefit grounds. Markets for resilience-enhancing investments may be thin if suppliers are unable to convincingly articulate the co-benefits or dividends paid to communities by these investments.

Another strategy to contend with suboptimal investment in resilience enhancements is to pursue sufficient interoperability so that the investments in one part of the grid can provide resilience services to adjacent parts of the grid. Improvements to the resilience of a given BA may prove useful to a neighboring BA if next door neighbors are more capable of tendering help when a hazard is encountered. Coordination across organizational units may prove as a catalyst for the realization of resilience benefits and encourage further socially efficient investment in hazard counter measures that would not be undertaken in a more isolated context. ${ }^{57}$ The degree to which such strategies are possible hinges on the extent and nature of interoperability.

\footnotetext{
${ }^{55}$ For further discussion and a summary of recent research on the resilience dividend concept, please see [61].

${ }^{56}$ For instance, the installation of DER at an emergency response facility could provide backup power when the larger grid is compromised and reduce the operating energy costs of the facility under normal conditions. In the absence of a major disruption, the regularly recurring benefits to operating costs are likely to form the justification for the investment in DER, even if the primary goal was resilience oriented.

${ }^{57}$ Investments that make one neighborhood's electric grid more resilient to hazards or threats could materially benefit others near-by. Efforts that reduce congestion in one region could lower the cost of delivering energy to an adjacent region.
} 
With time, as examples of resilience enhancing investments grow in number, utilities may have more success in convincing a PUC to allow such investments. The internal track to achieving resilience may thus catch up with the external strategy track.

\subsection{INTERNAL STRATEGIES AND COMPONENTS OF GRID RESILIENCE}

Conventional electricity markets have pursued an integrated approach to resilience in which load serving entities, balancing authorities, or other appropriate organizations have engaged in a selection of strategies that together function to ensure some level of grid resilience. Individual organizations have participated in numerous smaller markets for resilience enhancing products and services. What follows is a brief, non-exhaustive summary of some of these options.

Table 2 lists a variety of strategies that firms in the electric power sector employ to improve their operational resilience. The strength of the value proposition for interoperability improvements with respect to each strategy is indicated, with ++ denoting the opportunities perceived to be the most valuable. The perception of some positive value proposition is denoted by + , and indicates that the role of interoperability is relatively uncertain. Specific examples of these value propositions are also listed in Table 2.

Asset Management Systems (AMS) are software suites that can support the decision-making process of firms operating large technology portfolios. The services provided by AMS can include asset supervision and asset performance, through which the operating condition and economic performance of grid components can be evaluated, respectively [62]. The integration of myriad components with distinct interfacing requirements can contribute to the cost of asset management, maintenance, operation. Improved interoperability between components of the electric grid could reduce these integration costs and help operators to realize economic efficiencies.

Outage Management Systems (OMS) are of growing importance to electric utilities as extreme weather events lead to increasingly large sets of customers losing power, sometimes for long periods of time. Modern OMS allow for optimized response to outages through the rapid identification of problem locations, reducing the number of truck rolls necessary to get the grid back up and running. These systems improve operators' ability to estimate the response resources and time necessary to achieve restoration and facilitate information sharing with concerned customers. Interoperability between utility OMS and undisrupted DER could allow for operators to call on the latter class of assets to provide valuable services during contingencies. Interoperability enhancements in this vein could increase the value proposition of DER and increase the set of options available to grid operators. Some outages could be shortened or avoided with greater interoperability between the OMS and other grid components. 
TABLE 2: INTEROPERABILITY AND STRATEGIES FOR RESILIENCE

\begin{tabular}{|l|l|c|l|}
\hline Acronym & Resilience Strategy & $\begin{array}{c}\text { Interoperability } \\
\text { Value Proposition }\end{array}$ & Potential Benefits from Interoperability \\
\hline AMS & Asset Management Systems & ++ & $\begin{array}{l}\text { Lower asset management costs as } \\
\text { constituent devices are easier to integrate } \\
\text { into network. }\end{array}$ \\
\hline OMS & Outage Management Systems & + & $\begin{array}{l}\text { Improved information sharing during a } \\
\text { disruption. Coordination of DER service } \\
\text { dispatch with utility response efforts. }\end{array}$ \\
\hline MAG & Mutual Assistance Group & $\sim$ & $\begin{array}{l}\text { Improved communications and } \\
\text { coordination capabilities among outage } \\
\text { response workers. }\end{array}$ \\
\hline EIM & Energy Imbalance Market & ++ & $\begin{array}{l}\text { Expand the footprint of the EIM to include } \\
\text { additional compatible resources for } \\
\text { balancing. }\end{array}$ \\
\hline DER & Distributed Energy Resources & ++ & $\begin{array}{l}\text { Facilitate the marketing of new electricity- } \\
\text { related services by small grid-edge } \\
\text { resources. }\end{array}$ \\
\hline IED & Intelligent Electronic Devices & & $\begin{array}{l}\text { Improved system monitoring and } \\
\text { contingency response. }\end{array}$ \\
\hline TMS & Tree Management Services & + & $\begin{array}{l}\text { Improved management through monitoring } \\
\text { and communication of foliage } \\
\text { encroachment on delivery assets. }\end{array}$ \\
\hline
\end{tabular}

Mutual Assistance Groups (MAG) are entered by utilities around the country and organized by region so that when extreme events require restoration actions that are beyond the capacity of any individual firm to respond, other firms can lend aid and utilize idle human and capital resources. When hurricane Irma hit Florida in early September 2017, more than 50000 workers engaged in the restoration efforts to return power to the 6.7 million customer accounts that experienced outages [63]. The time to full recovery could have been considerably longer without the aid from the MAG. Coordinating 50000 people from a variety of organizations is no small task and improvements to organizational interoperability are crucial for the continuing success of MAG. Technological interoperability could improve the coordination of restoration workers and the triage process through which contingencies are handled.

EIMs, discussed at greater length in Section 3.4, may also provide for an improvement in system resilience. If hazards render local generation inoperable for a time, generation from neighboring BA within the EIM can help provide efficiently dispatched alternatives to load curtailment. Curtailment is generally less desirable than finding other generation options, and in the case of critical infrastructure such as police stations, fire stations, and hospitals, simply curtailing loads may not be an acceptable option. Interoperability between participating resources is a prerequisite for an EIM to function. As the group of interoperable resources grows, so too does the value proposition of the associated EIM. This value proposition is derived from the opportunities for mutually beneficial trades that the EIM makes possible.

Local energy storage and DER, sometimes deployed together, are increasingly affordable options for electricity end consumers, large and small. On-site generation options discussed further in Chapter 6 on microgrids, are undergoing greater levels of adoption. The option to self-supply electric power ensures that critical loads can be met, even when disruptions in the distribution or 
transmission grid preclude delivery from centralized generating assets. However, at present, many opportunities for DER to provide valuable services to the grid go unrealized due to a lack of interoperability between these distributed resources and conventional centralized system operators.

Several key resilience enhancing devices undergoing periods of greater adoption deserve specific mention. Automatic reclosers, sectionalizers, ${ }^{58}$ and other intelligent electronic devices (IEDs) that communicate with the rest of the system are crucial to managing operations during times of system stress, and quickly returning the system to a healthy state after the hazard has passed. As many disruptions are temporary in nature, such as a short circuit caused by a branch blown against a distribution line, automatic reclosers allow the distribution system to heal itself quickly and without requiring the intervention of restoration workers. While many of these devices are designed for isolated and automated operations, interoperability enhancements should enable the information collected by IEDs to be communicated in an actionable manner to system operators and grid end-users which could allow for proactive management of the system away from the next contingency.

Tree Management Services (TMS) are not new, but preventative care to minimize the threat to transmission and distribution assets from plant debris can go a long way towards improving resilience. Furthermore, preventative efforts have the advantage of being carried out on a consistent and predictable schedule, avoiding the cost of overtime and rush that is endemic after a hazard such as a hurricane. However, even the most-effective preventative efforts are unlikely to eliminate the need for restoration capacity after a major storm. Computer vision tools used to monitor the physical state of important delivery assets could, if rendered interoperable, communicate impending foliage-related problems to TMS organizations, enabling proactive treatment and more effective triage during periods of considerable system stress.

\subsection{EXTERNAL MARKETS FOR RESILIENCE}

Some actions to improve the resilience of electric power supply take place outside the boundaries of traditional electricity markets. While Section 4.3 discussed strategies organizations employ to improve the resilience of their supply chain, this section investigates the actions taken by electricity customers on other markets to improve the resilience of their supply of electricity. Next, attention is trained on analogs in the transportation services sector that may afford the reader some insight into broader trends in how organizations may achieve resilience.

Electricity customers generally cannot take direct steps to control the level of resilience that they enjoy in their service. ${ }^{59}$ Hospitals and critical facilities are prioritized within the context of recovery efforts, but many entities for which a high-quality electricity supply is a necessary input

\footnotetext{
${ }^{58}$ Abiri-Jahromi, Fotuhi-Firuzabad [64] notes that the, “[b]enefits of automated sectionalizing switches can be quantified in terms of the reduced duration of outage and reduced number of customers affected during permanent faults by fast restoration of power to unfaulted customers. This can be done by isolating the faulted part of the network by remote switching of sectionalizing devices and supplying the unfaulted part from other routes".

${ }^{59}$ To be sure, households or small businesses can take some of the steps outlined in Section 4.3, such as installation of DER or tree management to reduce the risk of outages at the edge of the grid. However, steps to mitigate risks and increase resilience at the distribution feeder or substation level are generally beyond the scope of individual customer actions.
} 
to production cannot choose to be treated as critical even if they were willing to pay for a higher quality of service. However, all facility operators have the option to purchase redundant supply options like backup generators and energy storage equipment on their respective hardware markets. Organizations that desire a level of electric supply resilience that is greater than that which is supplied by incumbent producers may make parallel investments in behind-the-meter (BTM) devices.

Two implications of this pattern of parallel expenditure are worth noting. First, the cost structures of these redundant generating and storage options generally do not enjoy sufficient economies of scale to make back-up generation not otherwise utilized fully competitive with utility supplied electricity. That is, there is a considerable premium attached to improving resilience through this strategy set. Second, these BTM investments are likely to have low capacity utilization rates due to the incomplete integration of their operation with the rest of the grid. BTM back-up generation may be ready in the event of a power outage, but most of the time, while the larger grid is functioning without problem, these contingency-oriented investments are not operated in a manner that supports overall grid performance. As a result, the full benefit of such DER investments remains unrealized. These two issues are most pronounced for residential and small commercial customers. Some commercial and industrial entities have had relative success in deploying DER for on-site power production that also improves resilience.

The commercial and industrial entities for which investments in resilient electricity supplies have exhibited the most success tend to have a need for higher-quality power supply than other firms. Industrial customers may buy onsite generation like fuel cells or PV with battery storage for the improved power quality and the ability to manage their reactive power impacts on the grid. In such cases, the additional benefit that comes from having a redundant supply source may be ancillary to the investment decision. Further investigation into the selection process through which some organizations pursue these investments while others do not could inform estimates of the value of resilient supply to customers. That is, through studying the conditions under which an organization will reveal its preference for additional resilience (by investing in redundant electricity supply) we can better model customers' willingness to pay for resilience enhancements.

While all recipients would generally approve of improved service quality, there is likely to be considerable heterogeneity in their willingness to compensate suppliers for additional resilience. As the customers making these parallel investments in resilient supply tend to be large consumers of electric energy and related services, their continued participation in electricity markets is important to the business prospects of conventional utilities and emergent firms. Aligning incentives of individual investments with those of legacy grid operators could mitigate the potential for expenditures on underutilized equipment and improve the implementation of the technologies that end up employed.

Among critical infrastructure systems, electricity and transportation deserve additional focus as each are consumed by most people on a daily basis, and each system spans the entirety of the U.S. geographic footprint. With respect to transportation, the impacts of High Occupancy 
Vehicle (HOV) lanes as well as High Occupancy/Toll (HOT) lanes on the resilience of the U.S. highway system warrants examination.

HOV lanes can be used for free by vehicles with sufficiently high occupancy (carpools) and some exempted vehicles, which often include designated low emission models. "The theory underlying HOV priority treatment is that the potential time savings gained by bypassing congested general-purpose lanes can promote ride sharing and use of public transit, indirectly relieving traffic density on adjacent general-purpose lanes” [65]. HOV lanes started as an investment in social engineering intended to stimulate carpooling. Over time, the implementation of HOV lanes has emerged as a common strategy to mitigate road congestion, simultaneously rendering the co-benefit of improved network resilience to other disruptions. ${ }^{60} \mathrm{~A}$ challenge facing the implementation of HOV lanes is that during some periods, HOV lane utilization will be low while regular lanes are congested. HOT lanes may address this challenge.

HOT lanes are similar to HOV lanes with the caveat that non HOV traffic may also use HOT lanes for a toll. These tolls are often implemented dynamically so as to reflect the changing congestion situation of the road. HOT lanes benefit from the ability of the toll, as a market mechanism predicated on congestion costs, to efficiently mediate access to the additional lanes. As congestion worsens in the main lanes of the road, drivers' willingness to pay for expedited travel rises. Some will opt into paying the toll to incur a marginal improvement in travel time. As congestion in the HOT lane rises, the price of the toll can increase as well to reach equilibrium with respect to how vehicles are distributed between HOT and regular lanes of traffic.

When traffic is sufficiently light as to completely avoid congestion, the shadow price for additional lanes of travel is effectively zero. However, once congestion rises to the point of the road experiencing a binding constraint on throughput, the value to the system of relaxing this constraint is positive and may attain considerable heights. Dynamic tolls can thus reflect the changing shadow price of additional infrastructure "bandwidth." The core tradeoff here is that volatility in the quantity and quality of transportation services demanded (a factor contributing to congestion patterns) is mitigated in exchange for volatility in the price of service. ${ }^{61}$ Household budgets thus work as shock absorbers when the physical constraints of the transportation grid bind. Of course, household budgets are themselves constrained, and the distributional impacts of investments in parallel infrastructures are worthy of discussion.

Interoperability has also played a key role in enabling the development of HOT lane resilient transportation infrastructures. Specifically, inexpensive car-mounted transponders for electronic toll collection that seamlessly integrate with vehicle registration and financial systems allow drivers to efficiently avail themselves of resilient transportation options across broad geographic

\footnotetext{
${ }^{60}$ The introduction of HOV lanes will have the biggest positive impact on transportation resilience for people with access to carpooling options or exempt vehicles (including first responders needing to circumvent severe congestion). Those unable to avail themselves of the HOV lanes directly may still benefit from the implementation of HOV lanes if the total number of vehicle miles traveled and thus congestion severity can be reduced through increased carpooling.

${ }^{61}$ A main selling point for Express Lanes operating in Northern Virginia is that they "use dynamic pricing to keep traffic free flowing and provide you with a predictable trip" [66]. The promotional material from Express Lanes touts the, "option to pay for a reliable trip" as among the benefits from implementing the HOT lanes.
} 
regions. The interoperability of these systems has also driven transaction costs so low as to allow many regions to offer discounted pricing for transponder-enabled vehicles, which in turn increases the economic benefit for all participants. Some regions have addressed the barrier to market entry for travelers without electronic tolling transponders by offering a parallel toll-byplate infrastructure which benefits from the interoperability of ubiquitous nationwide vehicle identification systems (license plates). But while the entry barriers have been reduced for these toll-by-plate systems, the transaction costs are elevated due to the lack of interoperability with existing financial systems and the fees for using resilient travel lanes are increased accordingly.

There are several important takeaways from this discussion on investments in parallel transportation infrastructure. First, if customers demand a level of quality (such as resilience or reliability) in a product or service that current markets fail to deliver, there is an incentive for new market entrants or the emergence of ancillary markets in the provision of that quality. ${ }^{62}$ The considerable fixed costs of designing, building, operating, and maintaining network infrastructure act as barriers to competing systems that fully parallel public investments, but there are portions of the whole network that could profitably be paralleled by independent private expenditure or public-private cooperation. The composition and distribution of benefits and costs of parallel investments in infrastructure are not guaranteed to mirror those of incumbent public utility infrastructure. The benefits will largely accrue to the participants in the original markets that are most capable of paying the additional marginal use costs of the parallel infrastructure. While tolls on parallel infrastructure can raise revenue for infrastructure investment, the best use of those funds is an open question. Toll revenues could be directed towards the mitigation of the original market failure on the legacy network infrastructure. However, revenues may also be directed to growing the parallel infrastructure network. Given the constrained nature of budgets, there is a tradeoff between funding levels for investments in each market. Care should be taken so that improvements to ancillary, parallel infrastructures (electric, transportation, etc.) benefit overall system performance and do not come at unacceptable costs to the public mission of legacy infrastructures.

\subsection{Potential Barriers to Grid Resilience}

Although there are myriad challenges to achieving the implementation of a resilient grid architecture, several broad conceptual issues are worth focusing on in the discussion of the economics of a high resilience electric grid here. Resilience enhancing investments generally entail considerable costs and must be undertaken at an organizational or community level rather than by individuals to be effective. ${ }^{63}$ Efforts to improve resilience must contend with the complications involved in the provision of public goods.

A quick review of the strategies and components of grid resilience in the previous section reveals that while local energy generation and storage measures or tree management could be undertaken by individuals, the most-impactful investments are sizable in scale, scope, cost, and complexity. Furthermore, grid resilience is most important for infrastructure and entities on which all of

\footnotetext{
${ }^{62}$ If there are considerable barriers to entry for existing markets, the emergence of ancillary markets is relatively more probable.

${ }^{63}$ A notable counterexample might be the installation of rooftop PV with islanded operating capabilities. However, implementing islanding capabilities would involve utility participation of some form.
} 
society relies. However, the considerable costs and planning efforts required for improving resilience often fall on a subset of economic actors. Therefore, there is need for organizational structures that align the incentives faced by firms with requirements of communities seeking to become more resilient.

Electric grid resilience is a public good. Public goods are defined by their non-excludable and non-rivalrous nature. Resilience is non-excludable in that benefits from investments that improve the resilience of the electric grid cannot necessarily be restricted to those ratepayers by whom the costs are borne. When the electric utility has an obligation to serve all customers in its service area, non-excludability is especially clear. Resilience is non-rivalrous in that the enjoyment of a resilient electric grid by one customer does not preclude other customers from those same benefits. The non-excludability of resilience may lead to a failure of the market to supply resilience.

[I]nvesting in a more resilient system has the classic characteristics of 'public goods' issues - localized and concentrated costs with broadly diffused and difficult-to-measure benefits - that are inherently difficult to address. It is unrealistic to expect firms to make voluntary investments whose benefits may not accrue to shareholders within the relevant commercial lifetime for evaluating projects [58].

\subsection{INTEROPERABILITY AND GRID RESILIENCE}

Interoperability is pivotal to the value proposition of resilience enhancing investments. Understanding the impact of a major storm on a given section of the grid will be easier if interoperability between components and systems hit first and those along the subsequent storm track allows for the sharing of actionable information to grid operators in the latter region. Interoperability may facilitate trade in resilience enhancing services between impacted and unimpacted regions. Restoration crews could benefit from reduced response time due to better information sharing. Restoration crews from distant utilities responding to calls for assistance sent out through MAGs could require less onboarding training and faster response times if system architectures, organizational structures, and device-level communications across the country exhibit greater levels of interoperability. Furthermore, interoperability may create markets for resilient services that expand beyond the utility and restoration activities. For example, interoperability could reduce barriers to entry and high transaction costs that currently prevent service providers from developing congestion management solutions on distribution grids.

\section{Track 3: High DER/High AutOMATION DistRiBUtion GRID (HADG)}

\subsection{ARCHITECTURE DESCRIPTION}

The third reference architecture track concerns a future in which distributed energy resources (DER) achieve considerable market penetration and the distribution grid is highly automated. The increasing reliance on variable generation (VG) DER motivates some of the structural 
changes discussed in this section. "Many of the tools necessary to manage the challenges of VG already exist, but the market structures may not be properly positioned to incentivize their efficient use or additional investment" [67]. Therefore, the development of incentive structures that align investment activity with the operational and long-term needs of the grid should be a priority.

This High DER/High Automation Distribution Grid (HADG) represents a counterpoint to the ABES architecture track, though the two are not necessarily mutually exclusive. While the ABES track sees interoperability implemented through the transmission and asset management functions of existing balancing authorities, the HADG track entails a focus of interoperability improvements within the distribution portion of the grid. Where ABES is an extension of business as usual, HADG constitutes a major change in the structure of the electric grid that decentralizes functional control by shifting it towards the edge of the grid. The development and deployment of distribution sensing and measurement equipment and the information technology to send, receive, process, and act on the signals generated by all nodes of the grid defines the HADG architecture track. The technological changes that drive the HADG architecture track will see the emergence of new firms and the competition between electric utilities and nonutilities that decide to enter the energy sector.

Analysts of the electric power sector ignore the myriad prevailing forces currently shaping the macro-environment at their own peril. While complex and numerous, these influences can be categorized for expositional clarity. Weiner, Nohria [54] anticipates that "[t]hree major forces regulatory and political, market, and technological - will ultimately lead to a disaggregated industry with great opportunities for those who can organize the overall value chain for consumers."

Incumbent and emergent organizations will work to understand and leverage technological forces to create value through the development of new strategies and business models. That is, changes to technology and centralization provide the impetus for follow-on changes to business strategy. Given sufficient changes to their business strategy, firms will need to develop new coherent business models through which to organize elements of strategy. Business strategists will need to de-conflict and coordinate these new elements of strategy to mitigate the potential for different parts of their firm to work counterproductively against each other.

The strategy formation process takes place within the context of regulatory and political constraints. This second set of forces shaping sectoral evolution will transform what is technologically possible into what is acceptable to the relevant political and regulatory entities. Elements and gestalts of strategy are formed iteratively in another prominent feedback loop as managers experiment. Initial tech change is likely to result in some outcomes that lead political or regulatory entities to call for the development and deployment of other technologies designed to deliver socially desirable outcomes. Therefore, additional feedback loops between the first two sets of forces (technological and regulatory) will influence sectoral evolution.

Market forces routinely conduct pragmatic evaluations of business strategies and models. With respect to assertions that a strategy is effective, the proof is in the profitability, or it is not. As the efficacy of any strategy is tied to the context in which it is employed, it is meaningless to 
attempt analysis of business strategy in the absence of market forces. Even in segments of the electric sector in which vertically integrated monopolists serve customers, these monopolists face the ramifications of market forces daily in the procurement of inputs to production and the marketing of their products and services. ${ }^{64}$ Centrifugal technological forces may be driving much of the initial change in strategy and structure, but market forces can exhibit a centripetal counterpart, pulling disparate entities into consolidated arenas of exchange.

New energy technologies are well documented, but consensus on the exact business models or market structures that will prevail on the electric grid remains elusive. Despite the host of different segmentation schemes advanced in industry, the academic press, and popular media accounts, some unifying concepts are consistently incorporated into the forward-looking efforts of electric sector analysts. This chapter endeavors to identify and evaluate several of these concepts, with a focus on the ubiquitous influence of interoperability. Interoperability is both a state and choice variable for actors in the electric power sector with implications for each of the three groups of forces shaping the macro-environment. An improved understanding of how interoperability decisions interact with other matters of strategic choice is crucial to the improvement of economic performance and the attenuation of unintended consequences.

\subsection{Technological Change And Decentralization}

Technological change in the electric power sector is enabling decentralization of operations through reducing the production and transaction costs of DER. ${ }^{65}$ The structure of scale economies in the sector is evolving from a focus on the scale of individual generating facilities to increasingly favor the scale of net benefits derived from indirect network effects. Effectively, competitive production options have grown from being prohibitively expensive for all but the best-capitalized organizations (e.g. a GW class power plant) to include options that are also affordable for typical American households (e.g. rooftop PV).

The rise of modular DER assets has driven further technological and organizational change downstream within the electric power sector. The modularity of DER reduces the financial barriers to entry into electricity markets, opening up the sector to an influx of competitive fringe producers. ${ }^{66}$ Therefore, technological change that increases the modularity of DER will entail follow-on impacts for the strategies firms choose as well as the structure, conduct, and performance of markets. Modularity in system components will tend to lower the switching costs for system operators should they decide to replace part of their technology stack. ${ }^{67}$ As will be discussed in the following section, the implications of modularity and other technological changes on switching costs will need to be addressed strategically by firms operating in the electric power sector.

\footnotetext{
${ }^{64}$ Publicly traded firms that fail to live up to their potential for value creation face the inherent threat of takeover by investors who think they can install management more capable of delivering economic success.

${ }^{65}$ Here, the reduction in production costs is intended to include improvements to the production of DER (PV modules) and production by DER (i.e. electricity, ancillary services).

${ }^{66}$ If financing costs rise for the sector, perhaps as a result of creditors reassessing the risks of the utility business, the premium on small modular projects with short lead times is likely to rise.

${ }^{67}$ Modularity may be obvious in physical manifestations, but the concept is readily applicable to software as well.
} 
While conventional generation facilities operated by incumbent utilities supply electricity markets through interconnections with the transmission system, emergent DER owners will need to access electricity markets first through their local distribution networks. Distribution networks are increasingly expected to facilitate new utilization patterns for which they were not explicitly designed. Radial network structures of conventional distribution grids will undergo continued pressure for change. New distribution network structures will need to accommodate economically efficient operations of local DER in a manner that can minimize or eliminate the negative impacts of endogenous and exogenous grid stress. ${ }^{68}$

Efficient operation of a highly decentralized distribution grid requires innovation in communications, control, and coordination technologies. The number of potential market participants in a future resembling the HADG architectural track is bounded only by the number of connected entities, systems, and devices. Hardware and software solutions will both play an important role in delivering enhanced capabilities to the growing number of entities participating in the electric power sector. The network structure of electricity markets implies the potential for actions by one participant to have significant impacts on many other participants. Market organization is predicated on the ability of economic actors to communicate with each other the information necessary to facilitate open exchange. As market participants proliferate, communications infrastructure will need to scale accordingly. Initially, incumbents will embrace innovations in communications resources to improve control of internal operations. However, in some markets fragmentation of the distribution grid may lead to a supplanting of the centralized control paradigm for one of decentralized resource coordination. Investments in communications infrastructure will support the feasible set of competitive strategies that firms can employ. However, technological change across the electric power sector is unlikely to proceed along a homogenous path.

Along with investments in communications channels, the actors in electric power sector will need to invest in 'content' creation through the development and deployment of advanced sensors and metering systems if they intend to achieve a highly automated distribution grid. As the barriers to entry in the IoT space are low, these sensing and measurement devices will be diverse in design and origin. Considerable effort may be needed to ensure that these devices and systems are interoperable with other components and systems of the electric grid. ${ }^{69}$ The value proposition of information gathering technology, like sensors, is a function of the technology's accuracy, precision, and ability to convey actionable information to the network of other components. This value proposition also scales with the size of the network to which the sensors are connected. In network terminology, both the degree of a sensing node and the strength or quality of its ties contribute positively to node's value proposition. Sensing the ambient air temperature around a given home is far more valuable if that information can be autonomously integrated into the heating and cooling control system. Not all investments in interoperability enhancement offer equally attractive value propositions. Innovation in this area will require firms to identify and prioritize the types of interoperability enhancements that generate the

\footnotetext{
${ }^{68}$ Distribution grid congestion is an example of endogenous stress. High winds from a hurricane constitute an exogenous stress on the grid.

${ }^{69}$ In the absence of proactive investment in interoperability, transaction costs are unlikely to fall through decentralization of the value chain. That is, the cost of inaction with respect to interoperability is probably even higher in the long run.
} 
greatest value. As the options that create the greatest value for an individual firm may not coincide with the options that are most beneficial to society when widely adopted, higher level institutions, like systems operators, may be called on to coordinate or direct investment activity.

The relationship between communicative capacity (bandwidth) and the need to create and disseminate information on the state of the electric power system for command and control purposes is likely to take the form of a horserace or a positive feedback loop. Additional bandwidth may enable new strategies reliant on intensive communications use. In turn, widespread adoption of these new strategies may place pressure on system operators to invest further in communications bandwidth.

Increased connectivity between components on an electric grid undergoing a decentralizing transformation will create new opportunities for both good and bad actors. The cyber-security of ultra-large-scale cyber-physical systems, like the smart grid envisioned in the HADG architectural track, is the shared responsibility of all users. Nevertheless, some system users are better positioned than others to meet the threats to electric grid. It falls to these leaders in the electric power sector to innovate new strategies for threat mitigation.

High levels of interoperability may eventually enable smart grid components that detect intrusions to communicate their findings to other grid components and systems capable of responding to the attack and preventing damages. As the trend towards connectedness continues, attackers may move to target gaps in interoperability between grid systems where automated defenses are least effective, that is, the weakest links.

\subsection{Business Strategy AND THE REgUlatory ENVIRONMENT}

Technological change can shake the economic fundamentals of the regulatory compact and incumbent business strategy. As the regulatory compact is concerned with the establishment of prices that reflect actual costs and the incentives necessary to ensure sufficient efficiency in serving customers [22], changes in core technologies and the shift towards decentralized control will impact the form of the regulatory compact that prevails in the electric power sector.

Public utility commissions and regulatory bodies must keep appraised of the technological developments that can help or hinder the efficacy of the compact with utilities, for the task of translating the technologically possible into the politically and economically acceptable still falls to them. If system ownership becomes more fragmented through decentralization of operations and control, regulators will need to consider the actions of a growing set of electricity market participants. It is up to utility managers to innovate business strategies and models that deliver value to stakeholders while staying within the socio-political boundaries of the evolving expectations around sectoral governance.

A result of decentralization is that technological change can impact electricity customers both directly (through the option to deploy DER) and indirectly (through their conventional utility service). The rising economic viability of an ever-expanding range of DERs leads organizations ranging from individual households to college and industrial campuses to make complex value judgements regarding the composition of conventional utility service (outsourcing) and DER 
(self-supply) that is to be employed in production. ${ }^{70}$ Customers must be able to weigh the relative merits of the two sets of strategies. This, in turn, requires the balancing of operating expenditures for utility service against the capital expenditures inherent in DER deployment. Utility managers must be aware of their customers' outside options and switching costs if they are to formulate effective business strategies for competing in an electric power sector that resembles the HADG architectural track.

Stagnant aggregate demand growth has attenuated a historically considerable force for revenue growth in the electric power sector. ${ }^{71}$ Where quantity-centric strategies prove less than adequate to the task of delivering value to stakeholders, managers have considered opportunities to increase revenues through improving the value proposition associated with their customers' connections to the electric grid. Efforts to differentiate the offerings of a firm from those of a competitor are central to the firm's ability to raise revenue when sales quantities are stagnant. Differentiation allows a firm to increase its price without losing sales to competitors that do not raise prices. In economic terms, the price elasticity of demand for differentiated products should be lower than that of commodities.

However, from first principles, the electron appears unamenable to differentiation. Indeed, Kirchhoff's laws make it impractical to market electrons as originating from differentiated generating facilities. ${ }^{72}$ Prevailing technological, regulatory, and market forces have generally increased the price elasticity of demand for electricity, further complicating efforts to drive revenue growth through differentiation. Utilities will seek to change their business models in ways that increase their customer's cost of switching to alternate supply options. As blatant constraints on customer choice are likely unacceptable to many regulatory bodies, firms will seek to offer additional services of sufficient value to dissuade customers from defecting to their competitors. At present, the relatively high level of reliability associated with most utility services may constitute the strongest differentiator when compared with self-supply alternatives.

Technological change and decentralization drives changes to the production structure and transaction costs. When the equipment needed to accomplish a given task changes, the optimal personnel mix may change as well. Organizational evolution may thus emerge from firms restructuring their business processes in response to technological change. Organizational change that transcends adjustment of individual business strategy elements will lead some firms to adopt entirely new business models. The aggregate effects of technological change and related decentralized control have produced conditions favorable for the ascendance of platform business models capable of handling the needs of customers across the electric power sector.

In an early study of the changing electric grid, Weiner, Nohria [54] envisioned a bifurcated distribution segment with distinct roles for emergent energy service companies (ESCOs) as creators of alternative value networks and conventional distribution companies or (WireCos).

\footnotetext{
70 The self-supply decision is discussed at greater length in Chapter 6.

${ }^{71}$ To be sure, some regions of the national electric grid have enjoyed demand growth derived from growth in electricity-intensive industrial and commercial enterprise, however, regions that have experienced recent deindustrialization often exhibit declining electricity sales.

${ }^{72}$ Some utilities have devised tariff structures that allow customers to pay a higher cost per kWh in order to contribute additional funds towards the development of renewable generating facilities.
} 
While naturally monopolistic WireCos will continue to possess the resources and competencies that form the technological core of the distribution segment, Weiner and Nohria claim WireCos are likely to find themselves primarily serving customers with relatively simple needs. ESCOs will rise to intermediate transactions between generation assets (both conventional and distributed) and the diverse set of end use customers. The "virtual player will aggressively manage its own assets and competencies, emerging as a sophisticated intermediary designed to optimize the value chain to deliver superior value to specific customers" [54]. Naturally, these ESCOs will target the most attractive (lucrative) customer segments to serve, including large commercial and industrial organizations with highly specific energy service needs. The threat of losing their best customers to more-innovative incumbents or energy startups should provide ample motivation for conventional utilities to take the emergence of ESCOs seriously.

One set of firms might focus on end use customers and develop platforms to interface individual electricity consumers with the distribution system operator (DSO) or distribution platform optimizer (DPO). Some of the services provided by this group of entities once fell to the customer service functions of integrated utilities. One possibility for the HADG architecture track involves several firms competing to provide hardware and software packages that aid in the automation of customer-grid interaction. It remains to be seen which firms will play the most prominent role in the provision of these customer-facing offerings. Some utilities may find themselves spinning off customer service departments or developing their own service platforms to continue liaising between customers formerly in their service area and new grid coordinating entities.

The emergent operational platforms have multiple objectives including increased utilization of existing assets, greater ease of integration of new assets, and improved coordination of different grid elements through incentive alignment and information exchange. Distribution system operators will have their choice of strategic and operational platform partners. Those firms most able to help the DSO deliver an optimized electric grid will enjoy the most success. Given the information intensive nature of these operational platforms, it is quite likely that relatively few firms will compete in any operational segment. ${ }^{73}$

Longer term and planning functions, formerly handled by integrated utilities, are still required in an evolving electricity sector. A third set of businesses are already developing platforms in support of long-term grid planning. These businesses will need to forecast future trends in electricity demand, fuel and other input prices, preferences, and technological innovation. With the best forecasts possible, these firms will offer services to system operators that help ensure long-term reliability. As the system operator will want to send the right signals and foster optimal behavior among operational and customer service platforms, high-quality information on long-term trends is of considerable value. Some of these planning platforms will come from consulting and data firms that currently operate in the energy sector, continuing existing relationships between the power sector and professional business services sector.

\footnotetext{
${ }^{73}$ The cost structure for the development and deployment of information systems is generally described by large initial fixed costs and nearly-zero marginal costs of operation [68]. Consequently, with average total costs of information services falling as output increases, these businesses can resemble natural monopolies, and are often few in number.
} 
As the resources feeding into the grid become more decentralized, the efforts to integrate and coordinate these resources must also change. While the increased market penetration of DER presents a challenge to firms that are not oriented towards providing distributed solutions, the same trend is a massive opportunity for other firms. Some organizations are figuring out how to obtain and exchange information that signals other entities to engage in beneficial siting and integration practices for DER. Current efforts by balancing authorities to estimate the DER hosting capacity of distribution networks offers one such example. The firm that can use the services provided by intelligently integrated DER to mitigate the problems posed by suboptimal integration of other DER will have arrived at a solid business model.

\subsection{Market Structure, Organizational CONDUCt, AND ECONOMIC PERFORMANCE}

Customer demands and system requirements will need to be reconciled constantly, efficiently, predictably, and cost-effectively for the HADG architecture track to succeed. The signals communicated to end use consumers through customer service platforms will originate with other customers, firm platforms, bulk generators, and the cyber-physical systems that distribute electricity. Without sufficient investment in interoperability, the transaction costs associated with managing such a system may prove a hindrance to further development along the HADG architectural track. The broader cyber-physical system may be coordinated by a DSO or similar organization, but developed, deployed, maintained and managed by third-party firms. At first, these firms may operate legacy business models in an ad-hoc fashion. Eventually, the cost savings from consistency and the advantages of distribution automation will be achieved through efforts to improve interoperability.

New market players will purchase existing resources from incumbents in some circumstances and deploy their own in others. Some incumbents will proactively sell off business functions that are no longer deemed core to their emergent business models, while others will pursue strategies intended to prevent the erosion of revenues lost to new competitors. These changes in the way the electric value chain is segmented are likely to increase sectoral fragmentation at first. In time, a shakeout may happen causing the trend towards decentralization to slow or reverse. Surviving incumbents will purchase some entrants and integrate their acquisitions into utility offerings. Other entrants will retain their independence and may eventually rival current utilities in size and complexity.

If DER penetration reaches a point of nearly full saturation, households might be able to supply electric power and related services to the commercial and industrial sectors of the economy. The presence of DER could thus go from an investment option for the few to a typical piece of home equipment that generates income. Of course, marketing opportunities for DER owners would still be predicated on the interoperability of their DER with the rest of the electric grid. There will likely be heterogeneity in the size and marketability of DER across households, and there is the potential for households or business establishments with high nameplate capacity DER installations to possess some degree of market power on distribution grids. If large DER installations operating at full output congest local distribution lines, the effect may be a temporarily segmented market in which locational marginal price varies by segment. The potential for distribution level market power may warrant future research. 
A firm has an incentive to deliver interoperability within its own platform and with suppliers. This incentive alignment is encouraging for the development of the smart grid. However, that same firm may find it beneficial not to pursue the same degree of interoperability between its platform and that of a competitor. Platform firms want to build up their complements and diminish their substitutes in an effort to increase switching costs for their customers.

Interoperability and switching costs tend to be inversely proportional. The competitive strategy space is changing in ways that are not necessarily well-understood by all affected market players. Care must be taken to ensure that anti-competitive behavior, manifested as suboptimal interoperability investment, does not emerge unidentified and unchallenged. Insufficient interoperability constitutes the most significant existential threat to the emergence of a highlyautomated and decentralized electric power sector.

\subsection{EXISTING EXTERNAL MARKETS WITH SIMILAR CHARACTERISTICS}

The electricity market segmentation described for the HADG architecture track lacks perfect analogues in other currently functioning markets. However, the most instructive examples may be drawn from the very technology space that is driving many of the developments in the smart grid space. Advancements in ICT have enabled the networking of large industrial systems like electric power for years. ${ }^{74}$ Recent movements down along the cost curves of core ICT and trends towards greater customer engagement in other sectors affected by this ICT evolution have influenced thinking in the electric power sector. Greater customer engagement and involvement must be reconciled with the need for an optimized electric grid that mitigates the negative network externalities that could arise out of the self-interested behavior of individual market participants.

To achieve success, multi-sided platforms seek to obtain a critical mass of customers from a given user group and leverage the supply or demand of that group to attract counterparts from other groups [70]. The value proposition of multi-sided platforms is predicated on their ability to bring together these distinct user groups. Some firms seek the achievement of critical mass on each side sequentially, while other firms pursue the acquisition of multiple customer groups simultaneously. Either way, a prerequisite for such mass participation is interoperability. Well-known mobile platforms have enjoyed success in their ability to deliver consistent, reliable user experiences due to their capability to "exchange and readily use information" across a variety of end user devices such as phones and tablets [1]. Part of the customer experience when someone hails a ride-sharing service is that they need not worry if the driver will accept their preferred payment method or if their directions will be understood. A request is made, a driver shows up, and a service is delivered, "securely, effectively, and with little or no inconvenience to the user" [1].

The platforms that are developed for the electricity sector will have to be interoperable with the diversity of residential dwellings, commercial buildings, and industrial parks that collectively comprise the edge of the electric grid. If a critical mass of platform users is to be achieved, the integration of individual homes and firms cannot occur at the slow pace of ad hoc solutions.

\footnotetext{
${ }^{74}$ In an evaluation of the technological change impacting manufacturing in the United States, Milgrom and Rioberts [69] recognizes "the costs of collecting, organizing, and communicating data, which have been reduced over time by the development of computer networks and electronic data transmission systems".
} 
Standards based integration into shared networks is necessary for the HADG architecture track to emerge. The higher the level of interoperability, the larger the potential market and the greater the incentive for third party developers to build the tools that will facilitate improvements to cost of service.

Tech firms such as Amazon, Apple, and Google have all entered the connected home device space, and are already offering home energy management services. ${ }^{75}$ These firms have built many of the platforms used every day for households to interact with markets for books, music, navigation, and increasingly non-information goods and services (e.g., Amazon acquired Whole Foods in August 2017). It is conceivable that these firms would be well-positioned to provide a trusted interface through which homes and small businesses can buy and sell electricity and other energy services.

Several major technology firms have built core competencies in the marketing of cloud computing services to a diverse clientele. Success in the cloud computing space requires the cultivation of a competency in the seamless marketing of high-quality services provided by a network of distributed resources. Firms in the electric power sector will need to master this competency if they are to succeed in a HADG future. The coordination of potentially dissonant resources in the creation of coherent value propositions is both the central challenge and largest opportunity for economic growth in an electric power sector resembling the HADG architecture track.

Online portals and mobile apps have proliferated as a means for companies to reduce transaction costs and provide a more responsive customer experience. The electric grid of the future may see customers choosing between competing EsCo platforms that facilitate the traditional customer service functions once handled by utilities as well as integrate emerging services such as demand response and energy efficiency improvements.

Firms that currently sell behind-the-meter rooftop PV solar generation assets, electrochemical storage devices, and other related products, are likely candidates for development of operations platforms that can improve the value proposition of their products through greater interoperability with the rest of the grid. Several market players are already developing business models that resemble such platforms. ${ }^{76}$ Where their business models differ from others most crucially is that their platforms are generally not open to third party developers. That is interoperability with third-party offerings has not been a uniform priority for these platform developers, so far.

\subsection{DiscusSion OF INTEROPERABILITy, PlatFormS AND THE SMART GRID}

\footnotetext{
75 The first forays into this space often amount to little more than basic functional integration of connected consumer devices. LED lightbulbs with embedded communications chips that can be controlled over a wireless internet connection are currently for sale from major lighting suppliers. The initial focus on smart phones as the control interface may give way to dedicated "smart home” devices produced by leading consumer technology firms.

${ }^{76}$ STEM and Advanced Microgrid Solutions are two firms making significant progress in their efforts to deploy storage, advanced power electronics, and control systems behind the meter. The ability of these firms to convince others of the economic viability of their business models is supported by the fact that they recently "raised $\$ 200$ million and \$100 million, respectively" [71]. The systems developed by these firms constitute platforms capable of providing valuable grid and customer services.
} 
In a study of the empirical aspects of multi-sided platform industries, Evans et al. [70] identified three necessary conditions for platforms to improve economic welfare. The discussion that follows argues that these conditions are met with respect to electricity markets.

There is an opportunity for a platform to increase social surplus when three necessary conditions are true: (1) there are distinct groups of customers; (2) a member of one group benefits from having his demand coordinated with one or more members of another group; and (3) an intermediary can facilitate that coordination more efficiently than bilateral relationships between the members of the group. [70]

The multi-sided platform through which customers can consume a variety of services often developed by third-party firms is increasingly common in myriad sectors of the economy. The success of these platforms is dependent not only on the quality and execution of internal strategy, but on the collective efforts of these third-party firms (complementors). Among the best-known examples are the prominent app stores on the Android and iOS operating systems. While Google and Apple engage in the development of software that is distributed through their respective platforms, both have enjoyed market ascendency in large part due to the proliferation of thirdparty offerings. The extensive development efforts of third-party firms improve the value proposition of each platform through creation of positive network externalities. In a future in which customers can choose amongst competitive electricity providers, the firms able to offer the greatest levels of service quality, customization, and convenience will occupy an enviable position in electricity markets. For instance, an electric utility could compete for customers through providing a platform on which third parties could develop automation tools to optimize household load profiles or trading algorithms to maximize the revenue from customers' DER generation.

Optimal pricing of platform access in the presence of network externalities requires crosssubsidization between sides. The side with higher price elasticity of demand for access to members of the other side is charged less for access [72]. Demand from the side of the platform with the fewest outside options will generally be more price inelastic. The relative demand elasticities of entities that would engage with an electric utility platform is an empirical question, the answer to which will determine whether end use customers or platform complementors are ultimately subsidized. In jurisdictions where end use customers have a dearth of supplier choices or switching costs are otherwise high, customers are likely to constitute the relatively inelastic side of the platform. Complementors will find platforms in which demand for their services is large, captive, and price-inelastic to be among the most attractive development targets. However, platforms need to be careful not to charge excessive prices to the relatively inelastic side as higher prices are easier for outside options to undercut. In the long run, high prices may induce entry. Mass defection from one side of a platform can lead to a collapse of the value proposition that the platform provides to its other side. Platforms developed by non-utility players are likely to be less bound by the historical segmentation schemes and governance structures of the electric power sector, enabling competition between platforms as well as with conventional incumbents. However, the physics of the grid are inescapable, offering a shared set of constraints for both incumbents and emergent platform operators. 
Electric sector platform businesses will compete with each other for the opportunity to be the gateway between customers and complementor services. The informational advantages enjoyed by such a market-maker may themselves provide enough value to the platform operator to warrant low prices on all sides. Relatively low platform prices tend to increase customer proclivity for multi-homing. Multi-homing, or the use of several (competing) platforms by individual customers, is a common empirical trend in non-electricity sectors. Customers may access multiple streaming services (software platforms) through several different hardware platforms in one house (i.e. cablebox, video game console, laptop). In the fragmenting electric power sector, some customers already employ a multi-homing strategy for platforms providing electricity related services. For example, a customer may use a smart home device from one vendor to control lighting services and a smart thermostat from another vendor to manage their HVAC system. A fall in the degree of platform differentiation or an increase in the number of complementor offerings on either platform will tend to increase multi-homing by customers [72].

Much of the discussion of interoperability has focused on its direct impacts on the value proposition of DER. However, the same investments that deliver interoperability between distributed generation could provide value to traditional generation as well. DER is distributed precisely for the purpose of capturing local opportunities and serving adjacent loads. If DER are interoperable, so too can be the loads DER are intended to serve. The perception among some is that variability from DER generation accompanies set load profiles resulting in variable residual loads that must be met by other generating facilities. ${ }^{77}$ Ramping production up or down relatively frequently can increase the operating costs of conventional generation. However, the variability in residual load can be driven by fluctuations in either DER generation or load. Interoperability can improve the capacity to coordinate loads across edge locations so that conventional generation is presented with a more favorable aggregate residual load profile. This might be achieved through the coordination of loads that can be shifted temporally, such as dishwashing or laundry loads. Effective coordination requires the timely exchange of actionable signals, the feasibility of which is predicated on interoperability and adequate communications infrastructure. Such coordination is one example of a service that could be delivered to a variety of grid participants through a platform organization.

\section{TRACK 4: MiCROGRID \& DISTRIBUTION GRID SEGMENTATION (MDGS)}

\subsection{ARCHITECTURE DESCRIPTION}

At the heart of the microgrid and distribution grid segmentation (MDGS) architecture track is the decision of whether (or to what degree) one should self-supply electricity and related services. The reasons to supply oneself as opposed to sourcing inputs from external entities are potentially manifold and will be discussed in the following paragraphs. However, it is helpful to recognize

\footnotetext{
${ }^{77}$ For the sake of this argument, residual load is that which is not met by on-site DER generation. That is, residual load is load net of local DER generation, and it can be positive, negative, or zero depending on the local energy imbalance or lack thereof.
} 
that this question of self-supply is not new to society, simply because the context of electricity provision seems novel in modern times. ${ }^{78}$ Organizations have always had to determine whether to devote resources towards the internal acquisition of key inputs or towards outsourcing through existing structures. Over the course of history, many of these external structures have been endowed or emergent, rather than intentionally architected. The following discussion is intended to identify and explore the economic considerations of architectures employing strategies of optional self-supply and segmentation.

A common reason for choosing to self-supply a key input can be that the existing markets or other allocative mechanisms fail to offer the good or service, either entirely or in the form or variety desired. ${ }^{79}$ The choice of transacting partner can factor prominently into the decision of whether to self-supply. Individual organizations have different internal requirements and preferences that impact not only what they are capable of doing for self, but who they are willing and able to do business with. Organizations rarely exist in a hierarchical vacuum, and the various structures of hierarchy, be they physical, economic, governmental, or institutional in nature, are not to be neglected in an effective analytical treatment. ${ }^{80}$ Households address the decision of self-supply within the context of their immediate neighborhoods. ${ }^{81}$ Neighborhoods develop within the context of their respective towns or cities. ${ }^{82}$ Cities form constellations of economic activity within the context of states and nations. Even nations engage in international trade or exist in a state of autarky with respect to the rest of the world.

Microgrids are increasingly common components of modern grid architectures and this growth offers opportunities to improve the economics of electricity markets within existing constraints as well as relax some constraints grounded in outmoded structures. The Department of Energy (DOE) defines a microgrid as follows:

A microgrid is a group of interconnected loads and distributed energy resources within clearly defined electrical boundaries that acts as a single controllable entity with respect to the grid. A microgrid can connect and disconnect from the grid to enable it to operate in both grid-connected or island-mode. ${ }^{83}$

As previously alluded to, microgrids are not entirely novel. Remote rural communities have long been configured as microgrids, sometimes with and sometimes without a connection to the larger electric power system. College campuses [73], large commercial and industrial facilities [74],

\footnotetext{
${ }^{78}$ Early electric grids in the United States and elsewhere were disconnected from each other and self-supply was more a fact of technological and economic constraints rather than a result of some conscientious choice between alternatives.

${ }^{79}$ When specific pieces of equipment needed for lab experiments at NIST do not exist on the market, or cannot be sourced within temporal or budget constraints, engineers and scientists occasionally use on-site 3D printing capabilities to fabricate their own solutions.

${ }^{80}$ Encoded in these hierarchies are the constraints, expectations, and codes which form the feasibility envelope.

${ }^{81}$ Backyard vegetable gardens and chicken coops are not uncommon in some towns where space and local ordinances, permit such installations.

${ }^{82}$ While places of work, residences, shopping, and all other forms of entities can generally be found in mixed-use urban centers, some suburban communities eschew the development of a subset of economic activity in favor of other amenities (quiet living, additional space, etc.). Cities tend to be unable to self-supply food resources sufficient for consumptive needs, and thus must outsource some production to agricultural regions.

${ }^{83}$ This definition was developed by the DOE Microgrid Exchange Group.
} 
and military bases [75] have built up microgrids optimized to meet the requirements of considerable local electric and heat loads while acting as a hedge against fluctuations in energy prices and a strategy for ensuring supply. Crucial facilities like hospitals, emergency management centers, data centers, and critical infrastructure have also seen the benefits of building and operating microgrids capable of delivering local energy supply under normal conditions that are also resilient and reliable in the face of contingencies. As discussed in Section 4 on the high resilience grid, many microgrid owners constitute electricity customers that have opted to acquire additional resilience services beyond those which are typically supplied by conventional utilities.

There exist several non-mutually exclusive justifications for implementing a microgrid. At its core the "business case for local energy provision rests on avoiding utility service costs" [76]. If energy can be provided at lower costs by local DER than it can be purchased from legacy suppliers, the business case for self-supply can be rather straightforward and compelling. However, savings from self-provision compared to reliance on conventional utility generation is only the most-readily measured potential value stream warranting attention. Few would argue against the value of a resilient power supply for critical infrastructure in the face of numerous threats and hazards. ${ }^{84}$ Microgrid implementation strategies may afford customers the ability to achieve a level of resilience or reliability that is differentiated from that provided by conventional suppliers to typical customers. ${ }^{85}$ Indeed, the future might find access to resilient power supplies through microgrid-enabled facilities to be yet another amenity offered to consumers of residential and consumer properties. ${ }^{86}$ Some stakeholders may derive additional value from microgrids capable of delivering electricity service that is differentiated along other dimensions such as extremely high power quality for semiconductor manufacturers or predominantly renewable supply mix for organizations attempting to meet their own environmental objectives.

As outlined in the DOE definition, microgrids are composed of many varied elements. "Advanced hardware, intelligent inverters, smart controllers, and compatible communications will be the enabling technology mix used to maximize a microgrid system's economic and operational benefits" [79]. Most microgrids are not completely isolated, but rather are connected to the larger electric power system (EPS) through their point of common coupling (PCC). Fed from a single substation, an advanced microgrid can sense local conditions and automatically transition between connected and islanded states. Microgrids necessarily serve some of their

\footnotetext{
${ }^{84}$ In developing a base-case estimate of the cost of electricity interruptions to U.S. customers, LaCommare and Eto [77] arrive at a value of $\$ 79$ billion each year. To put this value in context, the EIA reports that revenues from the sale of electricity to end use consumers fluctuated between a low of \$344 billion and a high of \$393 billion over the 10 years spanning 2007 to 2016 [78]. Given the size of these interruption costs relative to the annual sector revenue, enhancements to grid resilience constitute an important opportunity to improve the profitability of the electric sector. Furthermore, if these costly interruptions are not addressed by incumbent utilities, there exists ample economic incentive for customers to develop and deploy alternate solutions for which utilities might not be directly compensated.

${ }^{85}$ The customer will generally need to coordinate the development and deployment of the microgrid in conjunction with the existing utility to guarantee that resources are integrated safely and cost-effectively, and that the microgrid performs as intended.

${ }^{86}$ Access to high quality schools, parks, entertainment, and shopping all confer their amenity values upon sale prices in housing markets. The resilience value of living in a domicile that is part of a microgrid may someday be reflected in higher property values.
} 
own load through DER such as PV or small natural gas generators providing combined heat and power (CHP); the technology of choice can vary with customer requirements. A microgrid may thus rely on inverter-interfaced renewables, small conventional generators, or both. To operationalize economic integration with the larger EPS, microgrids require an energy management system (EMS) capable of controlling and coordinating individual loads, generators, storage, and power exchanges in a manner that quickly acts on the information that it exchanges across the PCC. For a more detailed discussion of the elements, objectives, and operating modes of microgrids, please see Bower, Ton [79].

The diversity of operational modes available to microgrid owners offers numerous opportunities to develop value propositions for the rest of the EPS. Advanced control systems allow microgrids to transition from transacting energy and related services with the grid to operating in islanded mode. Early implementations of microgrids tend to rely on dispatched and scheduled delivery of services. However, in time, advanced controls and interoperable power electronics should allow for autonomous decision making concerning the provision of services to the grid.

Microgrids can be designed for differentiated levels of service with respect to capacity for selfsupply and the provision of power to neighbors. Roach [80] envisions a classification scheme that differentiates microgrids along the percent of local loads met by self-supply as; energy assurance (30\% to $60 \%$ ), energy independence (100\%), and revenue microgrids (100\% to 300 $\%)$. A fleet of revenue class microgrids could act as a competitive fringe in the supply of electricity and a buffer against monopolistic competition. On the other hand, a coordinating entity (perhaps a platform) could operate a network of revenue class microgrids as a virtual utility that enjoyed some degree of market power.

\subsection{Possible SMART Grid MARKETS}

To evaluate what is possible for microgrids, one can look to current success stories. The University of California, San Diego (UCSD) is one such example.

While connected to the distribution system, the optimized microgrid can be viewed by the local utility as a 'dispatchable feeder' and provide it with services in support of grid reliability while helping the utility defer investments in capacity expansion. In parallel, the optimized microgrid could participate in the future wholesale markets in the form of energy balancing and ancillary services and can benefit from the market revenues received to accelerate the return on UCSD's distributed assets investments [73].

In addition to being able to service internal loads, the UCSD microgrid is a partner to the local utility in the provision of reliability services. A research university requires high quality power to serve a dense set of loads including those needed to operate laboratory spaces and computing resources. A university setting is also a strong candidate for the deployment of advanced microgrid technologies as the personnel necessary to carry out research and development are already present and vested in its success. As alluded to above, the way a microgrid is integrated with the larger grid can evolve over time as operators become more capable and technological improvements expand the set of what is possible. The long-term role played by microgrids could evolve along a variety of non-mutually exclusive paths. There is no reason to impose the specific model that has achieved success in San Diego on microgrids in other settings. However, 
there could be significant value in standardizing the components of the microgrid and the systems through which they are connected. Interoperability between components will be important if there is to be level competition within technology categories such as generation, storage, and management mechanisms.

One small but significant school of thought behind the development of microgrids is motivated by a desire to "cut the cord" and avoid participation in electricity markets. There is a distinct romanticism of complete self-supply, seemingly rooted in the tradition of American individualism. However, the settings in which truly disconnected small electric grids are the most attractive are likely locations for which integration with the larger EPS was too costly to begin with. Most microgrids are not intended to fully replace the existing system as much as they offer an opportunity to more efficiently integrate the needs of local communities with the capabilities of the larger EPS. The steady march of progress that has seen the uplifting of living standards around the world has been closely tied to the increases in productivity that efficiency offers. Complete and wide-spread disintegration of productive systems is unlikely to achieve gains in productivity in the way that decentralized, but effectively coordinated production can.

The evolution of microgrids as a part of the smart grid involves questions of who will deploy them, and who will enjoy the benefits that they can confer. High initial costs and efficacy of CHP technology have meant that many of the early adopters have been large institutions with considerable heating loads. New scalable and modular technologies have sufficiently compressed costs so that microgrids are becoming economical for smaller institutions and households operating under stricter budget constraints, but uncertainty around the distribution of costs and benefits of microgrid deployment across the electric grid remain.

Several evolutionary paths are conceivable that could arrive at very different outcomes. On the one hand, microgrids could evolve in a manner that allows for increased integration of local communities into the operations of the larger EPS through the provision and consumption of services. Another path might see the separation of electric enclaves with little need for services provided by the grid and little capacity to provide services for those beyond the boundaries of the microgrid. This second path is less likely in that business case for microgrids is improved through the ability to sell excess service capacity back into the market for electricity. Care should be taken to avoid disintegration that reduces overall system performance; physically, or economically.

The move towards a future with integrated microgrids may require a shift from "lifeboat ethics", in which members of a local community develop the ability to protect themselves through islanding to one of "coastguard ethics" in which the business models that prevail include the ability to provide services to neighbors afflicted with contingencies that are "offshore" of the islanded microgrid. In other words, the ability to secure electricity supply for a given community can be augmented through systems, components, and coordination mechanisms (perhaps markets) that allow excess capacity to be directed towards the provision of grid services to others. Business models that recognize and compensate these opportunities for larger-scale integration will be catalytic to the development and deployment of microgrids. An organization may reduce costs through self-supply, but revenue must be derived through what that organization can do for others (in exchange for compensation). 
The ownership structure is an important determinant of who benefits and to whom costs accrue during the operation of a microgrid. Several different structures exist [81]. A basic structure for microgrids entails the ownership of assets by a conventional electric utility. Another structure involves ownership of the microgrid by a landlord. This second structure could take the form of a district heating model if the primary outputs are heating services. A customer-generator model of ownership entails a single entity that owns, operates, and uses a microgrid. Finally, a group of entities, such as residents of a condominium complex or a neighborhood, could form a cooperative entity through which to own and manage the assets of a shared microgrid.

Ownership and management does not have to overlap. In fact, a new set of (platform) business models could emerge to present value propositions based on the effective management of various microgrids. These two-sided platforms could intermediate interactions between microgrid owners (households, neighborhoods, business districts, campus operators) and distribution system operators (who may themselves organize as platforms to intermediate transactions between end users and independent system operators).

\subsection{EXISTING EXTERNAL MARKETS WITH SIMILAR CHARACTERISTICS}

The discussion of microgrids can benefit from the body of theory and empirical evidence developed in the economics of international trade literature. The movement from autarky, or the strict abstinence from international trade, to a world in which such exchange comes to define international value chains, mirrors an evolution from the disconnected small grids of a century ago to that of the modern connected grid. The breadth of international trade research offers several valuable lessons for industrial organization across system boundaries. The point of departure of the MDGS architecture track with respect to the conventional grid is one of changing segmentation and organizational models.

Advances in ICT have driven changes in the industrial organization of many different sectors of the economy. Significantly, these changes have bridged international borders. Technological change powerful enough to overcome the physical challenges of coordinating economic activity and moving products around the world is likely not to be hindered by the boundaries of current ownership and management structures in the domestic setting of the electric grid. Helpman [82] discusses the impact of informational advances on international trade, noting that,

fragmentation of the production process across firms and countries is more prevalent now than ever before, and this has affected the sourcing strategies of corporations at home and abroad. The proximate cause of these changes has been developments in information technology (IT), which greatly improved communications, computer-aided design, and computer-aided manufacturing. These improvements enable producers to split the production process into stages that can be physically and geographically separated from each other and located in different regions of the same country or in different countries.

The third sentence from the discussion in Helpman [82] is especially relevant to the influence of ICT developments on the advancement of microgrids. Improvements in ICT that enable the fragmentation of production are facilitating the decentralization of electricity provision along supply chain and market segments. Without advanced communications technologies, large 
informational and control frictions necessitated the organization of linked production activities under the control of a single integrated utility. Advancements in ICT allow actionable data to flow between distinct entities in a manner that enables interfirm supply networks. As these advancements continue, and costs fall, smaller organizations can play a role of increasing importance in the overall organization of industrial activity. Microgrids represent market players operating in small segments, integrated into supply networks through advanced ICT. The degree to which this integrated but decentralized activity can take place is determined by the extent to which elements of the electric grid are interoperable with each other.

Models of industrial organization and international trade have evolved in response to changes in the underlying economic structure they venture to describe. Early trade models emphasized differences in labor productivity [83] and factor endowments [84] as determinants of trade flows between countries. The next wave of models recognized the influence of economies of scale, increasing returns, and monopolistic competition $[85,86]$ on trade patterns ${ }^{87}$ Additionally, product differentiation was recognized as an important determinant of patterns in intraindustry trade [88, 89].

An example of intraindustry trade may prove illustrative. American consumers buy European cars and Europeans buy automobiles produced by American firms. Both groups of producers have production facilities situated in the U.S. and Europe. The establishment of production facilities in a host country, known as foreign direct investment (FDI), is a common phenomenon across many sectors of the modern economy. ${ }^{88}$ Furthermore, one firm may produce engines or other components that they sell to subsidiaries and arms-length trading partners, both domestically and abroad. These patterns are not limited to the U.S. and Europe. It is important to note that while the structure of the world economy changes, some components of earlier structures remain central to patterns of trade. ${ }^{89}$

The structure of electricity markets and patterns of consumption exhibit some noteworthy parallels to the broader experience of international trade. A key takeaway from international trade research is that borders matter; economic activity that crosses these (political) system boundaries is subject to additional constraints. The long distances between locations favorable to the generation of hydroelectric power and large population centers acted as early barriers to the "trade" of electricity between regions endowed with productive capacity and regions with considerable potential demand. Technological advances to transmission, distribution, and the advent of means (other than hydropower) to generate large quantities of electricity rendered these barriers less constrictive. The realization of economies of scale and decreasing average

\footnotetext{
${ }^{87}$ By one formulation, trade flows can be modeled as a function of the "gravity" between the economies of trading partners [87].

${ }^{88}$ To continue the analogy between international trade and trade in electric services between legacy utilities and microgrids, patterns of FDI may be mirrored through the deployment by utilities of advanced power electronics and DER behind the PCC. This has already occurred with water heater focused demand response programs and could emerge as a preferred strategy for utilities if such investments increase the trustworthiness of microgrids with respect to their operating profiles and ease of integration with the larger EPS.

${ }^{89}$ Regions endowed with rich timber resources still export these products to arid areas with high levels of construction activity, and nations with strong institutions for the advancement of human capital still export high tech goods and services to countries of varying degrees of economic development.
} 
costs lent to the rise of monopoly provision of electricity for much of the history of the electric grid.

The physical requirements of electricity provision and legacy market structures have necessitated the presence of boundaries between segments of the grid operated by different electric utilities and balancing authorities. Improvements in ICT have enabled more efficient "trade" in electricity across these legacy boundaries and enabled the emergence of new market segmentation schemes (regionally, within firms, and between firms). The establishment of microgrids represents a growing pattern of segmentation. Analogous to patterns of intraindustry trade, microgrids with different internal components, structures, and use profiles may find it profitable to engage in patterns of trade where energy and related services are transacted in both directions as environmental conditions and internal needs dictate. ${ }^{90}$

We conclude the discussion of international trade and microgrids by returning to the issue of self-supply. In addition to seeking economical supplies of key inputs to production, entities require that their supply be of a sufficient quality with respect to its reliability and resilience to potential disruptions. Resilience in this context is the ability to maintain normal operation under situations of stress. When an input is crucial to production, organizations are generally willing to pay a premium for resilience in supply. Many strategies exist to achieve such resilience, but the decision regarding the extent of self-supply is the most salient to the discussion here.

Countries have an interest in maintaining resilient supplies of energy, food, medicine, defense, and a variety of other goods and services. Indeed, resilience in supply of such inputs to modern life is broadly regarded as a matter of national security. As such, few countries endeavor to abstain from some positive level of domestic production of these critical inputs even when a premium must be paid relative to sourcing from other countries. At the same time, threats such as natural disaster encourage diversity in sourcing and reasonably preclude strategies of pure self-supply. Electricity is among the most crucial inputs for maintaining modern living standards. Microgrids offer a set of strategies through which customers may achieve resiliency through diversity of electricity supply. As should be clear from this discussion, the value of this diversity is predicated on good communication across the PCC that segments but does not separate the microgrid from the EPS writ large.

Interoperability is a key determinant of the number and diversity of trading opportunities that will arise through new segmentation schemes. In addition to the improvements in ICT that allowed firms to fragment production across borders, containerization standardized the shipping industry and reduced the frictions of moving goods between distant and distinct ports. ${ }^{91}$ What is important about the container revolution to this discussion of interoperability is that the standardization enabled intermodal trade, that is, the movement of a goods in a single container between ship, truck, and rail without repackaging. This allowed for specialized organizations to

\footnotetext{
${ }^{90}$ Integrated neighboring microgrids may each act as net importers or exporters of energy and ancillary services as their internal loads and generation fluctuates. There is no reason that a given microgrid must only behave as a net supplier or consumer. While not as discrete as the automotive example with commodified parts explored earlier, a collection of energy and ancillary services must be coordinated by a utility or group of such entities to deliver the amalgamated reliable and resilient services of the electric grid that are enjoyed by end use consumers.

${ }^{91}$ For an empirical estimate of the impacts of the container revolution on world trade see Bernhofen, El-Sahli [90].
} 
carry out different segments of the transportation value chain. Interoperability between microgrids and legacy utility structures, as well as between the components of microgrids, will enable more efficient fragmentation and specialization in the resilient provision of electricity.

\subsection{MARKET SUCCESS OR FAILURE}

The market structures that emerge on the smart grid need to be able to coordinate the economic activity of a diverse set of market participants. As small players such as households become more active in production and consumption decisions and compete in markets alongside larger, incumbent and entrepreneurial organizations, matters of relative bargaining power and the potential exercise of market power deserve the attention of grid architects and market designers. Transactions between entities of vastly different scale or scope may not to be conducted on sufficiently equitable terms to ensure competitiveness. Microgrids could constitute a form of organization through which small players could aggregate their bargaining power to improve the load profile that together they present to the grid. ${ }^{92}$ The marginal supply curve of an electricity market served by many similarly sized microgrids will generally be more elastic than one comprised of few large producers.

The structure of grid segmentation between the components of microgrids, networks of microgrids, and larger balancing organizations will be a key determinant of the degree of competition within and between segments. The organizational forms that arise to handle economic activity within and between segments will occupy crucial control points. Given the standard set of activities that will need to be mediated, platform business models seem likely to evolve in this context. A crucial component of the platform business model is that if the platform can mitigate threats in the form of new entry and substitution away from the its platform services, ${ }^{93}$ and if the platform operator is in a position of optimal bargaining power relative to the supplier and buyers it encounters, it is likely to earn strong returns on investments. Such platforms, acting as a switchboard, could engender healthy competition in services provided by microgrids, while sheltering platform profits from the deleterious effects of competition. High levels of interoperability could help to prevent the use of high switching costs to extract excessive value from service providers using any given platform. The degree to which society accommodates monopoly in platforms is likely to be a function of the perception that electricity service consumers hold regarding the "fairness" of these platform business practices. A new regulatory compact could evolve to determine the share of market value facilitated by platforms that is "fair" for a given platform to take. The rise of electric grid platforms is unlikely to escape public debate around the ethics of enterprise and exchange in infrastructure sectors.

One challenge limiting the investment in microgrids by households is that the durable and spatially fixed nature of many microgrid components imply the possibility that the entirety of benefits associated with deployment and operation may not accrue to the original investor. To

\footnotetext{
${ }^{92}$ Microgrids, by definition, constitute networks of loads and DER. Bargaining power is tied to the scale of the value proposition that an entity can bring to market. The value proposition of integrated networks should generally exceed the sum of value propositions that all of the constituent networks could provide in isolation.

${ }^{93}$ This analysis draws heavily on the classic Porter Fiver Forces analysis [91]. Both of these threats can be attenuated through platform business strategies that increase switching costs and thus contribute to customer lock-in.
} 
the extent that microgrid investments are compensated in the sale price of property, investors will be less worried about failing to earn sufficient return on their investments. ${ }^{94}$ Rooftop solar installations are unlikely to travel with families when they move homes, but energy storage, some light DER, and other behind-the-meter devices such as internet of things (IOT) devices that can be linked to loads need not be left behind. The key to the question of whether various microgrid components travel with a household or organization that is changing location may be a matter of whether it continues to be interoperable with the electric system in the new venue. Standardization in electric outlets and plugs prevent households from having to acquire completely new sets of appliances for new homes. The generation side of the household electricity balance could evolve to mirror this state of compatibility. Buyers of buildings with microgrid components will value these amenities at relatively higher levels if they know them to be interoperable with the buyer's existing electric equipment. Interoperability between components and the built environment thus has the potential to reduce a barrier to investment in smart grid technologies.

\subsection{APPLICATIONS TO SMART GRID QUESTIONS}

While many of the devices and systems found in the MGDS architectural track are shared by the HDAG track, the role of segmentation decisions in determining grid structure is central to the evolution of microgrids. Segmentation schemes within and between firms tend to evolve in a manner that allows stakeholders to economize on production and transaction costs. Identifying and understanding the market and technological trends to which the microgrid development path is the most responsive is useful in tracking how electricity markets will evolve over time. Improvements to grid interoperability may increase or decrease the propensity for a given organization to deploy a microgrid. Interoperability enhancements that reduce the cost of integrating a microgrid into the EPS should increase the deployment of microgrid assets that augment a customer's electric power supply network. Interoperability enhancements that improve the value proposition of non-microgrid assets may slow the growth of microgrid installation through reducing the propensity of consumers to bypass conventional grid assets.

A feedback loop likely exists between grid conditions and the decision to invest in microgrid technologies. For example, insufficient reliability or high cost of service could induce a marginal consumer to invest in a microgrid that allows it to bypass the conventional utility supplier when it is profitable or necessary to do so. When a consumer bypasses the conventional market for electricity (partially or completely), there is a change in the underlying network model. These changes may be insignificant if the bypassing consumer is small. However, as many of the early adopters of microgrid technologies are hitherto large consumers, there is a possibility that the grid cyber-physical system and related market structures will change appreciably with microgrid adoption. Understanding, the responsiveness of grid key performance indicators (reliability, resilience, costs, and interoperability) to the bypass decision is crucial to predicting how market structures might evolve in the future. Fundamentally, smart

\footnotetext{
${ }^{94}$ Recent research has endeavored to place a value on the premium in home sale prices that can be attributed to the presence of solar PV systems. Hoen, Adomatis [92] finds that homes with PV systems sell for a premium on the order of \$ 4.18 / Watt, or “a premium of approximately \$15,000 for an average-sized system of 3.6 kW” above what would be earned by a comparable non-solar home. Solar PV is one example of technologies that will be increasingly implemented in the advanced microgrids of the future.
} 
grid investment decisions are endogenous to the history and present state of the electric grid. Future research can endeavor to improve our understanding of this endogeneity and the contributing role of grid interoperability.

\section{TRACK 5: URBAN CONVERGED NETWORKS (UCN)}

\subsection{ARCHITECTURE DESCRIPTION}

The fifth architecture track, Urban Converged Networks (UCN), entails the development of converged platforms for communication and the control of key infrastructure systems including electricity, natural gas, transportation, water, sewer, and waste. Each of these infrastructure needs is currently met through networks that can overlap in their use of inputs, especially communication resources. At the heart of the UCN architecture track is the transition from business models predicated purely on economies of scale to those based increasingly on network economies and the synergies that can be realized through combining existing networks.

City managers operate in environments with tightly constrained budgets and high expectations. The increasing fixed costs of meeting the needs of growing urban communities lead managers to seek efficiencies that can be gained within their respective systems and beyond. Furthermore, as will be shown in this section, physical and economic constraints on these systems have exposed the large degree to which these systems are interdependent and capable of enhancing or inhibiting each other's functionality. As network business models arise in many other aspects of our daily lives, it seems like only a matter of time before entrepreneurial endeavors seek to converge these assorted networks with those of critical infrastructure to generate new value streams.

\subsection{CONVERGENCE OF EleCtricity AND NATURAL GAS NETWORKS}

A primary component of the UCN architecture track is converged gas and electric systems. The low cost and modularity of natural gas generating equipment, along with technological advancements that have enabled the 'fracking boom' and brought to market large quantities of inexpensive natural gas, has displaced costlier generating resources in the economic optimization of the grid (often termed the 'dispatch stack'). This, in turn, has increased the exposure of electricity markets to developments in natural gas markets.

As the supply curve for natural gas has shifted outward and the market price of gas has fallen to historically low levels, there has been an increased incidence of electric utilities acquiring natural gas utilities. McMahon and Fong [93] argues that the main reason for this trend in acquisitions is due to "a focus on unlocking synergies between operating companies". ${ }^{95}$ Consolidation offers the ability for utilities to diversify revenue and reduce business model risk.

\footnotetext{
95 This focus on synergies arose from several market conditions including low load growth in many electricity markets, the potential for gas sourcing options that create economies of scope, and the realization of economies of scale based on opportunities for new pipeline infrastructure investment. Additionally, consolidation has occurred in waves during periods in which borrowing costs were relatively low. Consolidation activity slowed considerably during and immediately after the U.S. financial crisis [93].
} 
A core component of the strategy of convergence is the ability of firms to spread fixed investment and operating costs over a greater quantity of units sold, improving profit margins. Much of the natural gas distribution infrastructure runs underground. Electric utilities could gain access to underground infrastructure and rights of way through merger and acquisition activity. Common smart meters for multiple services can rely on a single communications protocol and network. Consolidation of back-office functions (e.g., billing, customer service, etc.) could yield meaningful efficiencies as well.

Supply disruptions and price volatility in natural gas markets have the potential to directly impact the economic performance of an increasing share of bulk generation and the electricity that flows over the interconnections between balancing authority areas [94]. The security and efficiency of natural gas markets is a function of the infrastructure that connects producing firms and regions with end consumers around the country and internationally [95]. The traditional challenge of getting gas to market through pipelines and storing it to accommodate seasonal and idiosyncratic fluctuations in demand have historically insolated domestic natural gas markets from extra-regional pressures. The increasing connectivity of our modern world has eroded these barriers and the glut of low-cost natural gas has led producers to advocate for and obtain the ability to pursue export opportunities.

Two results of the growing customer base are of note: investments in additional infrastructure to facilitate transport and export are desired by industry and some of these additional costs can be passed on to the new consumers. Markets will direct goods to those consumers with the greatest willingness to pay, subject to the constraints of the delivery system. ${ }^{96}$ Some newly accessible customers may constitute sources of increased revenue if their willingness to pay for natural gas is sufficiently high [96]. The prospect of additional revenues from international natural gas customers will enable some of the future investment in pipelines, export facilities, and the communication infrastructure that renders them operational.

Gas generators act as a coupling between two of the most important energy systems in the country [94]. As natural gas has accounted for an increasing share of electricity generation as well as space heating, a change hastened by the fall in domestic natural gas prices due to a suite of technological improvements sometimes referred to as the "fracking boom", the need to coordinate and de-conflict operations between natural gas and electricity systems has risen. As we saw in the polar vortex a few years ago, when demand for both electricity and direct consumption of natural gas (e.g., for home and building heating) are high, the transmission (pipeline) infrastructure can be overburdened and local supply shortages can lead to extreme price volatility and even shortages. By co-optimizing these systems (i.e., when they own both), utilities can manage the demand and obtain electricity from different sources not as a function of price, but as a function of managing overall supply given the transmission and distribution constraints [94].

\subsection{CONVERGENCE OF ELECTRICITY AND WATER NETWORKS}

\footnotetext{
${ }^{96}$ Customers not connected to pipeline infrastructure will have to source liquefied natural gas (LNG) that can be shipped overseas in tanker ships. Natural gas must be condensed to become LNG, a process that when combined with transportation, is similar in cost to the price of natural gas on the henry hub (at the time of writing).
} 
The collection in reservoirs, transport, treatment, distribution, and sanitation of water is exceedingly energy intensive. The generation of electricity at conventional power plants requires large withdrawals of water for cooling purposes. Much of this water is returned to its source at a warmer temperature after providing cooling services, but some is consumed in the process. Evaporation leads the generation of electricity at reservoir hydroelectric plants to entail considerable water usage [97]. ${ }^{97}$ The water energy nexus is an area of increasing interest, and the necessity of both resources to life and economic activity render the convergence of related communications networks an intriguing opportunity. Droughts lead to curtailments in hydroelectric production, which must in turn be replaced with alternate forms of generation, often using natural gas [99]. ${ }^{98}$ Here we see that interdependencies between infrastructure systems can lead to additional interdependencies with other systems still. Convergence of communication and control systems could lead to the internalization of these interdependencies and balancing of operational tradeoffs in a socially optimal manner. In sectors where energy and water are both inputs to production consumed in large quantities, such as is the case in irrigated agriculture, converged control networks could optimize the employment of both resources in concert. $^{99}$

\subsection{CONVERGENCE OF EleCtricity ANd TRAnSPORTATION NETWORKS}

A key affinity between electricity and transportation networks is the near universality of their use by individuals and organizations. Both systems are geographically dispersed and the large customer bases of electric utilities and transportation services imply that opportunities from convergence are likely to impact most Americans. ${ }^{100}$ Decades of accumulative technological innovation and a desire to reduce vehicle emissions have enabled and encouraged increased electrification of transport fleets, rebuilding the interdependencies between the electric grid and transportation systems. ${ }^{101}$ Therefore, opportunities for performance improvements through the convergence of communications infrastructure used by the two networks are legion and small improvements may be leveraged to effect large changes in agent coordination and system performance.

\footnotetext{
97 Torcellini, Long [98] finds that while evaporation at thermoelectric plants consumes 0.47 gal (1.8 L) of fresh water per kWh of electricity, reservoir hydroelectric plants average 18 gal $(68 \mathrm{~L})$ of fresh water per kWh of generation.

${ }^{98}$ Droughts also lead to curtailment of thermal generation due to temperature limits on once-through cooling systems, which while no longer built in the U.S. are still in operation.

${ }^{99}$ Agriculture may not be the best opportunity in some regions for water-electric grid convergence as many agricultural entities rely on well water and allocations from non-utility systems.

100 The Federal Highway Administration reported there to be 218 million licensed drivers and 256 million registered vehicles in the United States, circa 2015. The transport customer base is therefore a large target market for new services cultivated by convergence strategies.

${ }^{101}$ In earlier decades, electric generation and transportation systems were linked through oil as a common fuel source. After the 1973 oil embargo and associated price volatility of the 1970's, oil fired generation was intentionally removed from the Nation's resource mix, leaving only a small number of oil "peakers" still in use today. This trend in fuel mix effectively separated the electricity and transportation infrastructures. The move to electrify transport therefore reverses a 40-year trend of separation between the sectors but is not wholly unprecedented.
} 
Stakeholders in the electric power sector are increasingly cognizant of and acting on the unrivaled opportunity for sales growth presented by the mass deployment of electric vehicles (EVs). If supply side stakeholders can move past fears rooted in the reliability challenges presented by the integration of an emerging class of loads, they may realize a once in a generation opportunity to improve the environmental footprint of the transportation sector while developing a permanent new source of revenue from existing and new customers. While some households and businesses may see opportunities to combine self-supply and EV adoption, many EV adopters will find the reliability and low cost of grid supplied electricity an attractive source of fuel for their chosen mode of transportation.

The potential challenges of serving EV loads with the existing grid are real, but the opportunities to learn from these systems integration challenges and derive operational and economic improvements from the accompanying growth in load, revenue, and observability will be a net benefit to the electric power sector. Generation, transmission, and distribution system assets will need to be managed effectively to ensure that EV loads can be served while accounting for operating limits and consumer preferences. The prize for identifying innovative ways to turn these operational threats into business opportunities will be competitive advantages in future efforts to integrate emerging energy technologies. Careful integration of information on EV load profiles with the grid EMS could improve visibility into operational strategies that could create benefits for both the electric and transport grid.

Transportation and electricity traditionally had limited and similar metering opportunities using fixed points at the gas station or the building PCC. Now that sensors and controls have been installed extensively, both systems are experiencing a data revolution that is providing more comprehensive awareness of usage patterns and requirements. This data can be acted upon to improve state awareness, produce more accurate forecasts, and efficiently deliver services which are dynamically optimized to meet consumer demand with respect to quantity and quality. This improving awareness is complemented by the expanded physical coupling of the systems when EVs are charged. ${ }^{102}$ The coupling of systems with respect to information and control should enable new strategies for achieving operational flexibility. For example, grid operations can be adjusted strategically to accommodate anticipated changes in demand for transportation charging services. Alternatively, charging rates for EVs could be moderated to match grid conditions. That is, charging rates could be slowed when demand is high to avoid high costs to system operators that would otherwise need to be passed on to customers. These dynamic strategies could prove effective at mitigating the possibility for charging price volatility associated with the distribution system approaching its physical limits.

Both transportation and electricity systems could take advantage of converged communications networks operating within the footprint of existing infrastructures. Transportation right-of-ways are already forming the backbones for new urban communications and smart city optimization infrastructures. An early example of convergence between the electric grid and transportation infrastructure can be found in smart streetlamps. Navigant research evaluated the viability of these distributed infrastructure components to act as platforms for the deployment of additional

\footnotetext{
${ }^{102}$ While these systems have always been coupled, as electricity is needed to run gas pumps, the past relationship was unidirectional with one infrastructure serving the other. Moving forward, a coordinated coupling of control and operations, informed by economics, can improve performance for both infrastructure systems.
} 
smart city applications [100]. The most obvious applications entail the replacement of old lamps with energy efficient lighting technologies that can be coupled with smart controls to implement lighting schedules that align with prevailing road use profiles and deliver energy savings to cities.

Street lighting platforms could be developed to offer additional services including monitoring applications, operating systems, or critical systems. Applications that could monitor vehicle and pedestrian traffic, air quality, or noise would be possible while putting limited demands on communications networks. Applications in support of city operations generally require greater communications investments, but could enable smart parking, smart waste collection, or even gunshot detection. Critical systems would require the most reliable and secure communications investments of the applications considered for implementation through smart lighting platforms. However, public safety cameras or advanced traffic light controls may be sufficiently valuable to a municipality to warrant adoption. A fundamental tradeoff with respect to the applications cities decide to adopt will be between the additional value they provide and the costs of implementing and maintaining the communications networks required [100]. Converging a number of high-value applications over a given communications backbone could ensure that the communications investments achieve an acceptable cost benefit ratio.

Moving forward, the manner in which the EV fleet is owned and operated may change, especially as driver automation grows in prevalence. Vehicle communications requirements are set to evolve rapidly. ${ }^{103}$ Recently, sensor and communications equipment has been harnessed to allow vehicles to broadcast their location, speed, and other data, to improve safety and inform the active scheduling of maintenance and repairs. Once heavily instrumented and connected to the electric grid and other infrastructure systems through advanced communications resources, vehicles may be harnessed as platforms to host other applications. Ubiquitous smart phones held onboard by drivers already communicate detailed information on traffic and congestion patterns to drivers without the need for explicit integration into vehicle infotainment systems. In this sense, even vintage vehicles can and often do become mobile sensor platforms.

Electricity and transportation systems of the future will rely on robust, high-capacity communications infrastructure. Convergence offers an opportunity to share limited resources such as bandwidth that might otherwise be allocated to only one of the converging parties. However, shared network resources imply a shared need for mitigation of congestion. Mechanisms for de-conflicting information traffic arising from converged electricity and transportation systems will have to manage traffic in a manner that aligns with societal and organizational value judgements.

\subsection{LESSONS FOR CONVERGENCE AND INTEROPERABILITY}

\footnotetext{
103 By one estimate, each autonomous vehicle on the road is "predicted to generate and consume 4,000 gigabytes of data daily” by 2025 [101]. The communication of even a small portion of this data would require considerable invehicle transmission and receiving capacity. Such capacity built to meet the peak communications loads would likely sit idle for much of the day. Convergence of communications networks between the electric and transportation sectors could thus enable higher capacity utilization for vehicles and the communications equipment inside them.
} 
Interoperability is centrally important to infrastructure convergence. Interoperability facilitates greater information exchange, improving visibility into opportunities to realize new value propositions within a given network. As the value of any given network increases, that network becomes a more attractive target for pursuing convergence with other infrastructure networks. Furthermore, upon convergence of communication infrastructure, greater interoperability implies that the individual networks now forming a converged network are effectively larger, and the set of opportunities to find new value propositions should increases commensurately.

Network convergence will likely entail a tradeoff between an expanded strategy space for operations and an increased informational requirement. As networks converge, the sets of information that must be exchanged between nodes could increase as it becomes necessary that water and gas loads be communicated alongside electricity loads. An added benefit of communicating additional information is that a household interested in providing services such as demand response might be able to select for self-curtailment or shifting of loads (electricity, gas, water, etc.). ${ }^{104}$ On the other hand, as more information with respect to service requirements and market conditions is consolidated and communicated, household and enterprise privacy strategies will need to evolve. It may be easier to protect a consolidated communication channel, but the value of that channel is large enough to attract capable bad actors.

Convergence of networks will increase the set of interconnected assets with which DER might exchange services. If high levels of interoperability can be achieved among DER, there will be a significant incentive for other resources across infrastructure networks to improve their own interoperability in order to realize the benefits of convergence. For example, an owner of a distributed irrigation system could benefit from rendering attached pumping infrastructure interoperable with distributed energy resources in the area so that crop irrigation strategies can autonomously account for variation in energy prices and distribution network congestion.

\section{CONCLUSION}

Technological change continues to enable the fragmentation of value networks in the electric power sector. Functional control of electric grid operations is decentralizing as ever more capable devices and communications are pushed to the edge of the grid. Concomitant with the adoption of grid-edge resources is the devolution of the strategies that govern and optimize the system; operations once handled by the internal hierarchy of the firm increasingly require the coordination of multiple organizations. The transaction costs associated with decentralized operations could grow to problematic levels if sufficient interoperability is not achieved. Should these "costs of running the economic system" [27] rise in an unmitigated fashion, they may become so large as to preclude the emergence of otherwise valuable transactions. However, the first hurdle to wielding interoperability as a cudgel against the potential for bloating transaction costs is the development of consensus around how interoperability is to be achieved, measured, and valued.

\footnotetext{
${ }^{104}$ A household would not engage in full curtailment of any of these inputs crucial to our modern standard of living. However, a family might shift loads temporally to lower the cost of service in line with time of use price differences or devise strategies for reducing their water use. Curtailment strategies may be behavioral (shorter showers), technological (purchase of a high efficiency clothes washer), or some combination.
} 
There is a need to translate definitions of interoperability into requirements that can be usefully applied in product development and operational contexts, and metrics which can be used to validate performance. It is impractical to attempt to improve interoperability without the ability to quantify the current state of the system and measure it as the grid evolves. Because interoperability is a factor in numerous complex decisions made by stakeholders across the electric power sector, relying on a single index of interoperability level would likely be as uninformative as it would be challenging to develop. Instead, early efforts should focus on clarifying terms and developing requirements and metrics that meaningfully characterize the state of interoperability within the context of case studies or applications conducted at different organizational levels.

An advantage to conducting smaller case studies and developing application-specific interoperability requirements at first is that such work offers a tractable setting in which to develop estimates of interoperability's value proposition. Indeed, reliable valuations of interoperability will be the key to achieving an economically efficient allocation of interoperability across the electric grid. While further theoretical research into the concept and impacts of interoperability is needed, empirical study of the interoperability decisions facing practitioners promises to be of immediate benefit to a diverse group of stakeholders.

While a lack of consensus regarding interoperability definitions and measurement methodology is a current challenge, the value of any set of interoperability requirements or associated metrics will become clear as they are productively applied in the response to crucial stakeholder questions. Research applications demonstrating the suitability of a metric for answering stakeholder questions will increase the likelihood that other stakeholders attempting to answer their own questions will adopt the given metric. ${ }^{105}$

Developing common terms for describing IEI improves stakeholder understanding through reducing the information-related transaction costs that form barriers to becoming knowledgeable of interoperability concerns. In turn, a higher level of education among stakeholders and development of a common ontology will aid: regulators in crafting and communicating effective interoperability policy; utilities in formulating requirements to be met by vendors; vendors in developing components and systems for a modernized electric sector; and consumers through reductions in the cost of service. Moreover, a common ontology can support the development of new interoperability-dependent markets in which diverse stakeholders can participate. In the search for no-regrets investments in the smart grid, the development of practical interoperability requirements, metrics, and valuation methods may constitute the best targets presently available. In time, the development of organizations and institutions capable of accelerating interoperability improvement and systems integration may constitute the best no-regrets moves.

Definitions, metrics, and valuation methods are all critical inputs to ongoing efforts to answer stakeholder interoperability questions. Two core questions that should guide future research regarding interoperability within the smart grid context: where do current market and hierarchical institutions struggle to achieve economically efficient allocations, and how can

105 There are network effects associated with the adoption of any measurement standard as the value of adhering to the standard increases with the pool of other users. 
interoperability help to mitigate these challenges? In other words, where do frictions from transaction costs currently hinder market efficiency or preclude market formation entirely, and which interoperability strategies create the most value through ameliorating high transaction (or production) costs?

Ideas for future work efforts can be classified into near-term and long-term elements of the Smart Grid Program research agenda. This distinction recognizes that some efforts to characterize the influence of interoperability on the technology stack and economic phenomena endemic to the smart grid remain unexplored as a result of insufficient metrics and historical data. Answering the two core questions outlined above with a degree of empirical rigor will require organization-level data, which may itself require development and collection. Near-term research opportunities tend to use existing resources, while long-term opportunities are predicated on greater levels of resource development.

\subsection{FUTURE RESEARCH}

As interoperability enhancements accrue over time, it will become possible to determine if patterns of industrial fragmentation appear to change in response to these investments. Crucial questions for future study include whether specific interoperability enhancements change the structure of transaction costs and entry barriers sufficiently to encourage the formation of new economic entities and whether markets with greater levels of initial fragmentation are quicker to adopt interoperability enhancements on cost saving grounds?

Besen and Farrell [102] states that firms operating in network markets face a core strategic decision concerning whether to make products that are compatible with those of rival firms (pursue competition within standards) or make products that are incompatible (pursue competition between standards). The selection process through which firms and households invest in interoperability and smart grid technologies deserves the attention of future research efforts. Future work should strive to characterize the selection process through which households and firms decide to engage in DER installation, and the impact interoperability levels have on DER adoption. This information would prove valuable to efforts that attempt to prognosticate regarding future market structures.

The value proposition of improvements to the distribution segment of the electric grid is influenced by parallel advancements to the transmission grid. Transmission segment modernization efforts have proceeded for considerably longer than have similar efforts in the distribution segment. As the cost of sourcing electricity and related services from distant suppliers falls with the expansion of transmission resources, the value proposition of local sources may change. On one hand, the marginal effect of an improvement to operating efficiency will appear greatest in absolute terms when little else has already been accomplished towards that end. Holding market size static, the first ten percent improvement in efficiency is of greater absolute impact than the second or third to be implemented. On the other hand, while transmission improvements may increase the competition that local resources face from their distant counterparts, these same improvements will increase the potential market for services provided by local, highly interoperable DER. That is, greater interoperability and lower barriers to trade can enable the most efficient organizations and resources to contest larger markets. 
Yet distribution grid value propositions are not constrained solely to competition with and displacement of transmission-connected bulk generation. Indeed, improvements to distribution system interoperability which facilitate non-wires alternatives to conventional infrastructure investment have been shown to enhance the economic efficiency of distribution system infrastructure and bulk power generation alike. The flexible structure of interoperability enhancements allows firms to align investment strategies with their own resources and capabilities to a greater degree than is possible with conventional infrastructure investments. The modularity of interoperability investments makes them a relatively fast way to improve systems performance. This modularity-based speed advantage confers the benefits of lower costs and fewer risks associated with implementation. Consequently, interoperability investments can benefit many electric grid stakeholders while avoiding some of the sources of uncertainty that impede other strategies to improve performance outcomes. Performance improvements generated by modular interoperability investments may even be able to generate returns that can help to underwrite more expensive improvements to bulk power systems down the road. Future research should investigate the relationship between interoperability investments in and performance of both the distribution and transmission systems.

Enhancements to interoperability will impact the bargaining power dynamics seen in various segments of the electric power sector through enlarging or restricting the set of substitute options available to various market participants. Understanding how specific interoperability enhancements impact various actors differentially, especially with respect to their bargaining power in typical transactions, could aid in the targeting of investments that will offer acceptably distributed costs and benefits. Idiosyncratic investments in interoperability are likely to benefit certain groups of economic actors earlier and more significantly than others. ${ }^{106}$ While some variation in time of implementation is inevitable for a task as large as improving overall electric grid interoperability, care should be taken to ensure that the deployment strategies adopted do not undermine or attenuate the potential benefits.

Future research should investigate cases in which improvements to interoperability enable grid components and systems to offer services beyond that which they were originally designed to provide. Innovation may entail the aggregation or combination of disparate services into new composite offerings. The delivery of these aggregate and composite services has historically been associated with very high transaction costs. High transaction costs have formed significant barriers to entry, and in some cases, have blocked market formation for new grid services. Case studies that demonstrate how specific characteristics of existing systems contribute to or hinder the ability of the installed base to create new value may prove instrumental in guiding ongoing investment paths. Considerable benefit could be derived from efforts to understand when legacy specificity continues to aide operational performance and when it stands in the way of progress.

\footnotetext{
${ }^{106}$ For example, households with rooftop solar installations may see considerably more benefit from interoperability enhancements that allow them to sell into electricity markets, than do their solar-free neighbors in similar houses. There will be trade-offs between interoperability enhancements that offer small benefits for all and others that afford much larger benefits, but only to a subset of grid users.
} 


\section{REFERENCES}

1. NIST, NIST Framework and Roadmap or Smart Grid Interoperability Standards, Release 1.0. 2010: Gaithersburg, MD.

2. Taft, J.D., Grid Architecture 2. 2016, Pacific Northwest National Laboratory: Richland, WA.

3. Tirole, J., The theory of industrial organization. 1988: MIT press.

4. Jevons, W.S., Theory of Political Economy, in The world of mathematics: a small library of the literature of mathematics from A 'h-mosé the scribe to Albert Einstein, J.R. Newman, Editor. 1956, Simon and Schuster.

5. Stigler, G.J. and R.A. Sherwin, The extent of the market. The Journal of Law and Economics, 1985. 28(3): p. 555-585.

6. FERC, F.E.R.C. Guide to Market Oversight, Glossary. March 15, 2016 [cited 2018 July 16, 2018]; Available from: https://www.ferc.gov/market-oversight/guide/glossary.asp\#M.

7. Taft, J.D., GMLC 1.2.1 Grid Architecture: Architecture Track Description. 2017, Pacific Northwest National Laboratory.

8. $\quad$ Agency, I.E., World Energy Outlook 2018. 2018.

9. NYISO, Distributed Energy Resources Roadmap for New York's Wholesale Electricity Markets. 2017, New York Independent System Operator.

10. Gopstein, A.M., Energy Storage \& the Grid-From Characteristics to Impact. Proceedings of the IEEE, 2012. 100(2): p. 311-316.

11. DoE, D.o.E., Report on the First Quadrennial Technology Review. United States Department of Energy, Washington, DC, 2011.

12. Energy Information Administration, Electric generator dispatch depends on system demand and the relative cost of operation. Today in Energy, 2012.

13. Act, E.P. Energy policy act of 2005. in US Congress. 2005.

14. Shah, M., J.M. Valenzuela, H.A.B. Mora, K.M. Porst, A. Hasselager, S. Friis-Jensen, M. Vingaard, F. Wigand, S. Tiedemann, L. Bird, O. Zinaman, and J. Logan, Clean Restructuring: Design Elements for Low-Carbon Wholesale Markets and Beyond, in 21st Century Power Partnership Thought Leadership. 2016, National Renewable Energy Laboratory: Golden, CO.

15. Loutan, C., P. Klauer, S. Chowdhury, S. Hall, M. Morjaria, V. Chadliev, N. Milam, C. Milan, and V. Gevorgian, Demonstration of Essential Reliability Services by a 300-MW Solar Photovoltaic Power Plant. 2017: Golden, CO. 
16. Lawrence Livermore National Laboratory, Estimated U.S. Energy Consumption in 2017, https://flowcharts.llnl.gov/content/assets/images/energy/us/Energy_US_2017.png, Editor. 2018.

17. Energy Information Administration, Monthly Energy Review, June 2018. 2018.

18. Wulf, W.A., Great achievements and grand challenges. The Bridge, 2000. 30(3): p. 4.

19. Bresnahan, T.F., E. Brynjolfsson, and L.M. Hitt, Information technology, workplace organization, and the demand for skilled labor: Firm-level evidence. The Quarterly Journal of Economics, 2002. 117(1): p. 339-376.

20. Harris, R.G. and J.M. Carman, Public Regulation of Marketing Activity. Part I: Institutional Typologies of Market Failure. Journal of Macromarketing, 1983. 3(1): p. 4958.

21. Hill, L.J., A primer on incentive regulation for electric utilities. 1995, Oak Ridge National Lab., TN (United States).

22. McDermott, K., Cost of Service Regulation In the Investor-Owned Electric Utility Industry: A History of Adaptation. 2012. p. 60-60.

23. New York State Public Service Commission, Construction Work in Progress, in Glossary of Terms Used by Utilities and Their Regulators. 2014.

24. Gifford, R.L., R.J. Lunt, M.S. Larson, H. Wynne, and E. Selmon, The Breakdown of the Merchant Generation Business Model. 2017.

25. Weiller, C.M. and M.G. Pollitt, Platform Markets and Energy Services. 2013.

26. Williamson, O.E., The modern corporation: origins, evolution, attributes. Journal of economic literature, 1981. 19(4): p. 1537-1568.

27. Arrow, K.J., The organization of economic activity: issues pertinent to the choice of market versus nonmarket allocation. The analysis and evaluation of public expenditure: the PPB system, 1969. 1: p. 59-73.

28. Williamson, O.E., The economics of organization: The transaction cost approach. American journal of sociology, 1981. 87(3): p. 548-577.

29. Ramstad, Y., Is a transaction a transaction? Journal of Economic issues, 1996. 30(2): p. 413-425.

30. Foss, K., Modular Product Design: Creating Technologically Separable Interfaces. druid, WP, 1998(10).

31. European Smart Grids Task Force, Interoperability of interfaces for the large scale roll out of smart metering systems in EU Member States. 2016. 
32. Williamson, O.E., Transaction-cost economics: the governance of contractual relations. The journal of Law and Economics, 1979. 22(2): p. 233-261.

33. Comstock, O. Demand response saves electricity during times of high demand. Today in Energy, 2016.

34. Hendershott, T., C.M. Jones, and A.J. Menkveld, Does Algorithmic Trading Improve Liquidity? Journal of Finance, 2011. 66(1): p. 1-33.

35. Katz, M.L. and C. Shapiro, Network Externalities, Competition, and Compatibility. The American Economic Review, 1985. 75(3): p. 424-440.

36. Blind, K., Interoperability of Software: Demand and Solutions. Homo Oeconomicus, 2006. 23(3): p. 295-306.

37. Shy, O., The Economics of Network Industries. 2001: Cambridge University Press. 332332.

38. Economides, N., Compatibility and the Creation of Shared Networks, M.E. GuerinCalvert and S.S. Wildman, Editors. 1991, Praeger: New York, NY. p. 39-55.

39. North, D.C., Institutions and economic growth: An historical introduction. World development, 1989. 17(9): p. 1319-1332.

40. Acemoglu, D. and J.A. Robinson, Why nations fail: The origins of power, prosperity, and poverty. 2012: Crown Books.

41. $\quad$ MISO, Entergy Integration Benefits All Members. 2013, Midcontinent Independent System Operator.

42. $\quad$ MISO, MISO Completes Largest-Ever Power Grid Integration. 2013, Midcontinent Independent System Operator.

43. Jacks, D.S., K.H. O'Rourke, and J.G. Williamson, Commodity price volatility and world market integration since 1700. Review of Economics and Statistics, 2011. 93(3): p. 800813.

44. The Value of Transmission. 2016, Southwest Power Pool.

45. National Electric Transmission Congestion Study. 2015, United States Department of Energy.

46. Krishnan, V., J.D. McCalley, S. Lemos, and J. Bushnell, Nation-wide transmission overlay design and benefits assessment for the U.S. Energy Policy, 2013. 56(2013): p. 221-232.

47. Silverstein, K., Japan Circling Back To Nuclear Power After Fukushima Disaster, in Forbes. 2017. 
48. Sanchez, D.U.M., C.T. Perez, A.E.C. Franco, G. de la Torre Castro, and M. Eng, SERVICE QUALITY ON READY-MIX CONCRETE DELIVERY PLANNING. 2011.

49. Bushnell, J., S.M. Harvey, B.F. Hobbs, and S.S. Oren, Opinion on Initial Implementation of the Energy Imbalance Market and Related Market Design Changes. 2013. p. 1-32.

50. Turner, M. and J. Batakji, Business Practice Manual For The Energy Imbalance Market. 2017.

51. Leisch, J. and J. Cochran, Balancing Area Coordination: Efficiently Integrating Renewable Energy into the Grid, in Greening the Grid. 2015, National Renewable Energy Laboratory.

52. Macknick, J. and S. Cohen, Water Impacts of High Solar PV Electricity Penetration. 2015, National Renewable Energy Lab.(NREL), Golden, CO (United States).

53. Commission, F.E.R., Energy primer: A handbook of energy market basics. Federal Energy Regulatory Commission: Washington, DC, USA, 2015.

54. Weiner, M., N. Nohria, A. Hickman, and H. Smith, Value networks-the future of the US electric utility industry. Sloan Management Review, 1997. 38(4): p. 21.

55. Anders, J.C., Energy Imbalance Market Implementation Agreement Between California ISO and Portland General Electric ER16-366. 2015.

56. Western EIM Benefits Report: First Quarter 2019. 2019, California Independent System Operator.

57. Zichella, C., Energy Imbalance Market Progress and Why It Matters. 2017.

58. NASEM, Enhancing the Resilience of the Nation's Electricity System. 2017, National Academies of Sciences, Engineering, and Medicine: Washington, DC.

59. Powell, D.M., R. Fu, K. Horowitz, P.A. Basore, M. Woodhouse, and T. Buonassisi, The capital intensity of photovoltaics manufacturing: barrier to scale and opportunity for innovation. Energy \& Environmental Science, 2015. 8(12): p. 3395-3408.

60. Taft, J.D., Electric Grid Resilience and Reliability for Grid Architecture. 2017, Pacific Northwest National Laboratory: Richland, Washington.

61. Fung, J.F. and J.F. Helgeson, Defining the Resilience Dividend: Accounting for Cobenefits of Resilience Planning. 2017.

62. Vetter, C., T. Werner, and T. Kostic. Building an Asset Management System for Electric Utilities on a Component-based Environment. in International Conference on Power System Technology. 2000. Perth, Australia: IEEE. 
63. Hodge, T. and A. Lee, Hurricane Irma cut power to nearly two-thirds of Florida's electricity customers. 2017.

64. Abiri-Jahromi, A., M. Fotuhi-Firuzabad, M. Parvania, and M. Mosleh, Optimized Sectionalizing Switch Placement Strategy in Distribution Systems. IEEE Transactions on Power Delivery, 2012. 27(1): p. 362-370.

65. Safirova, E., K. Gillingham, W. Harrington, and P. Nelson, Are hot lanes a hot deal? the potential consequences of converting hov to hot lanes in northern virginia. RFF Issue Brief, 2003: p. 03-03.

66. ExpressLanes. Pricing Fact Sheet. December 19, 2017]; Available from: https://www.expresslanes.com/pdfs/pricing-fact-sheet.pdf.

67. Ela, E., M. Milligan, A. Bloom, A. Botterud, A. Townsend, and T. Levin, Evolution of Wholesale Electricity Market Design with Increasing Levels of Renewable Generation. 2014: Golden, CO.

68. Shapiro, C. and H.R. Varian, Information rules: a strategic guide to the network economy. 1998: Harvard Business Press.

69. Milgrom, P. and J. Rioberts, The Economics of Modern Manufacturing: Technology, Strategy, and Organization. The American Economic Review, 1990. 80(3): p. 511-528.

70. Evans, D.S., R. Schmalensee, M.D. Noel, H.H. Chang, and D.D. Garcia-Swartz, Platform economics: Essays on multi-sided businesses. Competition Policy International, 2011: p. 459-459.

71. Bird, C.B., Growth and Legal Implications of Energy Storage Technologies. Utah OnLaw: The Utah Law Review Online Supplement, 2017. 2017(1).

72. Carrillo, J.D. and G. Tan, Platform Completion: The Role of Multi-homing and Complementors. 2006, The Networks, Electronic Commerce, and Telecommunications Institute.

73. Washom, B., J. Dilliot, D. Weil, J. Kleissl, N. Balac, W. Torre, and C. Richter, Ivory Tower of Power: Microgrid Implementation at the University of California, San Diego. IEEE Power and Energy Magazine, 2013. 11(4): p. 28-32.

74. Hughlett, M., Microgrids like new one at OATI a trend in electricity, in Star Tribune. 2016: Minneapolis.

75. Prine, C., Miramar base to break ground on new energy facility, in The San Diego Union-Tribune. 2017.

76. Hanna, R., M. Ghonima, J. Kleissl, G. Tynan, and D.G. Victor, Evaluating business models for microgrids: Interactions of technology and policy. Energy Policy, 2017. 103(January): p. 47-61. 
77. LaCommare, K.H. and J.H. Eto, Cost of Power Interruptions to Electricity Consumers in the United States (U.S.). 2006, Lawrence Berkeley National Laboratory.

78. EIA, Electric Power Monthly with Data for September 2017, in Electric Power Monthly, R. Hankey, Editor. 2017, Energy Information Administration: Washington, DC.

79. Bower, W., D. Ton, R. Guttromson, S. Glover, J. Stamp, D. Bhatnagar, and J. Reilly, The Advanced Microgrid: Integration and Interoperability. 2014, Sandia National Laboratories: Albuquerque, New Mexico.

80. Roach, M., Community Power and Fleet Microgrids: Meeting climate goals, enhancing system resilience, and stimulating local economic development. IEEE Electrification Magazine, 2014. 2(1): p. 40-53.

81. Fernandez, A. and S. Blumsack, Distributing Electric Energy in Rural America Efficiently and Economically: The Micro-Grid Option, in Wealth Creation in Rural Communities. 2010, The Pennsylvania State University.

82. Helpman, E., Understanding global trade. 2011: Harvard University Press.

83. Ricardo, D., The works and correspondence of David Ricardo Vol. 1: On the principles of political economy and taxation. 1817.

84. Heckscher, E.F., The effect of foreign trade on the distribution of income. 1919.

85. Krugman, P., Scale economies, product differentiation, and the pattern of trade. The American Economic Review, 1980. 70(5): p. 950-959.

86. Krugman, P.R., Increasing returns, monopolistic competition, and international trade. Journal of international Economics, 1979. 9(4): p. 469-479.

87. Tinbergen, J., An analysis of world trade flows. Shaping the world economy, 1962: p. 1117.

88. Helpman, E. and P.R. Krugman, Market structure and foreign trade: Increasing returns, imperfect competition, and the international economy. 1985: MIT press.

89. Krugman, P.R., Intraindustry specialization and the gains from trade. Journal of political Economy, 1981. 89(5): p. 959-973.

90. Bernhofen, D.M., Z. El-Sahli, and R. Kneller, Estimating the effects of the container revolution on world trade. Journal of International Economics, 2016. 98: p. 36-50.

91. Porter, M.E., How competitive forces shape strategy. Harvard Business Review, 1979.

92. Hoen, B., S. Adomatis, T. Jackson, J. Graff-Zivin, M. Thayer, G.T. Klise, and R. Wiser, Selling into the Sun: Price Premium Analysis of a Multi-State Dataset of Solar Homes. Lawrence Berkeley National Laboratory. Berkeley, CA, 2015. 
93. McMahon, J. and J. Fong, An Uptick in Recent Electric Utility-Gas Utility MergersExpect More. Energy Litigation, 2015. 15(1).

94. U.S. Department of Energy, Quadrennial Energy Review First Installment: Transforming U.S. Energy Infrastrucutures in a Time of Rapid Change, Appendix B, Natural Gas. 2015, Department of Energy.

95. Skarzynski, N., Pacific Northwest sees highest daily natural gas spot prices in the U.S. since 2014, in Today in Energy. 2019, United States Energy Information Administration.

96. Kopalek, M. Permian Basin natural gas prices up as a new pipeline nears completion. Today in Energy, 2019.

97. Lee, U., J. Han, and A. Elgowainy, Water Consumption Factors for Electricity Generation in the United States. 2016, Argonne National Laboratory.

98. Torcellini, P.A., N. Long, and R. Judkoff, Consumptive water use for US power production. 2003, National Renewable Energy Laboratory.

99. O'Fallon, C., Shocked out of water: the effect of drought on wholesale electricity markets, in University of California Santa Cruz Working paper. 2015.

100. Elberg, R. and E. Woods, Smart street lighting as a smart city platform: Applications and connectivity best practices. 2017, Navigant Research, commissioned by Echelon.

Available at:

https://www.echelon.com/assets/blt339a50e1c88306c2/Navigant\%20Research-

Echelon\%20Smart\%20Street\%20Lighting\%20White\%20Paper\%20-

\%20Full\%20Report.pdf Accessed 12-09-2019.

101. Damodaran, B. and B. Stanley, The cognitive effect on automotive: Unleashing exceptional experiences from an abundance of data. 2017, IBM Institute for Business Value.

102. Besen, S.M. and J. Farrell, Choosing How to Compete: Strategies and Tactics in Standardization. The Journal of Economic Perspectives, 1994. 8(2): p. 117-131.

103. Wolak, F.A., R. Nordhaus, and C. Shapiro, An Analysis of the June 2000 Price Spikes in the California ISO's Energy and Ancillary Services Markets. California ISO Market Surveillance Committee, Sep, 2000. 6.

104. Kahneman, D., Maps of bounded rationality: Psychology for behavioral economics. American economic review, 2003. 93(5): p. 1449-1475.

105. Simon, H.A., Bounded rationality and organizational learning. Organization science, 1991. 2(1): p. 125-134.

106. Joskow, P. and J. Tirole, Transmission Rights and Market Power on Electric Power Networks. The RAND Journal of Economics, 2000. 31(3): p. 450-487. 
107. Ryan, N., The Competitive Effects of Transmission Infrastructure in the Indian Electricity Market. 2017.

108. Borenstein, S., J. Bushnell, and S. Stoft, The competitive effects of transmission capacity in a deregulated electricity industry. 2000. p. 294-325.

109. Energy Information Administration. Natural Gas Weekly Update for week ending January 3, 2018. Natural Gas Weekly Update 2018 January 4, 2018 [cited 2018 January 11, 2018]; Available from: https://www.eia.gov/naturalgas/weekly/archivenew_ngwu/2018/01_04/\#tabs-prices-2.

110. Cowart, R., Efficient Reliability: The Critical Role of Demand-Side Resources in Power Systems and Markets. 2001: Montpelier, VT. 


\section{APPENDIX A: MARKET FAILURES}

This appendix provides additional discussion on a few of the market failure matters listed in Table 1 and encountered throughout the text of this manuscript.

\section{Perfect Competition}

Imperfect competition in the electric power sector can trace its roots to the early electric grid when monopolies first began to supply disconnected urban centers with electricity. Natural monopolies arise in industries with high fixed costs of operation and therefore significant economies of scale. ${ }^{107}$ The high costs of developing central generating stations and delivery networks meant that one or few producers emerged in many localities. Whether these firms are monopolists or oligopolists, they will generally enjoy some degree of market power. Market power is defined as the ability of a firm to raise and maintain prices above the level that would be obtained under perfect competition. Compared to the efficient market outcome, the monopolist or oligopolist will restrict production and sell what is produced at a higher than competitive price, reducing social welfare. Even in parts of the country where multiple firms compete to supply customers with power, the physical constraints of the grid and legacy of large central power stations can enable the exercise of market power by generation owners [103]. Congestion on transmission or distribution lines may reduce the number of power plants capable of serving a load pocket at a given point in time.

A countervailing concern to imperfect competition is that of excessive competition. Harris and Carman [20] notes that excessive competition may become a concern when supply or demand fluctuates unpredictably, leading to excessive entry during periods of peak demand and excess capacity during periods of off-peak demand. Despite ongoing efforts to improve the forecasting of loads and intermittent generation, components of the generation-load balance remain difficult to predict. The specialized nature of capital in the electric power sector slows supply adjustments. The high cost of electricity storage influences the decision of producers to sell below cost in periods of low demand rather than cover the cost of storage until a higher price may be realized. In some markets, negative wholesale prices for electricity have been obtained during periods of low demand in which, solar, wind and hydroelectric generation are relatively high and where transmission constraints prevent excess power from reaching other high-cost market segments. Firms facing an excess of competition may respond through a reduction in service quality.

\section{Perfect Information}

Imperfect information encompasses a broad class of concerns that contribute to market failures. The nature of modern economic activity, complete with numerous firms and their diverse set of offerings in a geographically decentralized setting practically ensures some level of imperfection regarding information. The complexity and locational distribution of goods and services makes it costly for consumers to develop a complete and perfect understanding of their market

\footnotetext{
${ }^{107}$ Average total costs fall as output increases for firms with high fixed costs and low to zero marginal costs of production.
} 
opportunities both near and far. The trend towards greater fragmentation of industrial organization, enabled by ICT deployment, could lead to greater problems with imperfect information.

Information failures can exist in several forms. Classical economic theory generally assumes that people are guided by rational decision making. However, in practice, people and the systems they devise are bounded in their rationality $[104,105]$. Some information necessary to be perfectly informed may prove too costly to acquire. Information may be useless without other information that can place it in context or aid the cultivation of sufficient understanding. Ultimately, human limitations regarding the assimilation and use of information may imply behavior that is described as “bounded rationality”. Similarly, “cognitive dissonance,' which causes individuals to fail to acknowledge (or even 'receive') information even when presented to them” [20], may be a problem contributing to information imperfections.

Information is costly to acquire, store, and utilize. Therefore, it is likely that any given transaction takes place without the transacting parties being fully informed. Infrequent purchases, difficult to evaluate performance characteristics, rapid technical innovation, and rapidly changing terms of exchange all exacerbate the problem of incomplete information by increasing the cost of being informed [20]. Some types of information relevant to exchanges in the electric power sector are rather costly to obtain. Information on the state of the grid requires considerable investment in metering and sensor technology. End use consumers purchase power regularly, but a municipal utility may seldom replace its meters or make large acquisitions of power electronics only every few years. Performance characteristics, especially from the perspective of an end use consumer, may be difficult to gauge. The rate of change in technical characteristics and terms of exchange has been rapid in the electric power sector as firms race to install new equipment and adjust their business plans to evolving competitive pressures.

Building on the notion of costly information, it is important to note that economies of scale exist when working with information. The systems that collect, store, and analyze data tend to exhibit high fixed costs and nearly zero marginal costs. Entities that engage in transactions repeatedly will therefore tend to have better information. This is an example of asymmetric information. While these entities are generally sellers, in some instances, buyers may have the informational advantage. Producers (and to some extent customers) will take advantage of the informational high ground to extract more favorable terms of exchange. Given the complexity of electricity delivery systems, producers are likely to enjoy an informational advantage over end use consumers. However, it is quite possible that both producers and consumers enjoy some degree of informational advantage. For instance, generators may have better information regarding the costs of future fuel supplies, but individual households will have a better idea about when they intend to run their laundry or turn down their thermostat on a hot day (increasing their load). The nature of information asymmetries in the electric power sector is changing rapidly as firms improve their data systems and new start-ups attempt to develop value propositions based on improving the situational awareness of electric utilities.

Transacting agents may be imperfectly informed if some information simply does not exist or is misrepresented by one agent or another. Information on the long term environmental or health impacts are often difficult or impossible to know in advance of a transaction. There is no way of 
knowing with certainty how the population of a metropolitan area will grow over the next 50 years. Therefore, a local utility that contracts for the construction of a new power plant will necessarily enter into this transaction with imperfect information. Even if key pieces of information are known, there is often no guarantee that the party in the know will accurately and completely inform their counterpart. Within the electric power sector, the environmental impacts of generation have long been misrepresented, unwittingly and otherwise.

One class of rising firms in the electric power sector, trades not in energy, but in energy data. It is difficult to be fully informed when transacting for data. If both parties had the same information, there would be no impetus for exchange between such actors. The growth in information firms within the electric power sector could thus have the perverse effect of increasing certain kinds of information imperfections.

\section{Absence of Externalities}

Beyond information imperfections, many market failures are tied to the presence of side effects that are not fully incorporated into the terms of exchange. Internalities are side effects of exchange borne by the transacting parties. In the absence of information failures, internalities do not necessarily lead to market failures. One of the most salient varieties of internalities within the context of electricity markets is transmission and distribution line congestion. The costs of congestion can accrue to electricity consumers in the form of higher line losses and out of (merit) order dispatch of generating plants. Therefore, relative to a hypothetical electricity market with no congestion, the allocation of supply may prove inefficient when delivery infrastructure is congested.

Considerable levels of transmission congestion are present in some developing world markets and may be present in "load pockets" found in the developed world as well [106]. Ryan [107] finds that mitigating congestion through increasing transmission capacity leads to increased overall market surplus in supply constrained regions where firms behave strategically (that is, in an imperfectly competitive manner). The benefits from relaxing transmission constraints are relatively attenuated in the case of competitive firm behavior. Lest this phenomena be thought only to exist in the developing world context, Borenstein, Bushnell [108] presents evidence that "limited transmission capacity can give a firm the incentive to restrict its output in order to congest transmission into its area of dominance” in restructured California electricity markets.

Externalities are side effects of exchange imposed on entities not party to the transaction. These externally incident effects may be either positive or negative. Air and water pollution are two classes of negative externalities long known to be associated with the generation of electricity and the manufacture of infrastructure components. On the other hand, investments that improve overall electric grid reliability may benefit other grid users that do not pay explicitly for the improvements. Externalities are important to acknowledge as negative externalities will tend to imply production levels that exceed the socially optimal level that would obtain in a perfectly competitive setting devoid of external economies. Similarly, the presence of positive externalities not factored into the calculus of exchange tend to imply production and consumption levels below that which is socially optimal. Policy instruments for dealing with 
externalities generally attempt to force economic actors to internalize these external costs and benefits to induce private production and consumption decisions to mirror the social optimum.

Not all externalities are environmental in nature. Within the context of energy markets, national security externalities most commonly arise with respect to oil, and to a lesser degree, natural gas. As the U.S. and other developed nations became more reliant on oil sourced from regions of the globe with challenging security situations, the costs of ensuring sufficient security of oil shipments increased. These costs can include naval vessels patrolling shipping routes, the deployment of security forces to politically unstable regions, and the maintenance of diplomatic agreements intended to gain market access. Shifts from the internal combustion engine to electric vehicles may further reduce the externalities associated with oil as consumption falls, but other key inputs may take oil's place as an origin of national security externalities. Specifically, rare earth elements and other inputs to renewable generating technologies may be subject to supply concerns if sourced from regions with tenuous security situations.

A common form of externality with salience to energy markets are pecuniary in nature. The presence of pecuniary externalities is not itself an indication of market failure. An excessively cold winter might see a rise in demand for natural gas for home heating applications. This shift in demand would likely lead power producers reliant on natural gas as a fuel source to pay higher fuel costs. ${ }^{108}$ Power producers may be impacted by the heating-related choices of households, but no market inefficiency is introduced. The welfare of natural gas power plant operators may fall with that of households, but natural gas producers will see improved profits. Such a transfer of wealth is efficient, even if it may run afoul of society's notion of equitability or fairness.

\section{Public Goods}

Another source of market failure is the presence of public goods. Public goods are defined by their non-excludable and non-rivalrous nature. ${ }^{109}$ While the energy component of electricity is both excludable to those not interconnected to the grid and rivalrous in that two households cannot consume the same kWh of electricity, investments to improve system conditions impact all interconnected entities. Reliability (desired by all consumers to varying degrees) and grid resilience (discussed extensively in Section 4) are at least partially public goods. Indeed, the laws of physics ensure that "the essential attributes of adequacy, voltage, and frequency are available to all interconnected users simultaneously” [110].

\section{Barriers to Entry}

\footnotetext{
108 As many households heat their homes with electricity (potentially generated with natural gas), generators may enjoy increased electricity demand during the cold snap as well. Unseasonably cold temperatures across most of the northern United States, increased demand for heating and electricity at the outset of 2018. Natural gas quantity demanded hit a single day record of 150.7 billion cubic feet on January $1^{\text {st }}$, 2018. The price of natural gas on the henry hub increased from \$ 2.75 / MMBtu on Wednesday, December 27 $7^{\text {th }}, 2017$ to $\$ 6.88$ / MMBtu on Wednesday, January $3^{\text {rd }}, 2018$ [109].

${ }^{109}$ A good is considered non-excludable if the producer of the good is unable to prevent entities that do not purchase the good from enjoying its benefits. A good is non-rivalrous if its consumption by one entity does not preclude its consumption by another entity.
} 
In the long run, the supply of a good or service may be inelastic due to physical or institutional barriers. When supply cannot grow sufficiently over time, incumbent producers will benefit from additional revenues known as economic rents as the price rises to clear the market. This price will often exceed the competitive level, indicating a possible market failure. While not to be confused with basic factor payments, a textbook example of economic rents can be found in constrained land markets. Owners of beachfront property may realize a premium on the return to their property ownership as a function of the fact that additional coastal property is not being manufactured on anything other than a geological timescale. ${ }^{110}$

Overall, the long-run supply of electricity is unlikely to be defined by high levels of inelasticity as the number of generating technologies grow in variety and fall in cost. However, the spatial constraints on the grid could engender economic rents for firms that own crucial or critically located assets. For instance, limited land resources or zoning regulation may prevent the construction of additional traditional generating assets in a given "load pocket". The presence of a single transmission right of way between localities may facilitate the realization of rents by the transmission owner. Installation of rooftop solar PV generation could overcome the constraint on land in a "load pocket" and deliver value to end use consumers at the expense of the economic rents accrued by the incumbent generator. The rents, or additional revenues above that which would obtain under perfect competition, will fall as entry (new solar PV installations) competes down the market price of electricity.

\footnotetext{
${ }^{110}$ Coastal erosion and sea-level rise may both contribute to greater scarcity of coastal property and therefore, greater rents. In this example, scarcity could also be influenced by legal barriers to the development of certain portions of the coastline, such as is the case for much California's central coast.
} 